\title{
RESISTÊNCIA ADESIVA DE UM AGENTE DE UNIÃO EM \\ SUBSTRATO DENTINÁRIO NORMAL E HIPERMINERALIZADO
}

RENATO CILLI

Dissertação apresentada à Faculdade de Odontologia de Bauru, da Universidade de São Paulo, como parte dos requisitos para obtenção do título de Mestre em Odontologia, Área de concentração: Dentística - opção Materiais Dentários.

(Edição Revisada) 


\section{RESISTÊNCIA ADESIVA DE UM AGENTE DE UNIÃO EM \\ SUBSTRATO DENTINÁRIO NORMAL E HIPERMINERALIZADO}

RENATO CILLI

Dissertação apresentada à Faculdade de Odontologia de Bauru, da Universidade de São Paulo, como parte dos requisitos para obtenção do título de Mestre em Odontologia, Área de concentração: Dentística - opção Materiais Dentários.

Orientador: Prof. Dr. Paulo Amarante de Araújo 


\begin{tabular}{|c|c|}
\hline \multirow[t]{2}{*}{ C489r } & $\begin{array}{l}\text { Cilli, Renato } \\
\text { Resistência adesiva de um agente de união em } \\
\text { substrato dentinário normal e hipermineralizado / Renato } \\
\text { Cilli. - Bauru, } 2003 \text {. } \\
134 \text { p. : il. : } 29,7 \mathrm{~cm}\end{array}$ \\
\hline & $\begin{array}{l}\text { Dissertação (Mestrado) - Faculdade de Odontologia } \\
\text { de Bauru. Universidade de São Paulo. }\end{array}$ \\
\hline
\end{tabular}

Autorizo, exclusivamente para fins acadêmicos e científicos, a reprodução total ou parcial desta dissertação/tese, por processos fotocopiadores e outros meios eletrônicos.

Assinatura:

Comitê de Ética da FOB

No. do Protocolo: 003/2003

Data: $23 / 04 / 03$ 


\section{RENATO CILLI}

22 de setembro de 1973

Nascimento

São Caetano do Sul-SP

Filiação

Nilson Cilli e

Felícia Stelmack Cilli

1993-1996

Curso de Graduação em Odontologia, na Faculdade de Odontologia de Piracicaba, da Universidade Estadual de Campinas - UNICAMP

$1998-2000$

Estágio no Departamento de Materiais Odontológicos e Prótese da Faculdade de Odontologia de São José dos Campos, da Universidade Estadual Paulista "Júlio de Mesquita Filho" -

UNESP

2000-2003

Curso de Pós-Graduação em Dentística - opção Materiais Dentários, nível Mestrado, na Faculdade de

Odontologia de Bauru, da Universidade de São Paulo - USP 


\section{Dedicatória}

Dedico primeiramente esta humilde obra àvocês, meus pais, Nilson Cilli e Felícia Stelmack Cilli, e não poderia ser diferente. Se cheguei até aqui foi porque tive toda aquela atenção e estímulo que partiram de vocês. Sei que muitas vezes, mesmo sem entender muito bem o significado de tanto tempo de estudo, vocês estavam ali, creditando confiança em minhas atitudes e se desdobrando para tais.

Dedico também este trabalho àmemória de minha avó, Theophila Stelmach, que teve fundamental importância para que eu vencesse talvez a maior barreira até aqui, o concurso vestibular. E desta ajuda jamais irei esquecer.

Muito obrigado. 


\section{Agradecimentos}

Agradecimentos especiais:

Agradeço àvocês, pais de minha namorada, Dr. Prakki Satyamurty e

Sra. Prakki Alivelu Mangatayaru, pela confiança e estímulo que sempre me dedicaram.

À você, professora e amiga Maria Auxiliadora Junho de Araújo que, juntamente com seu esposo, o professor e também amigo, Lauro

Cardoso Villela nos orientaram (a mim e àAnuradha) durante os primeiros passos nesta complicada carreira acadêmica. Acreditem, vocês nos deram ensinamentos de vida que já estão servindo de base

e que valerão para toda nossa carreira. Felizes são aqueles que tiveram essa oportunidade, e que principalmente, souberam entender todas as piadas...

Agradeço àvocê, minha querida namorada, Anuradha Prakki. Companheira de longa data, já divide comigo, desde nossa formatura em 1996, todos os trancos e barrancos de nossa escolha profissional.

Mesmo tendo você negado, acredito que eu tenha tido uma participação em sua escolha, assim como você também teve na minha. 
Agradeço ainda, ao restante de minha família, em especial aos meus irmãos Fábio e Jefferson e aos meus tios Alfredo e Nilza, que também participaram diretamente de minha ascensão até este estágio profissional.

Também pelo mesmo motivo, agradeço ao restante da família de minha namorada, suas irmãs Purnima Prakki e Aruna Prakki, seu cunhado e meu amigo, Helder Parizi, e "nossos sobrinhos" Luísa Kalhani Prakki Parizi e Henrique Vinay Prakki Parizi.

\section{Agradecimentos não menos importantes:}

Agradeço ao Departamento de Bioquímica da Faculdade de

Odontologia de Bauru, um ambiente ao mesmo tempo agradável, sério e hospitaleiro. Agradeço em especial ao Ovídio e principalmente àTelma, que tiveram participação nesta pesquisa, preparando a solução hipermineralizante e aquelas necessárias para a microscopia

eletrônica. 
Agradeço ao Núcleo de Apoio àPesquisa/Microscopia Eletrônica Aplicada àPesquisa Agropecuária da Escola Superior de Agricultura da Universidade de São Paulo-ESALQ-USP, na pessoa do Prof. Dr. Elliot Watanabe Kitajima, por proporcionar o ensino da técnica e o uso do microscópio eletrônico de varredura.

Agradeço ao Prof. José Roberto P. Lauris, pela ajuda durante a análise estatística dos resultados.

Agradeço aos meus amigos da república Camorra, da época de minha graduação: Alessandro F. Abussafi (C.G.), Marcelo M. Carvalho (Met's), Marcelo Minatti, Edson Akira Shimoda, Dênis C. L. dos Santos, Everton Flaiban (Zé), Daniel Bueno (Bixo), Fabiano (Pirassununga), Luís Carlos Casarin (Buba), Rodrigo Senise (Cachorrão), Eduardo Scacchetti (Santos), Maria Verônica (Mara); aos pseudo-integrantes: Daniel Negrete, Fábio Marcelo Delazari, Veruska Rocha e ao Márcio Tadashi Furuno pela convivência e estímulo. 
Agradeço aos meus amigos e colegas de mestrado e do doutorado:

Heitor Marques Honório, Daniela Rios, Bruno B. Campos (e esposa Juliana), Rosa V. de B. Garcez, Eduardo Bresciani, Natália Henostroza, Diego Regalado, Nádia Svizero, Leonardo César Costa, Flávia B. Pazzinato, Linda Wang, Fernanda Garcia, Luís Marquezini, André T. Gomes de Sá, Carla G. C. Carvalho, José Henrique Bachiega, Anderson P. de Freitas e Humberto C. Pires.

Aos professores do departamento, agradeço pela amizade e ensinamentos: Dr. Paulo A. S. Francisconi, Dr. César A. de Freitas, Dr. José C. Pereira, Dr. Rafael F. L. Mondelli, Dr. José Mondelli, Dr. Mario H. S. e Souza Jr., Dra. Maria Teresa Atta, Dr. Carlos Eduardo Francischone, Dra. Maria Fidela de L. Navarro (Diretora da Faculdade). 
Agradeço também aos funcionários os quais sempre estiveram dispostos a ajudar no que fosse preciso, como o Nelson Queiroz e Clélia Rita C. C.dos Santos -da Dentística; Eloísa Elena Turbiani-da Diretoria; Vera R. C. Boccato e Rita de C. Paglione-da Biblioteca e, em especial para a Sandra C. P. Azuaga, Alcides U. da Costa e Lourisvalda de J. Celestino-de Materiais Dentários.

Agradeço ao meu orientador, Dr. Paulo Amarante de Araújo, pela amizade, ensinamentos e pela liberdade que me ofereceu na escolha do tema que realmente gostaria de estudar. 
Agradeço ao Governo do Estado de São Paulo, por ter me dado a oportunidade de ensino de qualidade e gratuito no antigo ginásio, em parte no colegial, graduação e pós-graduação e ao CNPq, por ter reativado minha motivação de pesquisar que tinha acabado e diminuído meu mau-humor através do financiamento dos últimos nove meses.

Finalmente agradeço àDeus e àNossa Senhora, pois sem Eles nada disso se concretizaria.

Muito obrigado àtodos! 


\section{SUMÁRIO}

página

LISTA DE ABREVIATURAS E SÍMBOLOS $\mathrm{x}$

LISTA DE TABELAS xii

LISTA DE FIGURAS xii

RESUMO xviii

1. INTRODUÇÃO 1

2. REVISÃO DA LITERATURA 6

3. PROPOSIÇÃO 62

4. MATERIAL E MÉTODO 63

5. RESULTADOS 81

6. DISCUSSÃO 92

7. CONCLUSÃO 107

8. ANEXOS 108

9. REFERÊNCIAS BIBLIOGRÁFICAS 113

ABSTRACT 129

APÊNDICE 132 


\section{LISTA DE ABREVIATURAS E SÍMBOLOS:}

\begin{tabular}{|l|r|}
\hline Bis-GMA & Bisfenol-A diglicidil metacrilato \\
\hline BPDM & bisfenil-dimetacrilato \\
\hline 10-MDP & 10-metacriloxidecildihidrogêniofosfato \\
\hline Di-HEMA & 2 - hidroxietilmetacrilato hidrogênio \\
fosfato \\
\hline dinas/cm & unidade de tensão superficial: dinas por \\
centímetro \\
\hline EDTA & ácido etilenodiaminotetracético \\
\hline ergs/cm ${ }^{2}$ & unidade de energia de superfície: ergs \\
& por centímetro quadrado \\
\hline et al. & e colaboradores \\
\hline Fig. & figura \\
\hline Figs. & figuras \\
\hline GPDM & Glicerofosfato dimetacrilato ácido \\
\hline H & ácido clorídrico \\
\hline HCl & unjunto H: dentina hipermineralizada \\
\hline Hd & Grupo Hd: dentina hipermineralizada \\
& que recebeu duplo ataque ácido \\
\hline HEMA & concentração molar: moles por litro \\
\hline HMDS & Grupo Ht: dentina hipermineralizada que \\
\hline Ht & recebeu ataque ácido tradicional \\
\hline ISO & International Organization for \\
& Standardization \\
\hline kgf & hexametildisilazano \\
\hline M.E.T. & unidade de voltagem: quilovolts \\
\hline
\end{tabular}




\begin{tabular}{|c|c|}
\hline M.E.V. & microscopia eletrônica de varredura \\
\hline M.F.A. & microscopia de força atômica \\
\hline $\mathrm{mL}$ & unidade de volume: mililitro \\
\hline $\mathrm{mm}$ & unidade de comprimento: milímetro \\
\hline $\mathrm{mM}$ & concentração molar: milimol/litro \\
\hline $\mathrm{mm} / \mathrm{min}$ & $\begin{array}{l}\text { unidade de velocidade: milímetro por } \\
\text { minuto }\end{array}$ \\
\hline $\mathrm{mm}^{2}$ & unidade de área: milímetro-quadrado \\
\hline $\mathrm{mol} / \mathrm{L}$ & $\begin{array}{r}\text { unidade de concentração molar: moles } \\
\text { por litro }\end{array}$ \\
\hline $\mathrm{MPa}$ & unidade de pressão: mega-pasca \\
\hline $\mathrm{mW} / \mathrm{cm}^{2}$ & $\begin{array}{l}\text { unidade de potência luminosa: miliwatt } \\
\text { por centímetro quadrado }\end{array}$ \\
\hline $\mathrm{N}$ & grupo $\mathrm{N}$ : dentina norma \\
\hline $\mathrm{nm}$ & unidade de comprimento: nanometro \\
\hline NPG-GMA & $\mathrm{N}$-fenil-glicil metacrilato de glicidila \\
\hline Obs. & observação \\
\hline$p$ & nível de confiabilidade estatística \\
\hline $\mathrm{pH}$ & potencial hidrogêniônico \\
\hline Phenyl-P & 2-metacriloiloxietil fenil ácido fosfórico \\
\hline PMDM & $\begin{array}{l}\text { produto da reação da adição de } \\
\text { dianidrito piromelítico ao HEMA }\end{array}$ \\
\hline 4-META & 4-metacriloiloxietil-trimelitato anidrido \\
\hline TEGDMA & tetraetilenoglicoldimetacrilato \\
\hline á & nível de significância estatística \\
\hline $\mathrm{X}$ & número de vezes (aumento) \\
\hline$\%$ & por cento \\
\hline$\mu \mathrm{m}$ & unidade de comprimento: micrometro \\
\hline$\stackrel{\circ}{\circ}$ & unidade de temperatura: graus Celsius \\
\hline
\end{tabular}




\section{Lista de tabelas}

página

Tabela 4.1.1: Materiais selecionados:

Tabela 4.1.2: Identificação do lote e prazo de validade dos principais materiais

Tabela 5.1: Quantificação das rupturas apresentadas pelos espécimes de acordo com o tipo e grupos estudados

Tabela 5.1.1: Desvio padrão entre os valores de resistência adesiva em cada grupo

Tabela 8.1: Espessura e área dos palitos de cada dente em seus respectivos grupos e valores em $\mathrm{kgf}$ e em $\mathrm{MPa}$ obtidos pelos mesmos durante 0 teste. Valores em negrito representas a média.

\section{Lista de Figuras}

página

Fig. 2.1: Diferentes ângulos de contato entre substrato e líquidos. (adaptado de Ruyter, 1992)

Fig. 2.2: Estágios principais durante o desenvolvimento do tecido dentinário (adaptado de van Rensburg, 1995

Fig. 2.3.a: Mecanismo de reação entre aldeído, proteína e HEMA, conforme declarado por Munksgaard (1986). (Adaptado de Ruyter, 1992)

Fig. 2.3.b: Ésteres metacrílicos de ácido fosfórico usados em alguns sistemas autocondicionantes. $\mathrm{n}=$ número de grupos metileno nos compostos.

Fig. 2.4.a: Esquematização de um teste de cisalhamento (modificado de Sudsangiam; van Noort (1999).

Fig. 2.4.b: criação de dobramento ou clivagem em testes de cisalhamento (adaptado de Sudsangian; van Noort, 1999). 
Fig. 2.4.c: Aplicação não-uniforme de tensão durante o teste de tração devido ao desalinhamento. (adaptado de Sudsangian; van Noort, 1999)

Fig. 2.4.d: Esquematização do método de micro-tração. (adaptado de Pashley et al., 1999)

Fig 2.4.e: Micro-cisalhamento. A- segundo Phrukkanon et al. (1998) e Bsegundo Shimada et al. (2002). (adaptados de Phrukkanon et

al. (1998) e Shimada et al. (2002)

Fig. 4.1: Fluxograma ilustrativo do experimento

Fig. 4.2-I: Modo de preparo da superfície de dentina através de lixamento/polimento;

Fig. 4.2-II: Ilustração do aparelho agitador magnético;

Fig. 4.2-III: Vista aproximada dos dentes na solução hipermineralizante sobre o agitador magnético. Entre os dentes podemos observar a barra imantada.

Fig. 4.2-IV: Vista superior do erlenmeyer, demonstrando o agitamento da solução

Fig. 4.2-V: Ilustração do modo de ataque ácido da superfície de dentina

Fig. 4.2-Vl: Ilustração da lavagem após aplicação do ácido;

Fig. 4.2-VII: llustração do modo de secagem e manutenção de umidade dentinária;

Fig. 4.2-VIII: Adesivo sendo dispensado no pincel aplicador

Fig. 4.2-IX: Aplicação do adesivo

Fig. 4.2-X: Fotopolimerização do adesivo

Fig. 4.2-XI: Resina composta sendo dispensada na espátula de inserção 
Fig. 4.2-XII: Inserção da resina

Fig. 4.2-XIII: Inserção da resina em camadas

Fig. 4.2-XIV:Finalização do bloco

Fig. 4.2-XV: Aspecto final do dente com o bloco de resina construído sobre a camada de adesivo

Fig. 4.2-XVI: Fixação do dente com godiva na plataforma para corte 66

Fig. 4.2-XVII: Seccionamento do dente na máquina de corte 66

Fig. 4.2-XVIII: Visão aproximada dos cortes sendo realizados 66

Fig. 4.2-XIX: Aspecto final do dente seccionado 66

Fig. 4.2-XX: Espécimes produzidos em forma de palitos 66

Fig. 4.2-XXI: Aspecto do conjunto de equipamentos para a produção dos ensaios mecânicos

Fig. 4.2-XXII: Vista frontal da máquina de ensaios, onde se observa o dispositivo para micro-tração acoplado

Fig. 4.2-XXIII: Dispositivo para micro-tração

Fig. 4.2-XXIV: Acelerador de presa do adesivo de cianoacrilato. Vê- se também, o burrifador utilizado para sua aplicação

Fig. 4.2-XXV: Vista aproximada do dispositivo para micro-tração com o espécime aderido com adesivo de cianoacrilato

Fig. 4.2-XXVI: Outra vista aproximada, mostrando o espécime aderido no dispositivo

Fig. 4.2-XXVII: Nova vista bem aproximada da colagem do espécime no dispositivo 
Fig. 4.2-XXVIII: Aspecto do espécime após o ensaio, ou seja, após ruptura

Fig. 4.2-XXIX: Aspecto dos espécimes montados em stubs e cobertos com camada de ouro para observação em M.E.V.

Fig. 4.2-XXX:Vista aproximada de um dos espécimes (cortes longitudinais do dente) para observação em M.E.V.

Fig. 4.2-XXXI: Outra visão de um stub com palitos preparados para observação em M.E.V.

Fig. 5.1a: Gráfico 1, representando a média de resistência adesiva obtida pela dentina de cada dente de acordo com seu respectivo grupo.

Fig. 5.1b: Gráfico 2, representativo da média da área adesiva dos espécimes submetidos ao teste de acordo com dente e grupo.

Fig. 5.1.c: Gráfico 3, representativo da variabilidade de resistência obtida pelos espécimes derivados de seus respectivos dentes e grupos. Obs: marcas representam a média.

Fig. 5.1.d: Gráfico 4, representando a média de resistência adesiva obtida pelos grupos

Fig. 5.2-I: Dentina normal, corte transversal da superfície; 85

Fig. 5.2-II: Mesma que 5.2-I, em maior aumento; 85

Fig. 5.2-III: Dentina normal: superfície condicionada por 15 segundos; 86

Fig. 5.2-IV: Mesmo que 5.2-III, em maior aumento; 86

Fig. 5.2-V: Dentina normal, superfície condicionada por cinco segundos, como tratamento prévio para a hipermineralização artificial;

Fig. 5.2-Vl: Mesmo que 5.2-V, em maior aumento;

Fig. 5.2-VII: Dentina hipermineralizada. Nota-se o aglomerado mineral com aspecto semelhante de coral; 
Fig. 5.2-VIII: Dentina hipermineralizada dentina hipermineralizada. As setas apontam para a ocorrência de precipitados minerais que se destacam sobre a superfície;

Fig. 5.2-IX: Dentina hipermineralizada, corte transversal da superfície; $\quad 87$

Fig. 5.2-X: Mesma que 5.2-IX, em maior aumento;

Fig. 5.2-XI: Fratura de espécime de dentina hipermineralizada em visão oblíqua;

Fig. 5.2-XII: Mesmo que 5.2-XI, em maior aumento;

Fig. 5.2-XIII: Outra fratura de espécime de dentina hipermineralizada em visão oblíqua, onde se pode verificar a camada hipermineralizada superficial (entre setas);

Fig. 5.2-XIV: Dentina hipermineralizada, condicionada por 15 segundos;

Fig. 5.2-XV: Dentina hipermineralizada, duplamente condicionada por 15 segundos;

Fig. 5.2-XVI: Interface adesiva, espécime (palito) representante do grupo $N$;

Fig. 5.2-XVII: Interface adesiva, espécime (palito) representante do grupo $N$;

Fig. 5.2-XVIII: Interface adesiva, espécime (palito) representante do grupo $N$;

Fig. 5.2-XIX: Interface adesiva, espécime (palito) representante do grupo $\mathrm{Ht}$;

Fig. 5.2-XX: Mesmo que 5.2-XIX, em maior aumento;

Fig. 5.2-XXI: Interface adesiva, espécime (palito) representante do grupo $\mathrm{Ht}$;

Fig. 5.2-XXII: Interface adesiva, espécime (palito) representante do grupo $\mathrm{Hd}$;

Fig. 5.2-XXIII: Mesmo que 5.2-XXII, em maior aumento; 89

Fig. 5.2-XXIV: Ruptura do tipo mista-resina; $\quad 89$

Fig. 5.2-XXV: Ruptura do tipo mista-resina/dentina; $\quad 89$

Fig. 5.2-XXVI: Ruptura do tipo mista-resina; $\quad 89$

Fig. 5.2-XXVII: Mesmo que 5.2-XXVI, em maior aumento; 90 
Fig. 5.2-XXVIII: Espécime onde se pode identificar fraturas nas diversas estruturas; 
Resumo 


\section{RESUMO}

Este estudo teve como propostas: 1- comparar a resistência adesiva de um agente de união em substrato normal e hipermineralizado artificialmente e, 2 avaliar o efeito de um condicionamento por duplo ataque ácido sobre a resistência adesiva em substrato dentinário hipermineralizado artificialmente. Nove de doze dentes terceiros-molares foram divididos em: Grupo $N$ : dentina normal -três dentes; Conjunto $H$ : dentina hipermineralizada -seis dentes. Os três dentes restantes foram reservados para análise em microscopia eletrônica de varredura. Os dentes foram lixados para a exposição de uma superfície dentinária oclusal uniforme e padronizada. $\mathrm{O}$ conjunto $H$ recebeu tratamento para hipermineralização desta superfície e foi dividido igualmente em dois grupos: $\mathrm{Ht}$ e $H d$. Aplicou-se o sistema adesivo Single Bond (3M-ESPE) para os grupos $\mathrm{N}$ e $\mathrm{Ht}$, sendo seguido da confecção de um bloco de resina composta (Z100, 3M-ESPE) de $4 \mathrm{~mm}$ de altura. $\mathrm{O}$ mesmo procedimento foi realizado para o grupo $\mathrm{Hd}$, com exceção do passo do condicionamento, o qual consistiu na realização de um duplo ataque ácido de 15 segundos cada. Após armazenagem em água deionizada por 24 horas, os dentes foram seccionados em forma de palitos e submetidos à ensaios de micro-tração. Um total de 58, 82 e 71 palitos foram obtidos para os grupos $N, H t$ e $H d$, respectivamente. Houve semelhança estatisticamente significante ao teste $t$ de Student entre os grupos $\mathrm{Ne} \mathrm{Ht}$, os quais apresentaram médias de resistência adesiva de 42,1 e 45,8MPa respectivamente. O grupo $H d$ apresentou média de 31,2MPa, sendo estatisticamente diferente do grupo $H t$. A dentina alterada pela hipermineralização artificial apresentou valores semelhantes de resistência adesiva em comparação 
com a normal. O duplo ataque ácido em dentina hipermineralizada resultou em queda nos valores de resistência adesiva. 
Introdução 


\section{1- INTRODUÇÃO}

A qualidade e a durabilidade do selamento da interface entre estrutura dentária e material odontológico são os fatores determinantes em termos de longevidade de uma restauração dental ${ }^{44}$.

A adesão entre material restaurador e estrutura dentária depende também da íntima relação entre os substratos, que pode tentar ser obtida através de um sistema adesivo. Embora a adesão ao esmalte com materiais poliméricos tenha já sido bem fundamentada através da técnica do condicionamento ácido ${ }^{67}$, em dentina o mesmo estágio de sucesso ainda não foi alcançado, se constituindo assim, numa matéria de grande importância e interesse.

Toda a problemática do processo de união à dentina está baseada justamente nas características ultra-estruturais desse substrato. A adesão em dentina é mais desafiante, pois trata-se de um tecido vivo, heterogêneo e de baixa energia de superfície ${ }^{44}$. A grande quantidade de água e conteúdo protéico tornam diferente a abordagem do procedimento em relação ao esmalte, que interage bem com adesivos hidrófobos. Os adesivos dentinários modernos incluem monômeros com características hidrófilas e hidrófobas, os bifuncionais, objetivando a interação, respectivamente, com a dentina e a resina restauradora. O principal mecanismo de união é a formação de uma camada híbrida, a qual é resultante de um processo de infiltração dos monômeros bifuncionais na camada de dentina desmineralizada pelo condicionamento prévio por ácido, permanecendo aprisionados micromecanicamente por entre as fibras colágenas depois de polimerizados $^{55}$. 
A natureza e a qualidade do substrato que será submetido ao processo adesivo têm também influência no sucesso do procedimento.

A dentina, como um tecido vivo, se defende de agressões externas alterando sua ultra estrutura e constituição ${ }^{72,97}$. As transformações que ocorrem geralmente são caracterizadas pela diminuição de sua permeabilidade, resultante de contínua deposição mineral inter e principalmente intratubular.

Essa forma de defesa pode ter causa meramente fisiológica ou patológica. A fisiológica advém dos constantes estímulos que o dente sofre durante o curso de sua vida, enquanto que os patológicos advêm do acometimento pelo dente de lesões estimulantes de longa duração, como cáries de longo processo, materiais restauradores, lesões por atrição, abrasão, erosão e abfração ${ }^{45,46,50}$. Obviamente, existe a possibilidade de conjunção de alguns desses diversos fatores.

A influência dos mesmos resultam num substrato dentinário com diferenças marcantes daquele considerado como normal, ou seja, sem ter sido afetado. A deposição mineral extra induz a formação de um substrato hipermineralizado, comumente denominado esclerótico ou transparente.

A maneira de se proceder em relação à obtenção de adesão confiável nestes substratos ainda é incerta. Segundo Pashley; Carvalho ${ }^{61}$ (1997), a penetração do adesivo é altamente dependente da porosidade superficial da dentina após o condicionamento com ácido. Com a diminuição de permeabilidade intratubular ao adesivo, a dentina esclerótica acaba prevenindo a correta formação de prolongamentos resinosos, ou tags ${ }^{41,47,69,72,97,103}$, e a uniformidade da camada híbrida, que freqüentemente é observada com reduzida espessura ${ }^{41,45,61,72, ~} 106$. 
A camada hipermineralizada parece restringir a ação dos ácidos condicionadores $^{41}, 45,63,97,106$, prejudicando a qualidade da desmineralização. Especula-se que estes substratos apresentem uma alta capacidade de tamponamento $41,42,105$.

A obtenção desses tipos de substratos para a realização de investigações de resistência adesiva é outro fator complexo. De regra, investigações com sistemas adesivos são feitas em substratos dentinários normais, geralmente de dentes terceiros-molares inclusos, onde certa padronização é conseguida. No entanto, quando tratamos de alguns tipos de substratos escleróticos, como aqueles que se encontram expostos ao meio bucal, se torna inegável a grande quantidade de variáveis que se fazem presentes. Oclusão, saúde e hábitos pessoais (higiene, alimentação e vícios) são apenas algumas delas. A dentina esclerótica pode variar, então, de indivíduo para indivíduo, podendo apresentar morfologias diferentes entre dentes de uma mesma boca e entre regiões de um mesmo dente.

Por ser o tipo de substrato mais representativo daqueles que freqüentemente encontramos na prática clínica ${ }^{14,40,46,56,57,61,63,64,97,106, ~ u m ~ n u ́ m e r o ~ c o n s i d e r a ́ v e l ~}$ de pesquisas visando o desenvolvimento de materiais e/ou técnicas necessitam ser produzidas, objetivando qualidade e durabilidade de adesão .

A demanda pelo tratamento de lesões cervicais, cáries radiculares e lesões de hiperestesia radicular tem aumentado consideravelmente ${ }^{73}$, uma vez que a Odontologia, no estágio de desenvolvimento em que se encontra, permite uma conservação mais duradoura dos dentes na cavidade bucal. Materiais adesivos são utilizados freqüentemente como opção mais conservadora e mais estética 
para a restauração e tratamento da maioria das enfermidades dentais associadas àdentina esclerótica.

Com o intuito de contribuir para o esclarecimento sobre o comportamento dos agentes adesivos em substratos hipermineralizados, resolveu-se desenvolver uma revisão da Literatura pertinente, a qual culminou numa investigação laboratorial. 


\section{Revisão da}

\section{Literatura}

Neste tópico, foram abordados sucintamente todos aqueles assuntos que julgamos pertinentes em relação àadesão em substratos dentinários hipermineralizados, os quais podem dar sustentação ao nosso trabalho de investigação. Dos princípios de adesão, passando pelas características dos substratos, pela evolução dos adesivos dentinários e pelas características dos testes mecânicos de resistência adesiva, fechamos com a união de todos eles, a qual é o objeto principal.

Certa atenção foi dada aos aspectos microscópicos relativos às características das alterações do substrato dentinário e sua interação com os diversos tipos de agentes adesivos, pois nosso estudo envolveu observações microscópicas de caráter ilustrativo e por também acreditarmos que a familiarização com estes dados é de fundamental importância para o entendimento de todo o processo de adesão. 


\section{2- REVISÃO DA LITERATURA}

\section{1- Adesão}

O fenômeno adesão pode ser definido como o estado em que duas superfícies estão intimamente unidas por forças físicas, químicas ou ambas, com ou sem a intermediação de um promotor de união, denominado comumente de $\operatorname{adesivo}^{12,33}$.

A adesão química é baseada em forças de valência primária, onde ocorre uma combinação atômica entre as moléculas dos materiais envolvidos, como no caso de ligações iônicas, covalentes e metálicas. Esta categoria de união é considerada forte ${ }^{11,12}$.

A adesão física baseia-se em forças de valência secundária. Essas forças de atração resultam da interação de dipolos moleculares e/ou atômicos. São elas: as forças de van der Walls e as ligações de hidrogênio (pontes de hidrogênio) ${ }^{11,12}$.

Diferentemente das ligações primárias, que são intramoleculares, as ligações secundárias são intermoleculares, sendo por este fato, mais fracas ${ }^{1}$.

A adesão física entre dois materiais dissimilares também pode ser conseguida utilizando-se princípios físico-mecânicos. Comumente, esta variante é denominada adesão mecânica. A adesão mecânica é referida à penetração de um material em outro em nível microscópico, perfazendo um embricamento ${ }^{12}$.

Para ocorrer adesão, as superfícies aderentes dos materiais devem-se atrair uma à outra em sua interface de união. A energia livre de superfície, que pode ser entendida como a energia disponível para ligações apresentada pelos átomos da superfície de um material, tem substancial importância. Como os átomos residentes no interior do material estão completamente interligados (condição que 
não ocorre na superfície) eles acabam exercendo uma atração entre os átomos superficiais, ocasionando uma tensão chamada de tensão superficial. A tensão superficial é expressa em dinas/cm, enquanto que a energia de superfície é expressa em ergs/ $\mathrm{cm}^{2}$.

A adesão entre dois sólidos é muito difícil de ocorrer. Por mais lisa que as superfícies aparentam ser, microscopicamente ou em nível molecular ou mesmo atômico, elas apresentam-se rugosas, dotadas de grandes irregularidades ${ }^{1}$. Isso impede aquele íntimo contato entre as moléculas ou átomos de ambas superfícies aderentes, o qual não deveria exceder $1 \mathrm{~nm}^{12}$. Como esta situação é quase impossível de ocorrer entre dois sólidos em toda extensão de suas superfícies aderentes, um promotor de união, o adesivo, deve ser utilizado. Este, geralmente em forma líquida, penetrará nas irregularidades superficiais, proporcionando um embricamento e, consequentemente, criará uma interface de união. Ele pode ser definido então, como um material que quando aplicado em superfícies de duas substâncias possui a capacidade de uni-las, oferecendo resistência à separação ${ }^{38}$.

O líquido adesivo deverá possuir, como requisito mínimo, uma tensão superficial igual ou ligeiramente menor que o valor de energia de superfície do material aderente. Desta maneira, ele se espalharia uniformemente e espontaneamente ${ }^{15,54}$. Entretanto, o mesmo acaba ocorrendo quando a energia de superfície do substrato aderente é bem maior que a tensão superficial do adesivo, devido à grande atração e disponibilidade para ligações que os átomos (e moléculas) desta superfície apresentariam. 
O grau desse espalhamento pode ser chamado de umedecimento, uma vez que é o resultado da capacidade de uma gota de um líquido em molhar a superfície de um sólido, ou o resultado da capacidade de molhamento ${ }^{12}$.

Esta capacidade de molhamento é determinada pelo ângulo de contato entre líquido e sólido. Quanto menor o ângulo de contato (próximo de zero), maior o umedecimento e, quanto maior, menor o umedecimento (Fig. 2.1) 1, 12, 15, 76 .

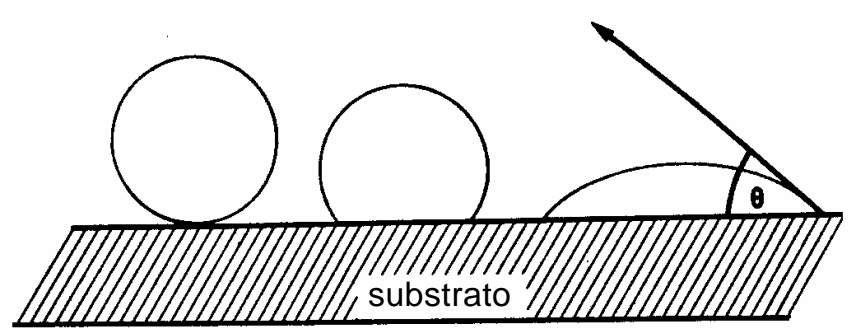

Fig. 2.1: Diferentes ângulos de contato entre substrato e líquidos. (adaptado de Ruyter, $1992^{76}$ )

Resumindo, sendo a tensão superficial do líquido adesivo menor ou ligeiramente menor que a energia de superfície do substrato aderente, isto determinaria um ângulo de contato próximo de zero entre os materiais, perfazendo um alto grau de umedecimento da superfície.

Todos esses conceitos podem ser observados e são bastante empregados na Odontologia para se obter adesão em tecidos biológicos como o esmalte e dentina. Usualmente, para adesão com materiais de origem polimérica, são utilizados sistemas adesivos.

O esmalte recém preparado apresenta uma tensão superficial de cerca de 28 dinas $/ \mathrm{cm}^{34}$, sendo esta condição incompatível com adesivos modernos que apresentam por volta de 41 dinas $/ \mathrm{cm}^{15}$. O ataque da superfície do esmalte com ácidos causa uma desmineralização seletiva, aumentando a superfície de contato, 
a rugosidade e, consequentemente, a tensão superficial. Valores em torno de 72 dinas $/ \mathrm{cm}^{34}$ são conseguidos com o condicionamento com ácido fosfórico a $40 \%$.

A dentina recém-preparada apresenta uma tensão superficial de cerca de 44 dinas/cm. Porém, após seu condicionamento com alguns tipos de ácidos, este valor pode cair para cerca de 28 dinas $/ \mathrm{cm}^{15}$. O referido decréscimo pode ser explicado pela criação de uma superfície irregular, porquanto porosa, com aumento de sua permeabilidade (exposição dos túbulos dentinários), e em conseqüência disso, dominada pelo afloramento de água proveniente de seu interior (fluido tissular). Ela possui características de uma membrana semipermeável, pois respeita os princípios da osmose. Quando soluções hipertônicas (como os ácidos) são aplicadas em sua superfície, ela tende a compensar o gradiente de concentração com o fluido tissular $59,62,68$.

Este problema fora solucionado com o tratamento prévio da superfície condicionada com soluções que continham monômeros resinosos em conjunto com solventes, os primers. Os solventes tinham função de deslocar a quantidade de água presente para infiltração simultânea dos monômeros. Como os primers apresentam uma tensão superficial de cerca de 41 dinas $/ \mathrm{cm}^{15}$, eles permitem um bom molhamento do adesivo nesta modificada superfície. Os fabricantes adequam a tensão superficial do adesivo para que seja ligeiramente menor que a do primer.

\section{2- Dentina}

A dentina é talvez um dos tecidos mais complexos do corpo humano. É o segundo tecido mais mineralizado, apresentando, segundo Marshall Junior et 
al. ${ }^{46}$, volume constituído de cerca de $50 \%$ de mineral rico em carbonatos, possuindo apatita deficiente em cálcio; 30\% de matéria orgânica -essencialmente colágeno tipo I; e $20 \%$ de fluido, semelhante ao plasma, porém, sem característica definida ${ }^{46,86}$. Em peso, segundo Mjör; Fejerskov (1986) ${ }^{48}$ apud van Meerbeek (1993) ${ }^{96}$, apresenta cerca de 75 \% de constituintes inorgânicos, cerca de $18 \%$ de substância orgânica e $12 \%$ de água ${ }^{48}$. Estes dados podem possuir variações ${ }^{4,14,64,101}$ na Literatura.

A fase inorgânica da dentina consiste quase que exclusivamente de apatita, principalmente a hidroxiapatita, embora uma quantidade de fosfato de cálcio amorfo esteja também presente ${ }^{101}$. Estes cristais de apatita são relativamente bem menores quando comparados com aqueles encontrados em esmalte -cerca de 300 vezes $^{4,86}$.

Na fase orgânica encontramos com predominância o colágeno, com 93\% de sua massa, sendo o restante constituído de 0,9\% de ácido cítrico, 0,2\% de proteínas insolúveis e $0,2 \%$ de glicosaminoclicanas e também a mesma quantia de lipídios ${ }^{86,101 .}$

Sua estrutura é formada por células odontoblásticas e substância intercelular, que reside entre os prolongamentos destas células, ou também, entre os túbulos dentinários. Alguns autores incluem os odontoblastos, como são chamadas estas células, como parte integrante do órgão pulpar e, portanto, denominam este conjunto dentina-polpa de complexo dentino-pulpar.

A substância intercelular é, nada mais, do que composta de fibrilas colágenas entremeadas em substância mineral. Esta matriz de fibrilas é disposta perpendicularmente quando próxima da junção amelo-dentinária, sendo esta 
região denominada de dentina do manto. Nesta região, as fibrilas se apresentam com maior calibre. A partir deste ponto, em direção àpolpa, elas se tornam mais finas, entrelaçadas e se dispõem perpendicularmente àdireção dos túbulos. Esta é denominada dentina circumpulpar.

Todas estas características podem ser mais bem elucidadas com análise da origem do tecido dentinário, a dentinogênese, sendo também necessária para o entendimento do processo dinâmico de mineralização deste tecido, que se prolonga por toda a vida do órgão.

Os estágios principais do desenvolvimento do tecido dentinário são ilustrados na seqüência de figuras (adaptadas de van Rensburg, 1995 ${ }^{101}$ ):

A - células mesenquimais indiferenciadas da papila dental

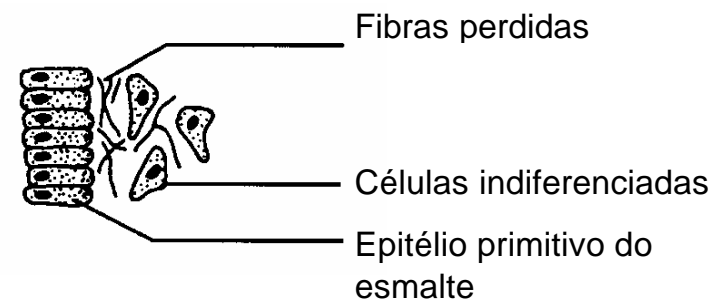

\section{C - Odontoblastos}

\section{B - Pré-odontoblastos}
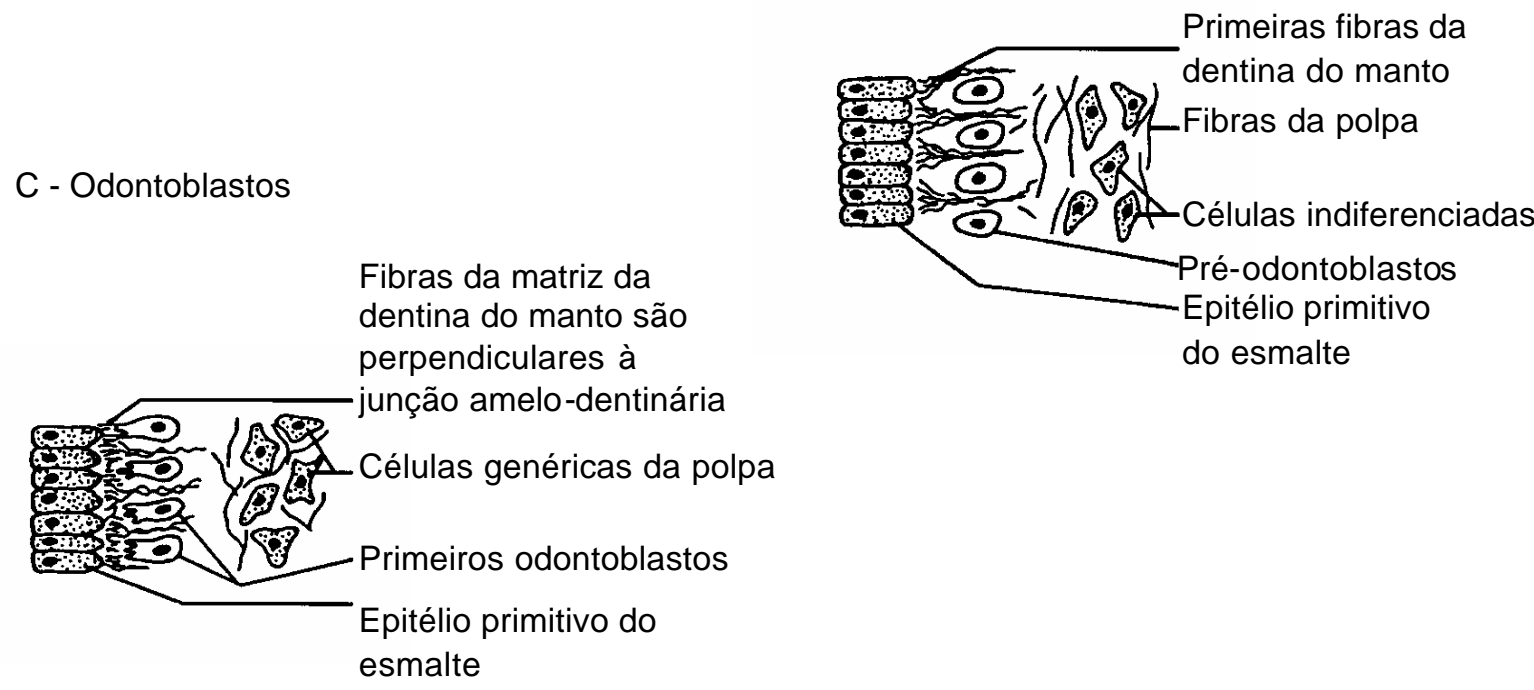


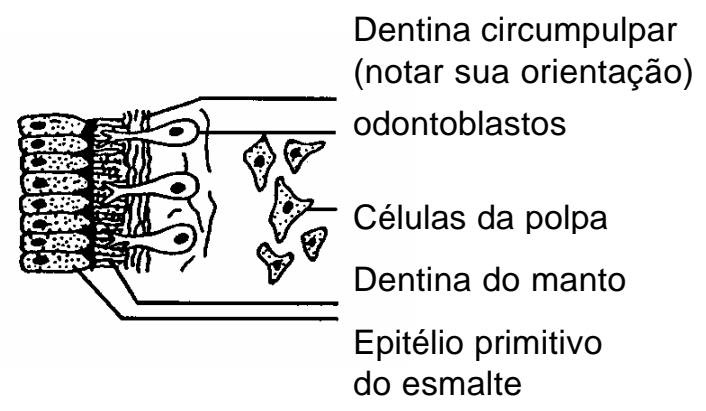

$$
\text { E - Formação da matriz e mineralização }
$$
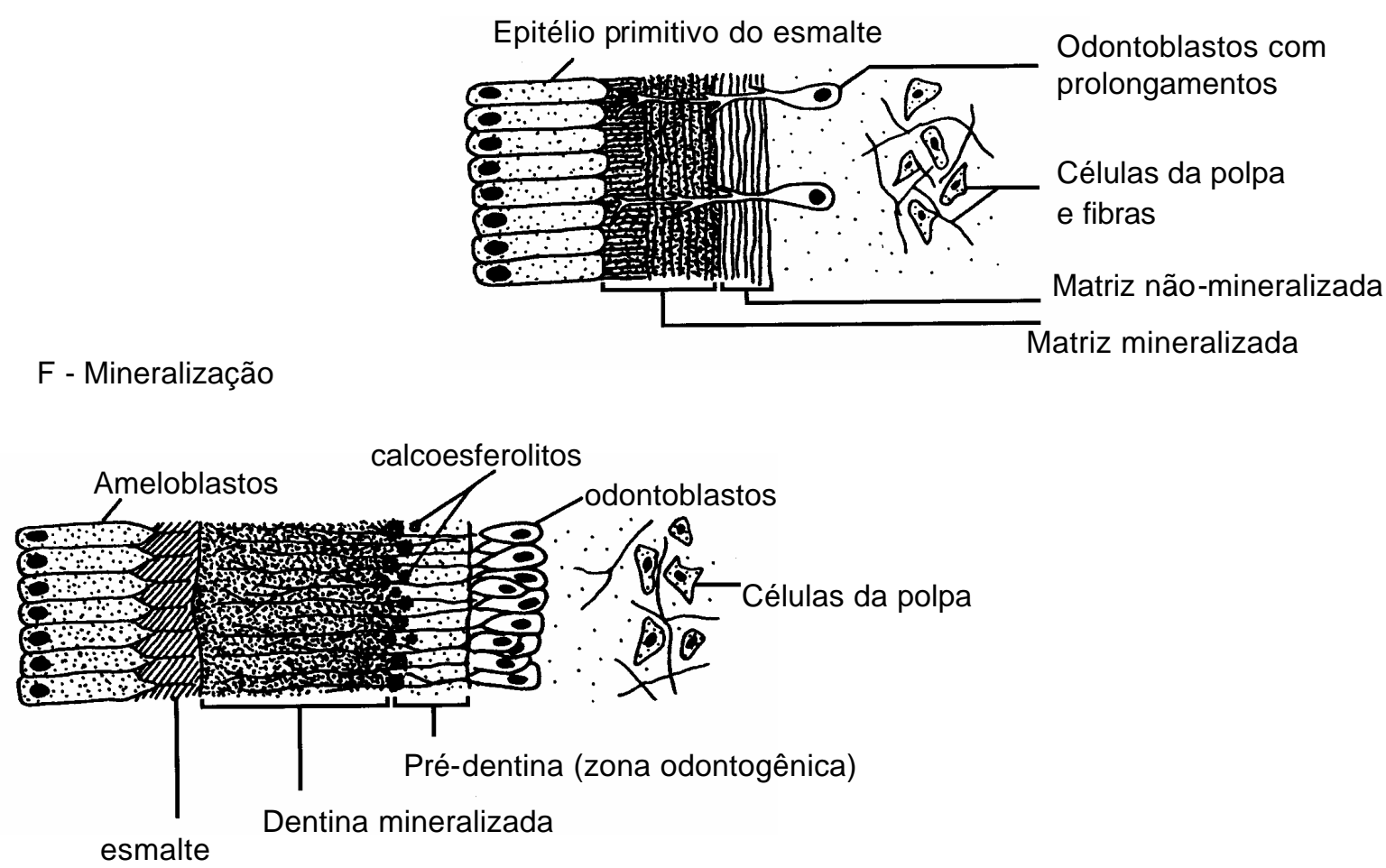

G - Dentina peritubular e intertubular (secção transversal)

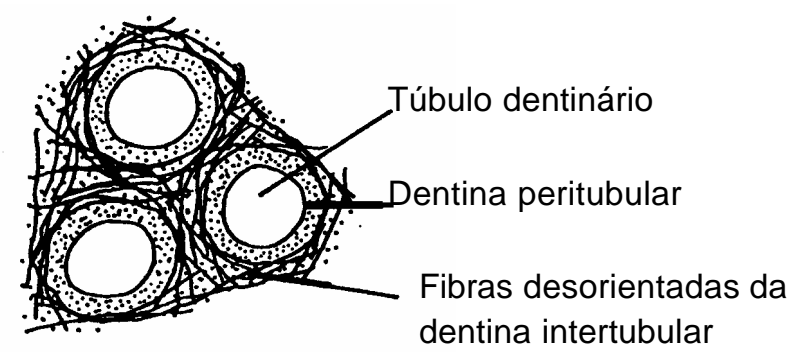

Fig. 2.2- Estágios principais durante o desenvolvimento do tecido dentinário (adaptado de van Rensburg, $1995^{101}$ ) 
Durante as fases embrionárias, é originado a partir do ectomesênquima, um conjunto de células conhecido como papila dental. Este conjunto de células inicialmente dispõe-se irregularmente, estando situado logo abaixo do epitélio do órgão formador do esmalte. As células são muito parecidas umas com as outras (Fig. 2.2.A). Antes da formação dos odontoblastos, uma fina camada periférica destas células é diferenciada no que se acreditam ser os pré-odontoblastos. Ela é produzida pela indução do mesênquima papilar pela camada de células do ainda precoce epitélio do esmalte. Fibras produzidas na periferia desta papila sofrem mudanças marcantes neste período (Fig. 2.2.B).

O primeiro estágio da formação da dentina é a deposição continuada de fibras colágenas numa substância amorfa rica em glicosaminoglicanas (Fig. 2.2.C e 2.2.D). Elas se arranjam numa rede com orientação perpendicular e justaposta ao imaturo epitélio do esmalte. São denominadas fibras de von Korff, e formarão a matriz orgânica da dentina do manto.

A partir deste ponto, a papila dental passará a ser chamada de polpa dental, sendo separada do epitélio formador do esmalte pelas fibras de von Korff.

Os pré-odontoblastos se diferenciam então em odontoblastos, perdendo a capacidade de realizar mitose, a divisão celular. As fibrilas começam a se depositar em direção paralela à superfície pulpar, tendo neste estágio, o início da formação da dentina circumpulpar (Fig. 2.2.D).

Conforme ocorre a deposição das fibras, o corpo dos odontoblastos acompanha o espessamento da dentina, sempre em direção à polpa, deixando um fino prolongamento citoplasmático por todo o curso (Fig. 2.2.E). Acredita-se 
que tanto os pré-odontoblastos como os odontoblastos sejam responsáveis pela produção de fibrilas colágenas neste estágio.

Quando a mineralização finalmente se inicia, túbulos dentinários são formados em torno dos prolongamentos odontoblásticos, se estendendo então, do corpo da célula até a junção amelo-dentinária (Fig. 2.2.F). Eles se assemelharão a cones, apresentando a base voltada para o corpo dos odontoblastos ou superfície pulpar. No entanto, são ondulados, devido aos movimentos espirais dos odontoblastos durante a formação dentinária. Ainda, em sua extensão, o túbulo dentinário apresenta uma série de canais laterais, originados pela mineralização de pequenos prolongamentos laterais que se encontram no percurso do maior. Estes canais estão mais presentes na dentina radicular do que em dentina coronária, sendo também mais finos.

A camada de dentina adjacente àpolpa permanece não-mineralizada através de toda a vida pulpar, e é conhecida como pré-dentina, tendo de 10 a $20 \mu \mathrm{m}$ de espessura (Fig. 2.2.F).

A mineralização é histologicamente vista como a formação de esferas, de calcoesferolitos ou material inorgânico que se coalesce e aumenta em tamanho para formar a dentina completamente mineralizada (Fig. 2.2.F). Os calcoesferolitos são secretados pelos odontoblastos e formam a hidroxiapatita, que é dispersa entre a trama de colágeno. Estes calcoesferolitos são transportados pelos prolongamentos citoplasmáticos através do fluido tissular, e precipitados da porção final para a base.

As fibrilas de colágeno são recobertas com os mucopolissacarídeos ácidos presentes na matriz e possuem a tendência de atrair minerais ${ }^{83}$. 
O mineral é depositado na direção da coroa para a raiz dental, em incrementos cônicos, resultando na formação de linhas incrementais (linhas de von Ebner).

Os calcoesferolitos se fusionam formando uma massa homogênea. Porém, numa certa região, essa fusão pode ser incompleta, resultando no aparecimento de espaços interglobulares. Essa região é chamada de dentina interglobular e se localiza logo abaixo da junção amelo-dentinária. A razão para o fenômeno ainda é incerta.

A dentina mineralizada situada entre os túbulos dentinários é denominada dentina intertubular e a dentina formadora dos túbulos é denominada dentina peritubular, ou intratubular. A dentina peritubular é cerca de $9 \%$ mais mineralizada que a dentina intertubular ${ }^{4}$ (Fig. 2.2.G).

Próximo àpolpa, os túbulos são mais calibrosos e em maior número, cerca de 65 mil túbulos $/ \mathrm{mm}^{2}$, enquanto que na periferia encontra-se aproximadamente 15 mil túbulos $/ \mathrm{mm}^{2}$ devido ao estreitamento de sua luz. No meio caminho entre as duas, encontra-se cerca de 35 mil túbulos $/ \mathrm{mm}^{2}$. O diâmetro médio dos túbulos varia de 1 a $5 \mu \mathrm{m}$, sendo que a média é de $1,5 \mu \mathrm{m}^{101}$.

Um dos constituintes mais importantes da dentina é o colágeno. Este é caracterizado pelo seu aspecto fibrilar, sendo constituído de moléculas alongadas de disposição helicoidal, que estão unidas por ligações cruzadas ${ }^{9}$.

O colágeno confere à dentina consistência e contribui com cerca de $30 \%$ em relação àresistência àtração ${ }^{79}$.

O colágeno encontrado na dentina é o do tipo I, embora uma minoria do tipo III também esteja presente. As fibrilas medem de 0,5 a $0,2 \mu \mathrm{m}$ de diâmetro e 
possuem estriações transversais a intervalos de $64 \mathrm{~nm}^{4}$. Da união de fibrilas, dáse a formação das fibras de colágeno. Elas se mantêm unidas neste feixe por meio de mucopolissacarídeos e mucoproteínas ${ }^{84}$.

A molécula básica do colágeno é formada por um grupo de três cadeias polipeptídicas, cada uma composta por uma série de mil aminoácidos e, quimicamente, os três principais aminoácidos encontrados são a prolina, a hidroxiprolina e a glicina, os quais perfazem cerca de $70 \%$ do tota ${ }^{54,9}$.

\subsection{1 - Variabilidade de constituição da dentina}

A dentina pode apresentar variações no seu padrão de normalidade, se assim podemos chamar as suas características (ou condições) básicas de morfologia e constituição, que já foram descritas. O padrão normal talvez seria aquele apresentado pela dentina antes do término do processo de formação radicular ${ }^{101}$.

Essas variações da normalidade incluem mudanças devidas a alterações fisiológicas ou patológicas, ou ainda à conjunção de ambas, e resultam geralmente num tecido dominado pela presença de minerais, ou hipermineralizado, por vezes desorganizado e com significante perda das características originais.

A dentina é considerada um tecido vivo, apesar de ser acelular. Apenas os prolongamentos dos odontoblastos participam de sua constituição. Porém, ela em conjunção com o tecido pulpar, são capazes de responder à estímulos externos agressivos que ameacem sua integridade ${ }^{87}$. 
Dentre esses estímulos destacam-se os mecânicos como cargas oclusais e abrasão (desgaste), e os de origem fisico-química como a cárie e erosão (corrosão) por ácidos.

As respostas para tais fatores incluem a dor e a deposição de minerais, geralmente adjacentes æ̀s regiões agredidas.

Quando o fator é a idade, e isto significa o tempo de trabalho (ou de função) do dente, temos a maior deposição de minerais na região de furca da câmara pulpar, acompanhada por uma diminuição do volume da câmara ${ }^{101}$. Este tipo de dentina é comumente denominada dentina secundária ou fisiológica, podendo ser referida como aquela que é formada após o término da formação radicular dos dentes e que é depositada continuamente, enquanto o dente possui vitalidade pulpar $^{14,101}$.

Fatores agressivos que levam à rápida perda de tecido dental como atrição, fraturas, cáries, preparo cavitário e material restaurador induzem a uma resposta imediata que se concretiza na produção de dentina para a cicatrização do local agredido ou a formação de uma barreira para o impedimento da progressão dessa agressão. Esta variável é denominada dentina terciária ou reparadora ${ }^{14,101}$.

Apesar de ser mais recente formada, a dentina reparadora apresenta diferenças morfológicas e de constituição, se comparada com a dentina normal. Ela é mais densamente mineralizada e possui túbulos com orientação desorganizada, além de serem mais escassos ou ausentes ${ }^{14}$. Muitos odontoblastos perdem função nesta situação. Células indiferenciadas presentes na polpa podem se diferenciar em odontoblastos, migrar para o local afetado e rapidamente, junto com as sobreviventes, produzirem o reparo ${ }^{4}$. Este reparo pode 
não ser uniforme, apresentando alguns túneis em seu interior (os chamados tratos mortos), devido ao aprisionamento de restos de odontoblastos ${ }^{87,}{ }^{101}$. Contrariamente à definição, Stanley et al. (1983) ${ }^{87}$ demonstraram haver a presença de dentina reparadora e tratos mortos em dentes não afetados por lesões, o que seria um indício de que o surgimento desse tipo de dentina também pode ter como fatores causais a idade e a freqüência de cargas mastigatórias.

Um outro tipo de alteração da normalidade é conhecido como dentina esclerosada ou transparente. Esta é decorrente de processos longos fisiológicos ou patológicos, tendo como finalidade a defesa (ou proteção) do complexo dentina-polpa. A resposta fisiológica advém de estímulos de carga oclusal e de desgaste fisiológico da estrutura dental decorrente da idade. O comprometimento patológico advém de lesões crônicas de abfração, erosão abrasão e cárie. A reação é caracterizada pela obliteração dos túbulos dentinários por aposição de dentina peritubular e por precipitação de cristais de fosfato de cálcio ou mesmo hidroxiapatita, sempre da ponta do processo odontoblástico em direção à base ${ }^{89}$, 96. Nesta região, os processos odontoblásticos exibem uma atrofia parcial e uma calcificação aparente ${ }^{96}$. Ela pode ser opaca ou transparente. A dentina esclerótica opaca apresenta seus túbulos obliterados com cristais de vários tamanhos e formatos enquanto que a transparente apresenta túbulos obliterados por cristais granulares diminutos ${ }^{37}$, tornando os índices de refração da dentina intertubular e peritubular bem semelhantes, o que resulta numa área com características ópticas de translucidez, chegando até mesmo àtransparência ${ }^{4,14,96}$.

O significado desta ocorrência é a formação de uma zona impermeável de dentina ${ }^{101}$ logo abaixo da perda de tecido dental. 
A dentina exposta para a cavidade bucal, como nos casos de lesões de abrasão, erosão e abfração, é considerada hipermineralizada, provavelmente porque apresenta deposição mineral adicional oriunda dos fluidos salivares ${ }^{37,} 106$ sobre dentina intertubular e peritubular, bem como no interior dos túbulos, tendo como resultado, a diminuição significativa de sua permeabilidade ${ }^{47,96}$.

\section{3- Adesão à dentina}

Infelizmente, e comparativamente com o que ocorre em termos de adesão com o esmalte, os adesivos dentinários não alcançaram ainda o mesmo estágio de sucesso. Para tal sorte, eles deveriam exibir valores de resistência ao deslocamento adesivo próximos aos que se obtém com substratos de esmalte dental, além de possuírem uniões duradouras, o que parece ser atualmente um dos grandes desafios.

As primeiras tentativas de se obter união de resinas com a dentina ocorreram com o desenvolvimento do composto dimetacrilato glicerofosfórico ácido (GPDM) por Oscar Hagger, em 195154, 86 . Por apresentar um grupamento fosfato hidrófilo, esta resina permitia ligação com o cálcio dentinário por quelação ${ }^{76}$. Este material foi denominado comercialmente como Sevitron Cavity Seal, sendo pela primeira vez avaliado por Kramer; Mc Lean, em $1952^{39}$.

Apesar de estes serem os primeiros indícios da utilização de ácidos para obter-se a união resina-dente, o grande marco da história da Odontologia Adesiva ocorreu com o sucesso de Michael G. Buonocore, em $1955^{7}$, que foi quem consagrou a técnica de condicionamento prévio do esmalte por ácidos para união de resinas acrílicas. Hoje se sabe que com esta técnica podemos mais que dobrar 
a tensão de superficial do esmalte (de cerca de 28 para até cerca de 72 dinas $/ \mathrm{cm})^{34,96}$, para assim, permitir uma maior facilidade de umedecimento da superfície pelo adesivo.

Buonocore et al., em $1956^{8}$, realizaram algumas das primeiras tentativas de condicionamento da dentina por ácidos ( $\mathrm{HCl}$ a $7 \%$ por um minuto), no entanto, sem o mesmo sucesso. Na ocasião, os agentes de união da época eram hidrófobos, e por esta razão funcionavam bem em esmalte e mal em dentina. A quantidade de água no esmalte é muito inferior àquela presente na dentina, além de haver a possibilidade de trabalharmos com uma superfície extremamente seca.

O que acontece, na realidade, é que não podemos considerar esmalte e dentina como substratos iguais ou parecidos, pois não são. Pelo menos quando tratamos de adesão.

As diferenças entre esmalte e dentina começam pela sua constituição. 0 tecido esmalte é quase que integralmente constituído de minerais, cerca de $97 \%$ em peso. A dentina como já foi descrita anteriormente, apresenta uma grande quantidade de mineral, no entanto apresenta um agravante, que é a sua parte protéica e fluidos ${ }^{67}$. Estes dois fatores compõem a chave da questão sobre adesão em dentina.

Ocorria durante os trabalhos que Buonocore liderava, uma redução da energia da superfície da dentina (ao contrário do esmalte) ao se realizar o ataque ácido. Dessa maneira, não se alcançava um bom umedecimento pelo adesivo hidrófobo. Outro agravante era a hipertonicidade que o ácido provocava na superfície, fazendo com que os fluidos tissulares fossem atraídos para esta 
região, acabando por provocar também a dificuldade do adesivo hidrófobo em penetrar no tecido.

A presença de fibras colágenas é responsável pela baixa energia de superfície da dentina desmineralizada por ácidos -cerca de 28 dinas $/ \mathrm{cm}^{15}$. Como a aplicação direta de adesivos hidrófobos necessita de uma superfície livre de água (e obviamente seca), as fibras colágenas expostas e desprovidas de suporte mineral se apresentarão colapsadas neste caso, devido à atração proporcionada pela energia livre de superfície da dentina mineralizada subjacente ${ }^{64}$. A dentina desmineralizada e seca atinge valores de até $65 \%$ de contração em volume ${ }^{10}$, limitando em muito os espaços entre as fibrilas para a difusão do adesivo.

Os trabalhos de Buonocore ficaram então esquecidos por longo tempo, pois adiante se iniciou uma série de discussões sobre os potenciais efeitos agressivos sobre a polpa pelo ácido quando aplicado em esmalte e dentina, que perduraram por muitos anos (quase 20) e se intensificaram principalmente durante a década de 1970. Somente em 1975, após a realização do simpósio internacional em St. Paul, Estados Unidos, o ataque ácido em esmalte foi genericamente aceito pela comunidade odontológica mundial ${ }^{86}$. Entretanto, persistia o ceticismo em relação ao condicionamento em dentina.

Devido ao pequeno sucesso de Buonocore e ao receio dos pesquisadores, os trabalhos que se seguiram, durante a década de 1980, buscaram a união química com a dentina, mais precisamente com a camada de detritos (smear layer) produzida após o preparo cavitário ou instrumentação. O pioneirismo foi de Rafael Lee Bowen ${ }^{6}$, com o desenvolvimento de uma resina, a NPG-GMA, que possuía propriedades de ligação com os componentes minerais da dentina por quelação. 
Esse agente de ligação estava presente (à época) nos agentes de união Cosmic Bond (De Trey Co.) e Cervident (SS White). Depois, seguiu-se uma nova geração de monômeros adesivos bifuncionais (hidrófilos/hidrófobos) baseados em fosfatos e fosfanatos, que também objetivavam a ligação com o cálcio dentinário ${ }^{76,86}$. Alguns representantes dessa época foram o Scothbond (3M), Clearfil New Bond (Kuraray), Adaptic Dentin Bonding Agent (Johnson \& Johnson) e o Prisma Universal Bond (Caulk-Dentsply).

Ao realizar a adesão por ligações químicas primárias (iônicas ou metálicas) com a porção mineral dentinária, estes adesivos objetivavam preservar a camada de detritos para oferecer proteção pulpar, devido à obliteração dos túbulos dentinários. Sendo assim, eles não conseguiam penetrar muito bem na dentina. Estes sistemas produziam valores muito baixos de adesão, isto é, por volta de 5 $\mathrm{MPa}$, sendo este valor relacionado à resistência coesiva da própria camada de detritos $^{32,61,91}$.

Tentativas de união química por ligações estruturais com os constituintes dentais também foram descritas. Asmussen e Munksgaard acreditavam promover uma adesão química (combinação estrutural) com o mineral e com o colágeno dentinários através de sistemas adesivos que removiam a camada de detritos e que continham glutaraldeído e $\mathrm{HEMA}^{3,76}$. Devido à presença deste último, os adesivos se tornaram mais hidrófilos, com maior capacidade de molhamento e de penetração através da camada de detritos ${ }^{61}$.

Entretanto, verificourse em trabalhos posteriores que a adesão nesta técnica era essencialmente formada por união micromecânica ${ }^{61}$. A eficiência de união com o colágeno promovida pela presença do aldeído na formulação do adesivo se 
existia, era considerada empírica e insignificante no resultado final. O mecanismo químico de combinação dá-se entre o grupamento aldeído, proteína (colágeno) e HEMA, segundo é representado na Figura 2.3.a. O adesivos representantes dessa época eram o Gluma (Bayer-Miles), que contém glutaraldeído e HEMA, e o Scotchbond $2(3 \mathrm{M})$, contendo HEMA. Este último, trazia em seu sistema um primer (Scotchprep), apresentando uma solução de ácido maléico (2,5 \%), HEMA (55\%) e traços de ácido metacrílico ${ }^{76,61}$, sendo lembrado como o primeiro primer autocondicionante ${ }^{61,76,98}$.

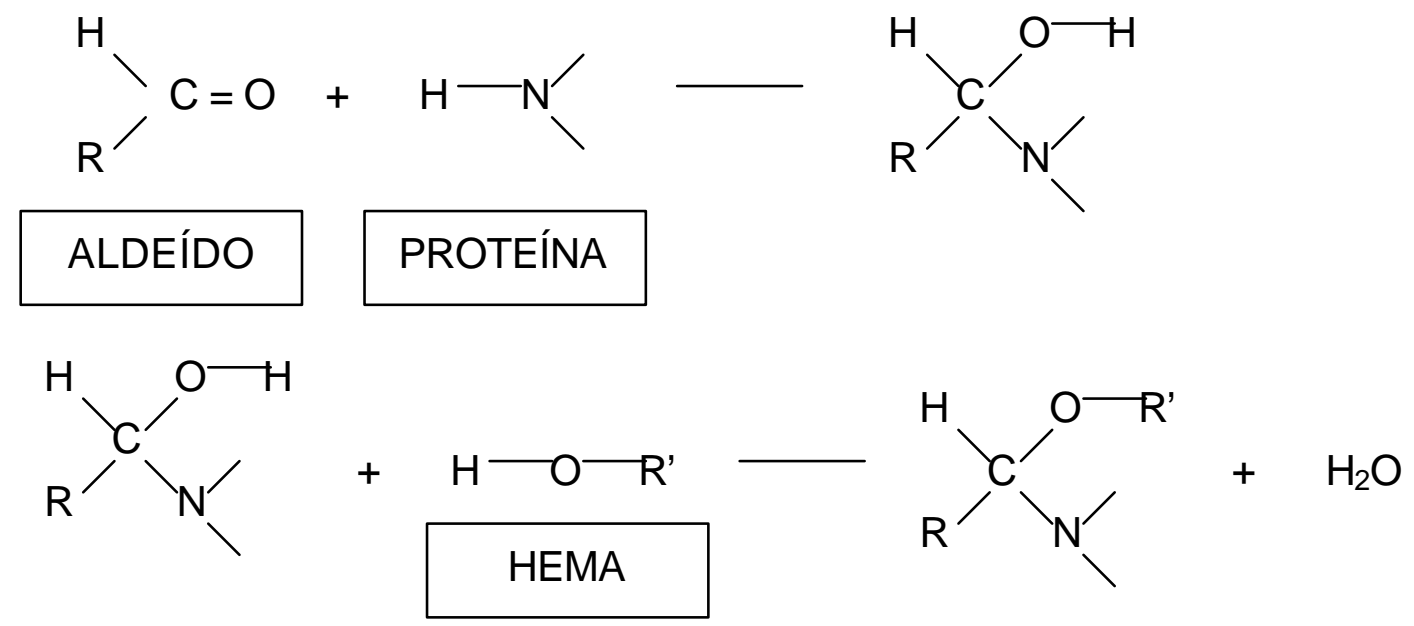

Fig. 2.3.a: Mecanismo de reação entre aldeído, proteína e HEMA, conforme declarado por Munksgaard (1986). (Adaptado de Ruyter, $1992^{76}$ )

Paralelamente à estes estudos, Takao Fusayama, no Japão, ao final da década de 1970 e início da de 80, insistia em seus trabalhos, no condicionamento ácido total, ou seja, de esmalte e dentina simultaneamente ${ }^{22}$. A técnica original consistia no condicionamento total da cavidade com gel de ácido fosfórico a $40 \%$. Provia uma satisfatória adesão em esmalte, porém ocorria um sobrecondicionamento da dentina, e o colapso das fibras colágenas, pois era 
recomendado a completa secagem da dentina com jato de ar. Mesmo assim, acreditava-se que com os adesivos específicos desta técnica (por exemplo, o Clearfil Liner Bond F, Kuraray) podia-se ter uma união química com a dentina ${ }^{21,54}$, obtendo bons valores de adesão.

Em 1982, Nobuo Nakabayashi et al. ${ }^{55}$, encontraram através de ensaios de tração, uma resistência de adesão à dentina por volta de $18 \mathrm{MPa}$ e a existência de uma zona de interdifusão de resina entre a camada de adesivo e a camada de dentina mineralizada subjacente, quando cortes foram observados ao M.E.V.. Essa camada hibridizada que, nada mais é que a inter-relação entre os monômeros resinosos infiltrados e a trama de colágeno desmineralizada, fora denominada de camada híbrida. A descoberta e o posterior entendimento deste mecanismo de adesão veio por derrubar a opinião daqueles que pensavam que a adesão à dentina dependia apenas da infiltração de resina nos túbulos, com a formação de prolongamentos ou tags.

Nakabayashi, Kojima e Masuhara ${ }^{55}$ utilizaram um sistema de união que apresentava um agente condicionante composto de uma solução de $10 \%$ de ácido cítrico e $3 \%$ de cloreto férrico. Este condicionador era aplicado em esmalte e dentina simultaneamente e provia a remoção total da camada de detritos dentinários. Acreditava-se inicialmente que o cloreto férrico atuava como promotor de polimerização. Anos depois, descobriu-se que o cloreto férrico, que interagia quimicamente com a dentina, também impedia parcialmente que a trama de colágeno se colapsasse. Especula-se que o mesmo atua na malha de colágeno promovendo ligações entre peptídeos, estabilizando-a ${ }^{54}$. 
A partir dessa época, sedimentou-se a idéia do condicionamento total para a remoção completa da camada de detritos, para então, promover a união com a dentina através da infiltração dos monômeros resinosos por entre as fibras colágenas expostas pelo ataque ácido. Este conceito é atualmente considerado como o principal mecanismo de união àdentina ${ }^{54}$.

Os sistemas adesivos desenvolvidos a partir desta época, no início da década de 1990, possuíam também características bifuncionais, ou seja, possuíam componentes hidrófilos e hidrófobos na mesma molécula de monômero e buscavam a adesão micromecânica proporcionada pela formação da camada híbrida. Resinas hidrófilas incluem monômeros baseados em fosfatos, ácido poliacrílico, HEMA, NPG-GMA, PMDM, 4-META, BPDM ${ }^{86,89 .}$

Sua utilização apresentava peculiarmente três passos durante 0 procedimento: o condicionamento ácido, a aplicação de um primer dentinário e a aplicação da resina fluida. No primer é que se encontrava a molécula bifuncional, além de solventes como acetona, água e álcool etílico que tinham como função deslocar (caçar) e promover a rápida evaporação da água presente entre as fibras de colágeno ${ }^{86,89,98}$, permitindo que o monômero preenchesse esses espaços. Os primers podem possuir um ou uma combinação destes solventes. A permeação do monômero bifuncional na dentina inerentemente úmida é facilitada pela presença de radicais hidrófilos em sua molécula.

Mais do que isso, e como já dito anteriormente, os primers promovem uma tensão superficial adequada para a interação com o adesivo hidrófobo (resina fluida), ou seja, eles transformam uma condição de superfície hidrófila para hidrófoba $^{98}$, por apresentarem radicais hidrófobos em sua constituição. $\mathrm{O}$ adesivo 
hidrófobo teria a função de estabilizar a camada híbrida, promovendo sua conexão com a resina composta restauradora ${ }^{44,98}$.

Adiante e recentemente, seguiu-se uma tentativa de simplificação desta técnica, devido à sua sensibilidade e desconforto (número de passos) que proporcionava aos clínicos. Foram introduzidos no Mercado, sistemas adesivos de dois passos (ataque ácido + adesivo), que incluíam a resina e o primer em um só frasco. Quase que em seqüência, foram lançados também os sistemas de passo único ou autocondicionantes (primers autocondicionantes e adesivos autocondicionantes).

Os sistemas autocondicionantes incluem a presença do ácido entre seus componentes. Ao mesmo tempo em que há a desmineralização dentinária, ocorre a permeação dos monômeros bifuncionais. Esta categoria de adesivos apresenta uma delgada camada híbrida, porém sem grande comprometimento de sua efetividade em relação aos seus predecessores de dois passos, pois até o momento, não há evidências de relação entre espessura de camada híbrida e resistência adesiva ${ }^{61}, 68,95$. A menor espessura teoricamente é devida à diminuição gradual da acidez do primer protagonizada pela capacidade tampão dentinária.

A diferença entre primers autocondicionantes e adesivos autocondicionantes está na agressividade ${ }^{94}$ (Fig. 2.3b) e na porcentagem de monômeros acídicos em suas composições, que está situada entre 5 a $6 \%$ para os primers e cerca de $20 \%$ ou mais para os adesivos ${ }^{64}$. 
<smiles>O=P(O)(O)O</smiles>

ácido fosfórico<smiles>O=P(O)(O)O</smiles>

Monoéster do ácido fosfórico<smiles>O=P(O)(O)O</smiles>

diéster do ácido fosfórico mais acídico

\section{menos acídico}

$\mathrm{R}=$ grupamento metacriloiloxi $=\mathrm{CH} 2+\mathrm{C}$ -

$\mathrm{COO}-[\mathrm{CH} 2] \mathrm{n}-$

\section{Di-HEMA}

hidrogêniofosfato ( $R=R^{\prime}$;

$$
n=2 \text { ) }
$$

Phenyl-P

$\left(n=2 ; R^{\prime}=\right.$ phenyl)

Fig. 2.3.b: Ésteres metacrílicos de ácido fosfórico usados em alguns sistemas autocondicionantes. $\mathrm{n}=$ número de grupos metileno nos compostos. Adaptado de Tay, F. R.; Pashley, D. H. (2001) ${ }^{92}$.

\subsection{1- Alguns dos maiores problemas atuais}

Mesmo com os avanços conquistados ao longo de quarenta anos, a adesão à dentina ainda não atingiu pleno sucesso, o que seria alcançado quando os materiais adesivos pudessem selar completamente a interface dente-restauração, com resistência que suportasse os ciclos mastigatórios e os ciclos térmicos inerentes ao ambiente bucal. Adicionalmente, é bom lembrar que estes materiais devam ser preferivelmente inertes, ou biocompatíveis, e que sua ação adesiva deva perdurar por longo tempo sem degradação.

O estágio em que nos encontramos atualmente é de grandes conquistas em termos de resistência de união e de intimidade dos sistemas com a ultra-estrutura 
dentinária. No entanto, a técnica se apresenta extremamente sensível, exigindo dos clínicos, habilidade, conhecimento altamente específico e atualizações constantes. Não é à toa que o sucesso do procedimento obtido em laboratório dependerá, na prática clínica, substancialmente do operador -o cirurgião-dentista.

Como já descrito anteriormente, a baixa resposta dentinária em relação aos primeiros adesivos hidrófobos conduziu os pesquisadores da área à formulação de sistemas bifuncionais, com certa afinidade pela água, um dos constituintes dentinários mais relevantes.

A umidade da dentina é outro fator preocupante. Os adesivos modernos, principalmente aqueles que utilizam um pré-tratamento com ácido fosfórico como passo separado, têm sua técnica baseada na adesão úmida, primeiramente apresentada por John Kanca III, em $1992^{35,36}$. A presença de umidade superficial (umidade extrínseca) previamente à aplicação dos adesivos é essencial para a formação da camada híbrida e ganho de resistência de união ${ }^{71}$.

Solventes como acetona e álcool etílico presentes nos primers, aumentam o vapor de pressão da água presente na dentina, deslocando-a ou promovendo sua evaporação da porção mais superficia| ${ }^{35,}{ }^{36}$. Com isso, permitem a infiltração concomitante dos monômeros bifuncionais. Então, a secagem excessiva previamente à aplicação do primer diminui a efetividade destes, pois não haveria umidade superficial suficiente para a ação dos solventes e penetração dos monômeros ${ }^{35,36}$.

Adesivos formulados com solventes com água ou água e álcool etílico parecem ser menos sensíveis a uma certa secagem da superfície (mas não em excesso) do que aqueles que somente apresentam acetona ou só álcool etílico, 
pois a água reumedeceria a porção parcialmente desidratada ${ }^{35,36}$. Entretanto, a presença de uma certa umidade (de aspecto brilhante) é recomendada para evitar o colapso das fibras colágenas da camada de dentina desmineralizada.

Por outro lado, foi demonstrado que o colapso da camada de dentina desmineralizada pela secagem exagerada é reversível. O volume colapsado é capaz de expandir perto de $100 \%$ do volume original com um novo umedecimento por água $^{10}$. No entanto, a injúria ao tecido pulpar talvez seja definitiva ${ }^{11}$.

O padrão de umidade segundo recomenda Kanca III, ou seja, de uma condição em que a umidade seja percebida apenas por tornar a superfície brilhante, deve ser respeitada. O excesso de umidade pode gerar o fenômeno overwet, descrito por Franklin Tay et al. ${ }^{93}$ como sendo o aparecimento de vesículas e de glóbulos de resina do primer no interior da camada híbrida. As vesículas são formadas pelo aprisionamento (recobrimento) de gotículas de água pela resina presente no primer. Os glóbulos de resina seriam decorrentes da diluição dos monômeros no excesso de água. Esses glóbulos e vesículas podem atuar como áreas concentradoras de estresses e prejudicar a resistência de união. Deficiências na formação de prolongamentos resinosos ou tags são observadas nas regiões correspondentes ao fenômeno ${ }^{93}$. Pereira et al., em $1999^{71}$, demonstraram através de análise em M.E.V. que mesmo em situações de ausência de pressão hidrostática intrapulpar positiva (como em testes laboratoriais), era possível ocorrer o fenômeno de overwet em regiões dentinárias próximas de cornos pulpares, principalmente quando se utilizam sistemas adesivos que dependem da técnica úmida e do ataque ácido prévio, agravandose quando estes apresentam somente acetona como solvente. 
O excesso de água presente na dentina pode ainda se combinar com 0 primer, alterando sua formulação e, consequentemente, pode comprometer seu mecanismo de ação.

A sensibilidade da técnica é aumentada também pela profundidade do preparo dental em relação àpolpa. Como já elucidado anteriormente, o número e o calibre dos túbulos dentinários cresce em relação à proximidade da polpa. Há de se esperar então, uma maior dificuldade de realização dos procedimentos adesivos, uma vez que teremos uma maior quantidade de água e menor quantidade de dentina intertubular. E devido àmenor área de dentina intertubular, eleva-se a importância da formação de prolongamentos de resina ou tags em relação à resistência total adesiva, enquanto que na dentina superficial a maior responsabilidade é devida à formação da camada híbrida ${ }^{60,61,64}$. Valores mais baixos de resistência adesiva são relacionados diretamente ao grau de profundidade dentinária ${ }^{35,36}$.

Os sistemas adesivos modernos também possuem dificuldade de preencher por completo toda a camada de dentina superficial que foi desmineralizada pela ação do ácido, resultando no aparecimento da denominada camada de dentina não-infiltrada. A primeira observação desta ocorrência foi feita por Sano et al. $(1995)^{81}$ notando a infiltração da solução contrastante de nitrato de prata nesta camada porosa não-preenchida pelo sistema adesivo. À este tipo de infiltração ele chamou de nanoinfiltração, termo que advém da espessura desta camada (de 20 a 100nm). A presença de nanoinfiltração pode levar a camada híbrida à degradação mais rapidamente, por hidrólise ${ }^{44,53,66,97 .}$

*Araújo, P. A.. Comunicação pessoal, 2003. 
Paul et al. ${ }^{66}$, em 1999, observaram em M.E.V. esta camada porosa de dentina não-infiltrada pelo sistema adesivo Single Bond (3M). Neste estudo, o aumento do tempo de condicionamento da dentina (30 e 60 segundos, contra o convencional 15 segundos) determinou uma maior extensão de desmineralização superficial, com conseqüente maior penetração de nitrato de prata pela zona de dentina nãopreenchida ou não-infiltrada pelo adesivo, o que só confirma a incapacidade dos monômeros presentes no sistema adesivo de preencherem grandes espessuras criadas pela desmineralização.

Os adesivos autocondicionantes contornam melhor este problema, pois ao mesmo tempo em que ocorre a desmineralização pelo grupamento ácido do monômero acídico, ocorre também sua penetração através da camada de detritos e dentina inter e intratubular ${ }^{61}$. Entretanto, é esperado que a possível diferença de tonicidade, entre a superfície (que está ácida e seca) e o interior da dentina, pode fazer aflorar água para esta superfície (umidade intrínseca dentinária), como manutenção do equilíbrio osmótico. Isto poderia ocorrer mesmo antes e durante a foto-polimerização do adesivo, como também depois. Recentemente foi demonstrado por Tay et al. ${ }^{94}$ (2002) que a camada adesiva formada por esta categoria de agente de união atua como uma membrana semipermeável depois de fotopolimerizada, permitindo a difusão de líquido do interior da dentina para a superfície do adesivo. O fenômeno ocorre pela formação de um gradiente de concentração entre os túbulos dentinários, que apresentam baixa quantidade de soluto, e a superfície do adesivo (mais precisamente a camada inibida pelo oxigênio), que apresenta alta quantidade devido a presença de proteínas dissolvidas, monômeros hidrófilos não-polimerizados e íons inorgânicos 
resultantes do processo de desmineralização. A presença de água na superfície pode afetar tanto a capacidade de adesão do adesivo à dentina como sua interação com os materiais resinosos hidrófobos. Este tipo de especulação ainda merece ser melhor investigada.

Ambas as umidades dentinárias extrínsecas e intrínsecas devem ser consideradas para a promoção de uma adesão bem sucedida ${ }^{71}$ (Pereira et al., 1999).

Alguns primers autocondicionantes, como o Prime \& Bond 2.1 e NT, apresentam a recomendação da técnica do ataque ácido total pelos seus fabricantes. Nesta técnica, e em teoria, os primers autocondicionantes acabariam desmineralizando uma quantidade adicional de dentina superficial, o que resultaria em maiores chances de incapacidade dos monômeros em preencher toda a camada de colágeno exposta.

Outro importante fator a ser considerado durante o processo adesivo é a contração que os monômeros resinosos proporcionam durante polimerização. Esta pode causar concentrações de estresses em certas regiões da superfície dentinária, que podem resultar em defeitos que levariam ao deslocamento total da restauração. Esses estresses podem ser maiores se forem utilizados materiais restauradores de alto módulo de elasticidade ${ }^{86}$. As tensões geradas pela resina restauradora durante a polimerização podem chegar ao valor de 7MPa. Entretanto, este dado varia de acordo com a configuração cavitária, o Fator $C^{16,86,}$ 89 


\section{4- Testes de resistência à adesão}

Os estudos clínicos são os mais indicados e os mais confiáveis em termos de avaliação de materiais restauradores. Neles, estarão incluídas praticamente todas as variáveis e condições específicas à avaliação do comportamento de um determinado material odontológico. Como estudos dessa natureza são relativamente onerosos, e necessitando também de longo tempo de avaliação e cooperação de todos os envolvidos (principalmente de pacientes com características adequadas e em número suficiente), estudos laboratoriais de curto a longo prazo possuem grande interesse ${ }^{3,89}$. Com observações em testes físicos, mecânicos e químicos, pode-se obter uma previsão muito aproximada do comportamento destes materiais quando utilizados na cavidade bucal. Analogias ou relativas comparações podem ser realizadas.

Os estudos laboratoriais são muito utilizados pelos fabricantes para realizar comparações e demonstrar a qualidade de seu material em relação a seus competidores. Os resultados são utilizados para promoção comercial, estando presentes em encartes e em propagandas de seus produtos.

Os testes de resistência à adesão compreendem basicamente duas formas principais: a resistência à tração e a resistência ao cisalhamento. No campo dos agentes adesivos, freqüentemente testes de resistência ao cisalhamento são usados como indicadores de qualidade de desempenho clínico ${ }^{89}$.

As forças exercidas num dente ou restauração quando em função na cavidade bucal são muito complexas em sua natureza e, portanto, acredita-se que nem os testes de tração nem os de cisalhamento podem realizar uma simulação de maneira ideal. Não se pode também esquecer que elas atuam em conjunto 
intrabucalmente. Segundo Van Noort et al. $(1989)^{100}$, quando uma resina composta aderida a uma superfície dentinária planificada e submetida a forças de tração ou cisalhamento, a distribuição de tensões ao longo da interface se torna extremamente irregular ${ }^{42,88,100}$. Essas tensões são dependentes de detalhes como a geometria da carga e da forma, tamanho e módulo de elasticidade do aderente $^{100}$.

Os testes de cisalhamento, bem como os testes de tração, são caracterizados pela adesão de um cilindro de resina restauradora numa superfície de dentina planificada e padronizada através do preparo da mesma com lixas especiais. A norma da ISO (ISO TR11405) ${ }^{33}$, que trata dos testes de adesão à estrutura dental, recomenda a confecção destes cilindros com 3mm para altura e diâmetro. No entanto, na Literatura encontramos dimensões de 3 a $4 \mathrm{~mm}$ de diâmetro e de 2 a $5 \mathrm{~mm}$ de altura ${ }^{18,19,49,51,52}$. Isto torna muito difícil a realização de comparações entre trabalhos.

Durante o teste de cisalhamento, uma força gradual é aplicada paralelamente às superfícies aderidas (Fig. 2.4.a) até a ocorrência do deslocamento. Entretanto, este teste pode ser transformado num teste de clivagem ou dobramento dependendo dos dispositivos utilizados; onde tensões de cisalhamento não são as dominantes $^{88}$ (Fig. 2.4.b). 


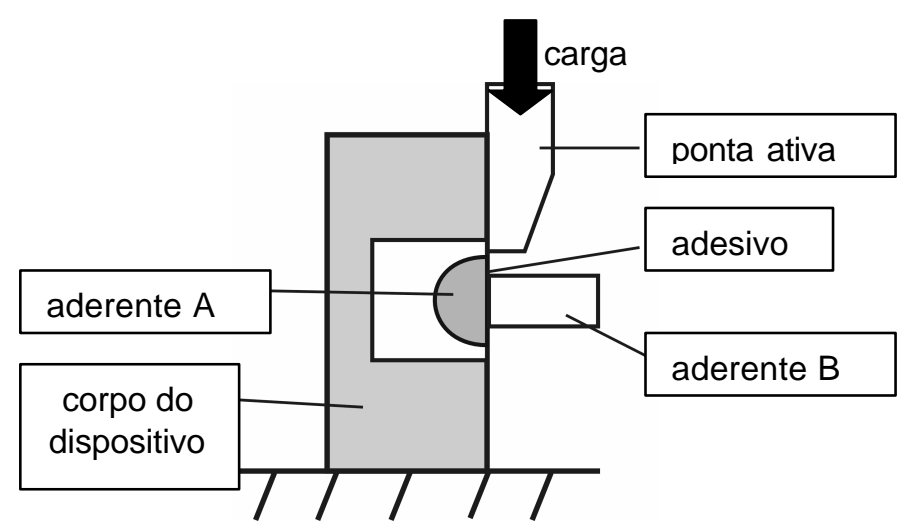

Fig. 2.4.a: Esquematização de um teste de cisalhamento (modificado de Sudsangiam; van Noort (1999) ${ }^{88}$.

\section{carga distribuída}

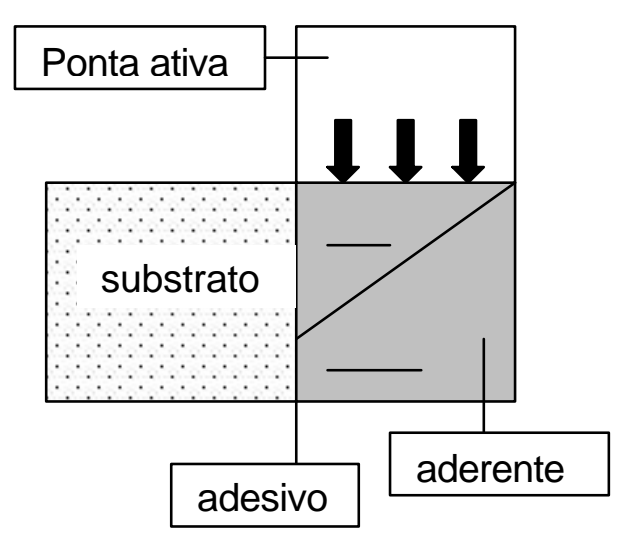

dobramento carga na interface

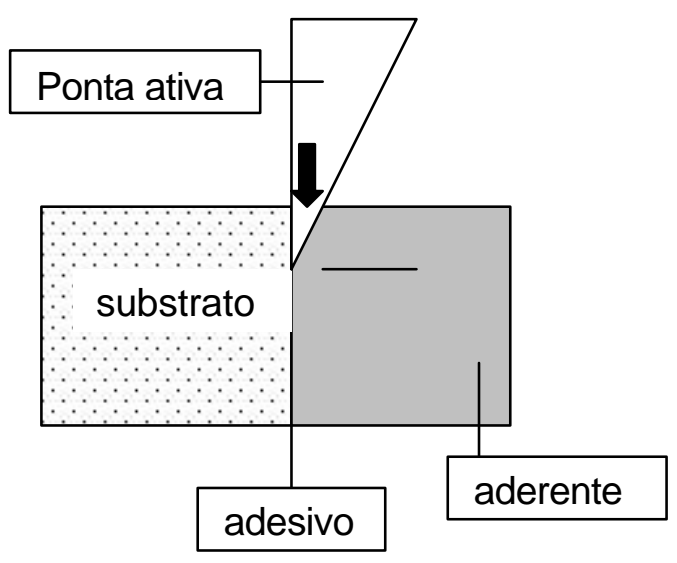

clivagem

Fig. 2.4.b: Criação de dobramento ou clivagem em testes de cisalhamento (adaptado de Sudsangian; van Noort, $1999^{88}$ ).

Uma outra forma de aplicação de tensões de cisalhamento é a realização do teste por meio de um dispositivo que deixa o cilindro de resina em direção perpendicular à célula de carga da máquina de ensaios. Um laço de fio ortodôntico de aço é acoplado à célula e ao redor do cilindro de resina e 
tracionado de encontro e paralelamente com a interface de união, proporcionando o deslocamento do espécime com o aumento da tensão ${ }^{51,52}$.

No teste de tração, o cilindro de resina é tracionado em relação ao dente que permanece fixo ou é também tracionado em sentido oposto. Com o aumento da força, ocorre o deslocamento. Este tipo de avaliação é muito criticado, pois há uma dificuldade de manter o correto alinhamento do espécime durante o procedimento adesivo e durante o teste, que poderia acarretar em concentrações de tensões em determinados pontos, devido à incorreta geometria da interface adesiva $^{61,88}$ (Fig 2.4.c). Uma tensão não uniforme de tração seria aplicada, desmerecendo o trabalho.
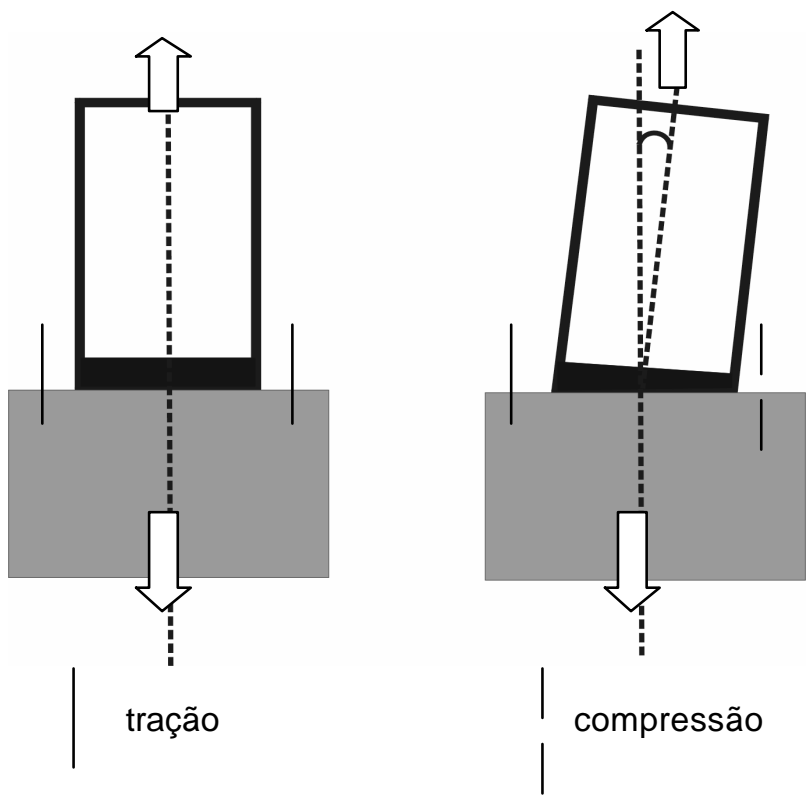

Fig. 2.4.c: Aplicação não-uniforme de tensão durante o teste de tração devido ao desalinhamento. (adaptado de Sudsangian; van Noort, $1999^{88}$ )

Houve tentativas ${ }^{20,22}$ para contornar este problema, haja vista o trabalho de Takao Fusayama, de 1979, onde desenvolveu um dispositivo complexo constituído de roldanas e pesos que eram ligados à uma plataforma onde se 
fixava o conjunto dente-restauração. Tal aparato conectado à uma máquina de ensaios universais permitia, através do equilíbrio, o correto alinhamento do espécime. No entanto, seus espécimes eram confeccionados acoplando-se um conector de pesca metálico àresina, o que pode causar falhas prematuras devido àformação de valas entre ambos ${ }^{20}$.

Os testes de resistência à tração foram os pioneiros, mas foram desacreditados devido à crença de que os de cisalhamento prediziam melhor o comportamento adesivo dos materiais através de seus resultados, além de serem de fácil confecção e reprodução. Isto os tornou bem populares.

Os testes de cisalhamento foram, e ainda são, os mais largamente utilizados, tendo sido de grande valia para o aperfeiçoamento de materiais e técnicas adesivas.

Um importante aspecto relativo aos testes de resistência adesiva é o modo como ocorre a ruptura do conjunto unido. As rupturas podem ser adesivas $(100 \%$ localizadas na interface de união), coesivas (100\% da fratura em algum dos substratos) ou uma mistura de ambas ${ }^{56}$.

E como as técnicas e materiais evoluíram, os valores de resistência adesiva se tornaram cada vez mais altos. Por causa deste fator, os testes de cisalhamento começaram a ser ainda mais criticados, pois estaria ocorrendo um grande percentual de falhas do tipo coesiva, em dentina ou resina. Essas falhas estavam freqüentemente sendo observadas com valores em torno de 15 a $20 \mathrm{MPa}^{88}$.

Acredita-se que, devido à grande área adesiva ocupada pela resina restauradora, este fenômeno estaria ocorrendo pela presença de defeitos ou de pequenas áreas concentradoras de estresse na interface ou nos substratos 
envolvidos. Com a aplicação da tensão (cisalhamento ou tração), estas áreas iniciariam e dominariam a propagação da fratura ${ }^{61,64,80}$. Devido æ̀s tensões não se distribuírem de maneira uniforme ao longo do conjunto, os valores obtidos seriam muito baixos em relação à real resistência da interface adesiva. Apenas como parâmetro, valores de resistência coesiva à tração de espécimes de dentina situam-se entre 50 e $138 \mathrm{MPa}^{88}$.

Com o propósito de contornar estes problemas e de permitir a avaliação da adesão em diferentes regiões da superfície dentinária, um novo tipo de teste foi criado por Hidehiko Sano e colaboradores ${ }^{80}$, que consiste num teste de tração realizado em espécimes com pequenas áreas adesivas, de 1,6 a 1,8 mm².

Para o teste, superfícies planas de dentina são preparadas (Fig. 2.4.d-B), onde se realizam o tratamento adesivo e a inserção da resina composta em camadas, até que se forme um bloco de aproximadamente $4 \mathrm{~mm}$ de altura (Fig. 2.4.d-C). O conjunto resina-adesivo-dente é montado numa plataforma de uma máquina de cortes seriados de maneira que a interface adesiva fique perpendicular àdireção do corte do disco diamantado. Através da série de cortes, originam-se fatias retangulares de resina-adesivo-dente de espessuras reduzidas, podendo variar de 0,5 a 3mm usualmente (Fig. 2.4.d-E; E’'). Adicionalmente, estes espécimes são desgastados através de pontas diamantadas finas (Fig. 2.4.d-F) (ou com o próprio disco diamantado (Fig. 2.4.d-G)) em sua interface adesiva, de ambos os lados, até que se obtenha uma pequena área adesiva central entre resina e dentina (formato de ampulheta).

Estes espécimes são colados com adesivo de cianoacrilato em dispositivos específicos acoplados a uma máquina de ensaios que realiza a tração. O uso de 
tal dispositivo diminui o risco de eventuais desvios de alinhamento, assegurando a aplicação de tensões puras de tração, evitando torques ${ }^{65,66}$ (Fig. 4.2-XXIII).

Esta técnica se torna extremamente interessante quando se deseja avaliar a resistência adesiva em regiões do dente afetadas por cáries ou por outras alterações como esclerose ou lesões de erosão. Outra característica seria a possibilidade de avaliação de regiões alteradas por degradação ou fadiga que ocorrem com o tempo na camada de união.

O maior achado do estudo de Sano foi de ter estabelecido a relação inversamente proporcional entre a resistência à tração e o módulo da área adesiva, a qual era muito difícil de ser percebida nos testes tradicionais devido à grande área adesiva ocupada pelo espécime que, como já foi dito, era sujeita a defeitos. Na realidade, Sano acabou confirmando para testes de tração de adesão à dentina, a teoria de Griffith $^{23}$, postulada para materiais de natureza friável, a qual estabelecia que quando se submetem materiais uniformes à tração, a resistência decresce com o aumento do tamanho do espécime. O aumento do tamanho do espécime afetaria os resultados devido àmaior presença de defeitos, e assim, quando o espécime é submetido ao estresse, a concentração das forças ocorre nos defeitos, iniciando a fratura.

Como a área adesiva dos espécimes nos testes de micro-tração é extremamente reduzida - portanto com menor presença de defeitos e melhor distribuição de estresses, a maioria das falhas que ocorrem são de natureza adesiva $^{65,73,80}$. Isto se traduz numa maior confiabilidade nos resultados de resistência à adesão ${ }^{99}$. Apesar de Sano ter recomendado em 1994 que os testes devam ser realizados com espécimes de área de secção transversal variando 
entre 1,6 a 1,8 $\mathrm{mm}^{2}$, devido a menor disparidade encontrada entre os resultados de seu trabalho, ele já alertava para a necessidade do aprimoramento da técnica para testes em áreas menores que $1 \mathrm{~mm}^{2}$, para avaliação de diferenças regionais na dentina de um mesmo dente em cavidades complexas ou mesmo planas.

Uma alternativa à confecção de espécimes em forma de ampulheta é a produção de espécimes em forma de haste ou palito (Fig. 2.4.d-D”), os quais são obtidos através de cortes seriados da união dente-resina com disco diamantado ultra finos (Fig. 2.4.d-D').

Esta morfologia permite a avaliação de áreas de até $0,25 \mathrm{~mm}^{2}$ (correspondente à espessura de um palito de $0,5 \mathrm{~mm} \times 0,5 \mathrm{~mm}$ ) sem agravar a sensibilidade da técnica. Ainda, acredita-se que exista uma melhor distribuição das forças de tração com este tipo de desenho ${ }^{88}$. Contrariamente, Phrukkanon et al. em $1998^{73}$, e em $1999^{74}$, afirmaram que a área de secção deste tipo de desenho (entende-se palito ou ampulheta), ou seja, área em forma de quadrado, não seria viável, pois haveria uma distribuição desigual das forças na interface adesiva durante o teste. Nestes trabalhos, eles propuseram o torneamento dos espécimes na forma de palitos para permitir uma área de secção em torno da interface de forma circular (Fig. 2.4.d-D"'). Entretanto, seus resultados pareceram ser semelhantes àqueles encontrados comumente na Literatura para os espécimes de área quadrada ${ }^{65}$. 


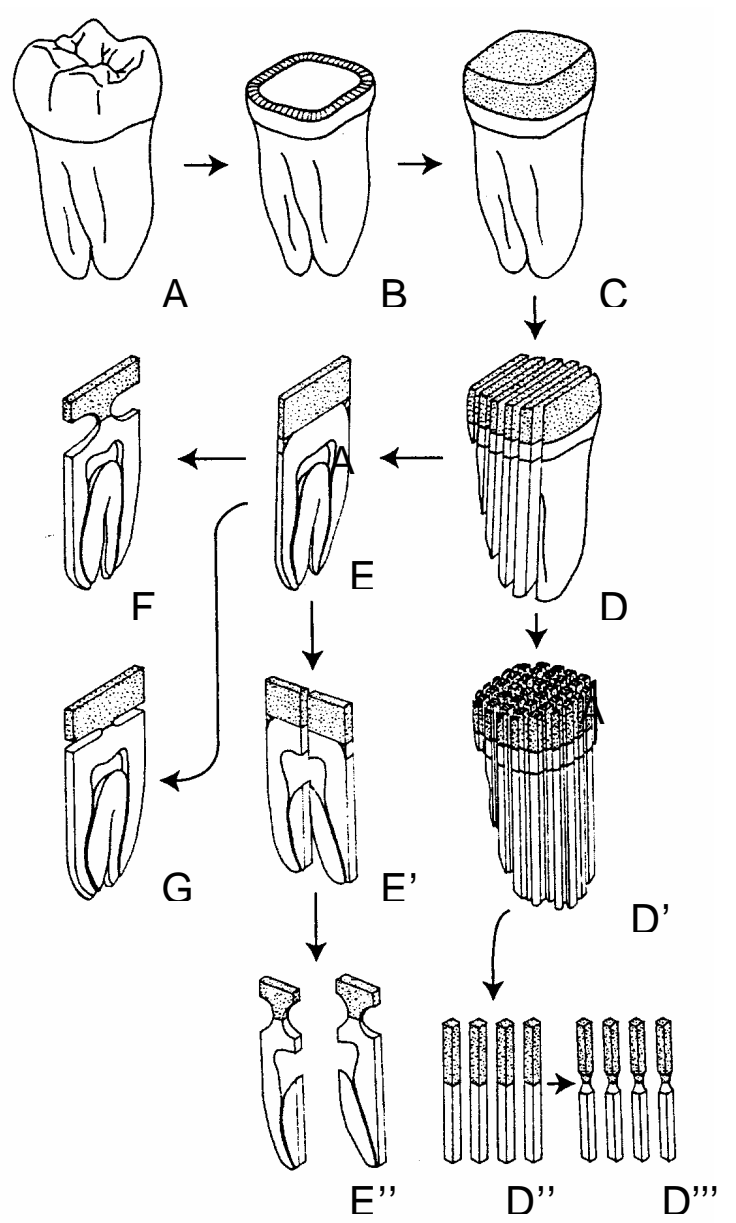

Fig. 2.4.d: Esquematização do método de micro-tração. (adaptado de Pashley et al., 1999 ${ }^{65}$ )

A técnica de micro-tração possui inúmeras vantagens se comparada com as tradicionais. A diminuição do tamanho dos corpos-de-prova permitiu a avaliação em laboratório de diversas situações clínicas que por muitos anos permaneceram mal entendidas. Neste aspecto, puderam ser avaliadas: a superfície dentinária de lesões de abrasão e/ou erosão e também áreas de dentina afetada por cárie ou esclerose. Permite a avaliação de resistência adesiva em cavidades dentais restauradas sob influência do fator de configuração cavitária, o fator $C^{16}$. A resistência adesiva de postes ou pinos intracanais, bem como a de união entre cimentos e peças protéticas também pode ser testada. 
Com respeito ao tecido dentinário, relações entre sua profundidade e adesão podem ser obtidas, bem como avaliação de suas propriedades mecânicas, com espécimes homogêneos de dentina.

No que diz respeito aos materiais adesivos, o teste de micro-tração pode ser extrapolado para a avaliação de reparos entre os mesmos, bem como da união adesiva de materiais de diferentes naturezas.

Recentemente, foi apresentado o método de avaliação pelo teste de microcisalhamento $^{73,}{ }^{85}$. A preparação dos espécimes segundo 0 trabalho de Phrukkanon et al. ${ }^{73}$, obedece quase a mesma seqüência utilizada para o teste de micro-tração. Após a obtenção dos palitos, procede-se o torneamento dos mesmos até que se produza espécimes com forma semelhante à de rebites, sendo que a cabeça e parte do corpo desse rebite são constituídas pela resina composta e o restante pela interface adesiva e dentina (Fig. 2.4.e-A) ${ }^{73}$. Estes espécimes eram fixados e testados numa modificação do dispositivo utilizado para micro-tração. Já no trabalho de Shimada et al. ${ }^{85}$, o objetivo era a avaliação de resistência de adesão de cilindros de cimentos resinosos dual em superfícies de porcelanas vítreas, com diferentes tratamentos superficiais. Cilindros de cimento resinoso de $0,75 \mathrm{~mm}$ de diâmetro e $0,5 \mathrm{~mm}$ de altura eram confeccionados através de matrizes de teflon sobre três ou quatro regiões de uma placa de porcelana vítrea de $15 \mathrm{~mm}$ de comprimento e $10 \mathrm{~mm}$ de largura. O conjunto foi aderido com cianoacrilato a uma nova modificação do dispositivo original utilizado para micro-tração. Um fio de diâmetro $0,2 \mathrm{~mm}$ foi usado para envolver metade da superfície externa de cada cilindro e submetê-los a tensões de cisalhamento pela tração exercida no fio contra a interface adesiva ${ }^{85}$ (Fig. 2.4.e-B). 

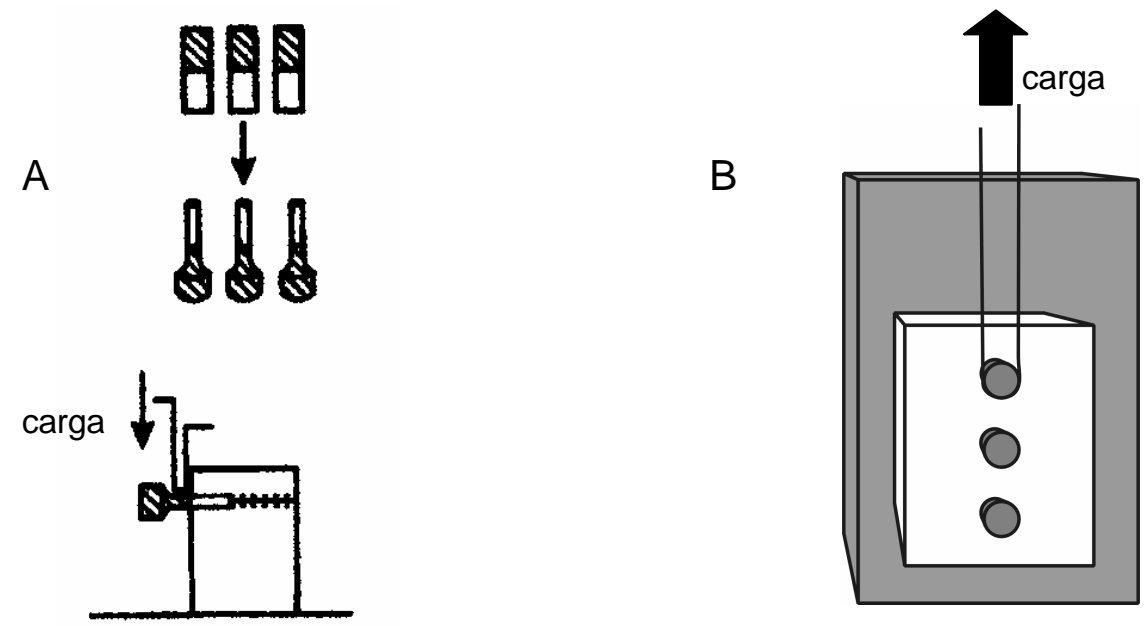

Fig 2.4.e: Micro-cisalhamento. A- segundo Phrukkanon et al. (1998) e B-segundo Shimada et al. (2002). (adaptados de Phrukkanon et al. $(1998)^{73}$ e Shimada et al. $(2002)^{85}$

\section{5- Adesão àdentina hipermineralizada e sua importância clínica}

O cotidiano na prática clínica é envolvido pela presença constante do tipo de substrato dentinário hipermineralizado, tendo fundamental importância nos procedimentos adesivos $^{14,40,46,56,57,61,63,64,97,106}$. No entanto, a imensa maioria dos estudos laboratoriais sobre adesão ou sobre o comportamento de adesivos envolve substratos do tipo normal, isto é, são realizados em dentina de dentes terceiros-molares inclusos extraídos, os quais apresentam dentina normal intacta. Esta, não apresenta em sua microestrutura as mudanças fisiológicas e patológicas que ocorrem em ambiente bucal ${ }^{90,97}$. Alguns autores admitem que a dentina destes dentes não é representativa daquela que é freqüentemente encontrada na cavidade bucal ${ }^{14,56,63,105}$. Porém, é fácil compreendermos que para que haja o desenvolvimento e evolução dos sistemas adesivos estes devam ser testados em condições das mais padronizadas possíveis, e isto é necessário, inclusive, para que se possa realizar comparações. Os dentes inclusos então, 
serviriam como forma de padronização para pesquisas. Já dentes em função na boca, podem apresentar grande variabilidade de substratos dentinários (com vários graus de esclerose fisiológica ou patológica), podendo apresentar até, num mesmo dente, regiões com diferentes substratos.

Essa variabilidade é considerada uma das maiores barreiras para o sucesso clínico dos agentes adesivos ${ }^{98}$. A qualidade de adesão em dentina hipermineralizada por processo fisiológico ou patológico é considerada como mais difícil de se obter do que com dentina não afetada ${ }^{42,98}$.

A dentina hipermineralizada (ou esclerose dentinária) pode ser encontrada em dentes de indivíduos idosos, em lesões de erosão, abrasão, abfração, em lesões de hiperestesia, em reparos teciduais biológicos (pontes de dentina), sob cáries de processo lento e sob restaurações antigas. Obviamente, a utilização dos adesivos dentinários deveria ser viável em todas essas situações, adaptando-se a cada uma delas. A morfologia diferenciada desses substratos fere os princípios do funcionamento dos adesivos atuais, principalmente no que diz respeito à permeação destes, nestes tecidos.

A penetração de resinas nos espaços intertubulares da dentina é altamente dependente da porosidade superficial obtida através do condicionamento ácido ${ }^{61}$, 86.

O condicionamento ácido prévio, ao modo do realizado em dentina normal, parece não ser potencialmente desmineralizante para desobstruir os túbulos dentinários e para expor a trama colágena da dentina intertubular hipermineralizada o que pode prevenir a formação de prolongamentos resinosos ou $\operatorname{tags}^{27,28,64}$. A composição e ultraestrutura da dentina esclerótica indicam que 
ela possui um potencial mais ácido-resistente quando comparada à dentina normal e, portanto, parece ser menos susceptível ao condicionamento ácido ${ }^{24,42,}$ 45, 57, 89, 106. Tal ocorrência compromete a difusão do adesivo no substrato aderente, diminuindo as chances de se obter uma boa adesão. Adicionalmente, a superfície dentinária de lesões não-cariosas expostas ao meio bucal e em contato com a saliva, possui a característica de ser menos solúvel devido aos constantes ciclos de desmineralização e remineralização ${ }^{61,64,96}$. Observa-se nestas lesões a presença de uma camada hipermineralizada adicional na superfície ${ }^{42,106}$.

O aumento do tempo de condicionamento é defendido por algumas autoridades $^{41,64,97,98,99}$ na tentativa de desmineralizar os cristais mais ácidoresistentes, aumentando a permeabilidade dentinária. Entretanto, Perdigão; Lopes $(2001)^{67}$, afirmam que se o ácido permanece em contato com a dentina por um tempo maior que 15 segundos, a profundidade de desmineralização não aumenta proporcionalmente com o tempo. Entre 88 e $90 \%$ do ácido fosfórico não é absorvido pela dentina, sendo retirados com a lavagem. Entretanto, os mesmos afirmam (e demonstraram) que um re-condicionamento, ou nova aplicação do ácido, aumenta substancialmente a desmineralização. Van Meerbeek et al. $(2001)^{99}$ afirmam que somente a dentina esclerótica pode ser condicionada por um tempo maior sem o risco de desmineralização muito profunda, tornando este tipo de substrato mais receptivo à adesão. Outras abordagens sugeridas incluem a utilização de ácidos mais agressivos e a retirada mecânica (desgaste) da porção mais superficial desse substrato, afim de se diminuir a quantidade de minerais ácido-resistentes ao remover a camada superficial hipermineralizada, aumentando assim a permeabilidade $25,41,98$. 
O aumento do tempo de condicionamento pode não ter relação diretamente proporcional com a capacidade de desmineralização do ácido. É especulado que o poder desmineralizante do ácido condicionador é enfrentado pela capacidade de tamponamento da dentina, protagonizada pelo conteúdo mineral e fluidos tubulares $^{67,68}$. Portanto, a quantidade usual de ácido que é empregada teria poder limitado. Agrava-se ainda o fato de os ácidos modernos possuírem a forma de gel, tendo o poder de difusão diminuído (quando comparados æ̀s soluções líquidas), agindo preferencialmente na superfície ${ }^{59}$.

Foi especulado por Pashley; Carvalho $(1997)^{61}$ que em situações de esclerose dentinária, seria hipoteticamente indicado o uso de agentes adesivos auto-condicionantes posteriormente ao condicionamento ácido tradicional, o que seria um retorno à técnica do condicionamento ácido total. $\mathrm{Na}$ prática, isto significaria em um duplo condicionamento, porém, na realidade dos fatos, ainda não sabemos muito bem como estes adesivos mais modernos se comportam em substratos hipermineralizados. O que se sabe, é que os monômeros ácidos, que constituem parte destes adesivos, foram desenvolvidos para que simultaneamente desmineralizassem e permeassem através da camada de detritos, modificando-a. Este tipo de sistema encontra certas dificuldades em se difundir através de dentina hipermineralizada, ou até, através da camada de detritos resultante do preparo cavitário em dentina hipermineralizada. Possuindo alto conteúdo mineral, esta camada de detritos pode também apresentar uma alta capacidade de tamponamento ${ }^{41,42,105}$ à soluções ácidas, capacidade essa, protagonizada pelos detritos da dentina hipermineralizada recém-preparada e pelos detritos dos cristais intratubulares. Os poucos e recentes estudos estão 
demonstrando a pobre interação desses sistemas com substratos afetados pela

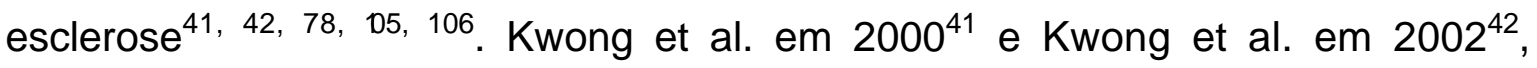
chegaram a investigar a proposta de Pashley; Carvalho, porém com primers autocondicionantes, menos agressivos que os modernos adesivos autocondicionantes. Encontraram valores de resistência à adesão em dentina esclerótica cerca de $25 \%$ inferiores em comparação com dentina normal. Investigações futuras deverão comprovar a real eficácia destes adesivos nestes substratos e a real influência desses fatores.

Uma abordagem diferente e interessante para adesão em dentina esclerótica foi explorada por Kusunoki et al. ${ }^{40}$, em 2002. Após limpeza da superfície da dentina com solução a $0,5 \mathrm{~mol} / \mathrm{L}$ de EDTA por 60 segundos, um primer experimental, baseado em gliceril mono-metacrilato, é espalhado por iguais 60 segundos previamente àaplicação de um agente de união dual contendo 10-MDP (Clearfil Photo Bond, Kuraray). O EDTA teria por função condicionar a superfície, limitando a desmineralização à remoção da camada de detritos apenas. Isto seria importante, segundo os autores, porque o monômero funcional presente no agente de união (10-MDP) combina o cálcio dentinário. O primer experimental tem como função impedir tanto a penetração desses monômeros funcionais na dentina como o afloramento de água do interior para a superfície dentinária. Os autores encontraram, neste trabalho, uma total prevenção de formação de fendas marginais em cavidades preparadas em dentina normal e esclerótica com o uso desta técnica. Quando omitida a aplicação do primer durante os procedimentos, encontrou-se a formação das fendas, sendo menos expressivas em dentina esclerótica, a qual é mais calcificada (mineralizada). 


\subsection{1- Achados de investigações sobre resistência adesiva em substratos}

\section{hipermineralizados:}

As primeiras evidências de baixa resistência à adesão em relação ao substrato dentinário esclerótico foram contemporâneas ao adesivo Scotchbond (3M) e Scotchbond $2(3 \mathrm{M})^{43}$. Duke; Lindemuth ${ }^{13,14}$ (1990 e 1991), confirmaram a extrema dificuldade que este último agente de união tinha para obter com dentina esclerótica os mesmos resultados encontrados com dentina normal.

Heymann et al. ${ }^{31}$, em 1991, também observaram uma alta incidência de falhas retentivas em restaurações do tipo classe $\mathrm{V}$ realizadas com a utilização do Scotchbond 2 em pacientes de idade avançada. Isto significa que a qualidade de adesão obtida, nessas condições, não foi capaz de suportar fatores diretamente relacionados à esta região dental, como forças flexionais resultantes da mastigação.

Tagami et al. ${ }^{90}$, em 1993, resolveram avaliar o efeito da idade dental na eficiência de quatro adesivos representantes da época: Clearfil Liner Bond, Super Bonder D-liner, Resto Bond 3 e Clearfil Photo Bond. Superfícies planas de dentina foram preparadas nas regiões proximais de pré-molares de jovens e idosos. Os autores optaram por esta região com referência à trabalhos anteriores que demonstravam que molares humanos apresentavam maior permeabilidade dentinária nessa região. Ensaios de tração foram realizados com os sistemas, que ao final, demonstraram não haver relação entre idade dental e resistência adesiva, apresentando valores muito próximos. Os autores sugeriram que a 
dentina proximal de pré-molares pode não ser afetada pela idade, como também a dentina oclusal.

Com o interesse de avaliar a resistência adesiva de substratos dentinários com diferentes graus de composição mineral, Perdigão et al. ${ }^{69}$, em 1994, compararam em laboratório, grupos constituídos de espécimes preparados de dentina normal, hipermineralizada artificialmente e desmineralizada artificialmente. Estes dois últimos, foram submetidos a tratamentos que consistiram, respectivamente, na imersão em solução hipermineralizante por 14 dias, segundo Heilman; Wefel $(1989)^{30}$, e imersão em solução desmineralizante por sete dias, que remove minerais mas não dissolve o colágeno -segundo van Strijp et al. ${ }^{102}$ (1992). Sobre os substratos foram confeccionados cilindros de resina composta após a aplicação de quatro tipos de agentes adesivos comerciais contemporâneos da época. Antes do teste de cisalhamento convencional com ponta ativa em forma de faca, os espécimes foram termociclados. A análise de variância dos valores obtidos indicou haver diferença entre os diferentes tipos de substratos. Todos os adesivos testados apresentaram altos valores de resistência em dentina normal em comparação com a dentina hipermineralizada e desmineralizada, apresentando quase todas as falhas de natureza adesiva, entre dentina e resina. Os valores para dentina desmineralizada foram os mais baixos entre todos os grupos.

Nakajima et al. ${ }^{56}$, em 1995, procuraram avaliar, através do teste de microtração, a resistência adesiva de três sistemas (All Bond 2 (Bisco), Scotchbond MP (3M) e Clearfil Liner Bond II (Kuraray)) frente à substratos de dentina afetada por 
cárie e dentina normal de dentes molares humanos. Dentre os dentes cariados, foi dada a preferência para aqueles com lesões limitadas à porção oclusal e que apresentavam dentina normal remanescente ao redor da lesão. Durante a confecção dos espécimes em forma de ampulheta, a qual era confirmada quando observados os espécimes em nível microscópico, percebeu-se que muito da dentina esclerótica afetada por cárie tinha característica de transparência em luz transmitida e coloração marrom-claro em luz refletida. Diferentemente, a dentina normal era opaca em luz transmitida e branca em luz refletida.

Somente 0 adesivo Scotchbond MP não apresentou diminuição estatisticamente significativa $(p>0,05)$ para a variação de condição do substrato. Os outros dois sistemas apresentaram uma redução de cerca de 50\% nos valores de resistência adesiva para dentina afetada por cárie quando comparados com os valores obtidos em dentina normal.

Yoshiyama et al. ${ }^{106}$ em 1996, procuraram através das vantagens do método de micro-tração, avaliar a resistência adesiva em dentina de lesões cervicais naturais em forma de cunha, consideradas teoricamente, mais ácido-resistentes. Procuraram ainda, comparar os espécimes obtidos na porção de dentina localizada na parede gengival das cavidades com aqueles produzidos em dentina localizada na parede oclusal (incisal) de dentes caninos. O grupo controle foi representado como dentina normal, resultante do preparo de cavidades artificiais de formato análogo em dentes hígidos com turbina de alta-rotação. Três adesivos comerciais foram testados: All Bond 2 (Bisco), Scotchbond MP (3M) e Clearfil Liner Bond 2 (Kuraray). Houve diferença estatística entre o grupo controle e o 
grupo representado pelas lesões naturais. A resistência adesiva em dentina de lesões naturais apresentou valores na faixa de 25 a $45 \%$ mais baixos comparados com a dentina normal das lesões artificiais, dependendo do adesivo empregado. Não houve diferenças significativas entre as regiões oclusal e gengival das cavidades. Em lesões naturais (escleróticas) não houve diferença estatística entre os valores obtidos pelos diversos adesivos, por outro lado, houve diferenças quando comparados com os valores obtidos em dentina normal. O Clearfil Liner Bond 2 apresentou maior resistência, seguido do All bond 2 e Scotchbond MP.

Yoshiyama et al. ${ }^{105}$ em 2000, também se utilizaram do método da microtração para comparar a resistência adesiva de dois agentes de união (Single Bond (3M) e Fluorobond (Shofu)) em dentina normal e em regiões de dentes que apresentavam dentina afetada por cárie. Dentes molares foram selecionados e preparados para obter-se uma superfície plana de dentina oclusal. A dentina afetada por cárie foi preparada e padronizada com a ajuda de soluções evidenciadoras de cárie seguidas de inspeção visual. Para o adesivo Single Bond, dois grupos foram criados. Em um deles, um leve jato de ar de dois segundos foi aplicado à superfície lavada após a aplicação do ácido. No outro, foi realizada a técnica úmida. Para o Fluorobond, um adesivo auto-condicionante, também um leve jato de ar foi aplicado à superfície, antes da aplicação do primer. Realizados os testes, o adesivo Single Bond apresentou valores significativamente maiores para técnica úmida em dentina normal (46MPa) em comparação com a mesma técnica em dentina afetada por cárie $(27,1 \mathrm{MPa})$. Na técnica com secagem, os valores de Single Bond em dentina normal $(26,4 \mathrm{MPa})$ também foram 
significativamente maiores que em dentina afetada por cárie (18,1MPa). Fluorobond apresentou valores significativamente menores $(28,2 \mathrm{MPa})$ que Single Bond/técnica úmida em dentina normal, o mesmo acontecendo quando comparados em dentina afetada por cárie (17,5 contra 27,1MPa, respectivamente).

Também pelo método de micro-tração, Nakajima et al., em $2000^{57}$, procuraram avaliar a resistência adesiva de dois adesivos de frasco único, Single Bond (3M) e One-Step (Bisco), em dentina normal e em dentina afetada por cárie, variando-se a concentração do gel ácido empregado para condicionamento da superfície. Quatro grupos foram formados: ácido fosfórico a 35\% + Single Bond; ácido fosfórico a 10\% + Single Bond; ácido fosfórico a 32\% + One-Step e ácido fosfórico a 10\% + One-Step. Os valores para dentina normal foram todos maiores se comparados com aqueles obtidos com dentina afetada por cárie nas respectivas concentrações de ácido. No entanto, para o grupo One-Step/32\% ácido fosfórico não houve diferença estatística na comparação.

Yoshiyama et al. ${ }^{107}$, em 2002, avaliaram a eficácia de um adesivo auto condicionante experimental, o $A B F$ (Kuraray), e de um adesivo comercial de dois passos, o Single Bond (3M-ESPE), em superfícies de dentina normal e em superfícies de dentina infectada e afetada por cárie. O teste consistiu na avaliação da resistência adesiva à tração pelo método da micro-tração. Não houve diferenças estatisticamente significativas quando comparados apenas os dois adesivos em cada tipo de substrato, apesar de o Single Bond ter apresentado 
valores maiores em todas as condições. Houve diferenças estatísticas entre os valores médios na comparação entre os substratos para cada um dos adesivos. Os valores mais altos foram observados em dentina normal, seguidos dos obtidos em dentina afetada e dentina infectada por cárie.

Kwong et al. ${ }^{42}$, em 2002, resolveram avaliar o efeito da aplicação da técnica do condicionamento total quando utilizado o primer autocondicionante Clearfil Liner Bond 2V (Kuraray) em substratos dentinários de lesões cervicais naturais de dentes pré-molares e em substratos dentinários normais de lesões semelhantes artificialmente preparadas em dentes hígidos do mesmo tipo. Cada um dos substratos recebeu dois tipos de tratamento: 1) ataque com ácido fosfórico a $40 \%$ por 15 segundos + primer (30 segundos) e, 2) primer somente (30 segundos). Através do método de micro-tração, verificaram não haver diferenças estatisticamente significantes quando comparados os dois tipos de tratamento entre os mesmos tipos de substrato. Os valores de resistência para o substrato dentinário esclerótico foram significativamente menores que os valores em dentina normal, independentemente do tipo de tratamento.

\subsection{2- Observaç̃es microscópicas:}

As estruturas características da esclerose dentinária como a presença de cristais e bastonetes, decorrentes do gradual acúmulo de minerais nos túbulos dentinários, são freqüentemente observadas na Literatura. Apesar de alguns relatos afirmarem que estas estruturas são originadas por aposição da dentina peritubular, ou seja, da deposição de sucessivas camadas sobre aquela 
naturalmente formada ${ }^{50,96,97}$, Vasiliadis et al. ${ }^{103}$ (1983), discordam, descrevendoas como estruturalmente diferentes. Durante seu estudo, perceberam que principalmente os bastonetes que ocluem os túbulos se separavam da dentina peritubular durante a fratura para observação. Dessa maneira, não pertenceriam à dentina peritubular. Além do mais, a presença de um certo espaçamento entre as duas estruturas, como foi observada, indicaria a diferença de constituição entre elas. Acreditavam eles, estas estruturas serem oriundas de processos coordenados pelo órgão pulpar.

Estas estruturas são observadas em dentinas hipermineralizadas influenciadas pela idade e naquelas decorrentes de processos patológicos de longa duração como lesões de abrasão, erosão e cárie. No entanto, os estudos que incluem testes ou observações morfológicas em dentina cariada, pecam ao não descreverem se tais lesões eram conseqüentes de lesões crônicas de cárie ou agudas. Em razão de freqüentemente ser relatada a presença de tais estruturas e a presença de dentina afetada por cárie ser sempre bem caracterizada, conclui-se tratar-se de lesões apresentando certa cronicidade. Entretanto, o aspecto da padronização dos espécimes permanece obscuro. Somente a extensão de profundidade de dentina afetada parece não ser definitiva para a padronização. Observações em nível microscópico das lesões, antes e depois dos testes de resistência adesiva como proposto por Nakajima et al. ${ }^{56}$ (1995), apresentam melhor confiabilidade. A Literatura também necessita de investigações que estabeleçam melhor uma relação entre tempo e o aparecimento de tais estruturas, seja por processos fisiológicos e/ou patológicos. 
A dentina modificada pela idade parece apresentar certa homogeneidade no grau de obliteração dos túbulos numa dada área. Em processos patológicos, a obliteração dos túbulos fica mais localizada na região onde ocorre o estímulo. No entanto, em lesões cervicais, principalmente aquelas que apresentam hiperestesia, são observadas regiões com túbulos abertos adjacentes à regiões com túbulos completamente obliterados. Yoshiyama et al. ${ }^{104}$ em 1989, analisando em M.E.V. regiões com e sem sensibilidade dolorosa a partir de biópsias realizadas em lesões cervicais em forma de cunha, observaram que as regiões com hiperestesia correspondiam à aquelas caracterizadas por apresentarem a maioria de túbulos abertos (cerca de $75 \%$ ), enquanto que as regiões nãosensíveis eram correspondentes à aquelas que apresentavam grande parte de túbulos obliterados (cerca de 70\%). A superfície das regiões não-sensíveis em microradiografia era mais radiopaca que nas regiões sensíveis, demonstrando apresentar uma camada de maior densidade mineral, isto é, uma hipermineralização.

Marshall Junior et al. ${ }^{45}$, em 2000, observaram em M.F.A. a capacidade de desmineralização pelo ácido cítrico 0,018M $(\mathrm{pH} \mathrm{2,5)}$ de espécimes de dentina esclerótica e de dentina normal em vários seqüenciais períodos de condicionamento. Concluiu que a presença dos aglomerados minerais que ocluem os túbulos tornam o substrato dentinário esclerótico mais ácido-resistente, concordando com as prévias observações de Gwinnett; Jerdensen ${ }^{24}$ (1978) e Mixson et al. ${ }^{47}$, em 1995. Este fator implica diretamente na formação posterior da camada híbrida, tornando-a com aspecto alterado ${ }^{97}$. Van Meerbeek et al. ${ }^{97}$ (1994) 
observaram ao M.E.V., assim como Kwong/Tay et al. ${ }^{41}$ (2000) também observaram ao M.E.V. e ao M.E.T., a protusão dos bastonetes e cristais minerais presentes nos túbulos após condicionamento ácido. A incompleta ou não desmineralização dessas estruturas faz com que a camada híbrida as envolva, diminuindo a formação de prolongamentos resinosos devido à permanência de obstrução dos túbulos.

A camada híbrida em substrato esclerótico é freqüentemente descrita como sendo mais delgada quando comparada com a dentina normal, apresentando deficiência na formação de prolongamentos resinosos.

Características semelhantes foram observadas em M.E.V. por Harnirattisai et al. em $1992^{27}$ e $1993^{28}$, mesmo quando estenderam a aplicação do condicionamento com ácido fosfórico a $37 \%$ para 60 segundos para uso com o adesivo Clearfil Photo Bond (Kuraray). Van Meerbeek et al. ${ }^{97}$, em 1994, observaram em M.E.V. pouquíssima formação de prolongamentos resinosos quando o adesivo Clearfil Liner Bond (Kuraray) fora aplicado em dentina esclerótica de lesões de abrasão e erosão. Prolongamentos mais finos foram observados em M.E.V. por Perdigão et al. ${ }^{69}$ (1994) em dentina artificialmente hipermineralizada, pela interação desta com os adesivos AmalgamBond Plus (Parkell) e All Bond 2 (Bisco).

Comparando através do M.E.V. os adesivos Clearfil Liner Bond 2 (Kuraray), All Bond 2 (Bisco) e Scotchbond MP (3M) quando aplicados em dentina esclerótica, Yoshiyama et al. ${ }^{106}$ (1996), observaram que o Clearfil, um primer 
auto-condicionante, não apresentou uma camada híbrida muito evidente, enquanto que os outros adesivos apresentaram esta camada com variadas espessuras, em média muito finas e com deficiência de prolongamentos resinosos.

Prati et al. ${ }^{72}$, em 1999, mesmo aumentando o tempo de aplicação do ácido fosfórico de 15 para 25 segundos, obteve também formas alteradas de camada híbrida quando comparadas dentina esclerótica e normal com os adesivos Prime Bond 2.0 (Dentsply), Optibond FL (Kerr), One Step (Bisco), Scotchbond MP (3M) e Single Bond (3M). Elas eram ao M.E.V. mais delgadas que as produzidas em dentina normal, além de apresentarem seus prolongamentos resinosos menores e com variações marcantes de espessura ao longo de seus comprimentos.

Kwong et al. $^{41}$ em 2000, verificando em M.E.V. a morfologia de lesões cervicais em forma de cunha quando condicionadas com ácido fosfórico a $40 \%$ por 15 segundos, perceberam que a superfície de dentina esclerótica condicionada mostrava uma aparência granular apresentando aglomerados minerais semelhantes à corais, ao contrário da dentina normal. Ao a nalisar em M.E.T. o padrão da camada híbrida formada pelo primer auto condicionante Clearfil Liner Bond 2V (Kuraray), observou que a extensão da mesma era muito pequena $(1 \mu \mathrm{m})$, apresentando em algumas áreas, sítios de colonização bacteriana. A formação de prolongamentos foi rara. Camadas híbridas não autênticas foram observadas mesmo quando este adesivo foi associado ao condicionamento prévio com o ácido fosfórico a 40\%. Foi rara também a 
observação de canais laterais nos prolongamentos resinosos em todos os espécimes de dentina esclerótica examinados no M.E.T.

Os canais laterais também foram raramente observados em M.E.V. por Sakoolnamarka et al. ${ }^{78}$ (2002), em camadas híbridas formadas pelo adesivo OneCoat Bond (Coltène) em dentina esclerótica de lesões cervicais. Em dentina normal, por outro lado, eles foram claramente identificados. A camada híbrida produzida pelo adesivo Clearfil SE Bond (Kuraray) também foi analisada, exibindo poucos prolongamentos resinosos, sendo que quando identificados, apresentavam-se muito finos e mal formados.

Kwong et al. em $2002^{42}$, confirmaram em seu estudo (em M.E.T.) a presença de uma camada hipermineralizada em lesões cervicais naturais, que provavelmente é gerada devido à exposição dentinária ao meio bucal. Esta chegava à e spessura de $14 \mu \mathrm{m}$. Ainda, como no estudo anterior ${ }^{41}$ de 2000 , perceberam que esta camada apresentava grande quantidade de bactérias (em camadas), as quais permaneciam entremeadas na camada híbrida quando se tratavam estas lesões com o primer autocondicionante Clearfil Liner Bond $2 \mathrm{~V}$ (Kuraray). Este fato ocorria mesmo com o preparo manual prévio das superfícies com pedra-pomes e clorexidina. Foi observado que o primer autocondicionante não foi capaz de desmineralizar a camada de dentina esclerótica logo abaixo da camada superficial hipermineralizada. Utilizando-se tratamento prévio com ácido fosfórico a 40\%, foi observado que a profundidade desmineralização foi dependente da espessura da camada hipermineralizada. Quando delgadas, elas 
foram completamente removidas, por outro lado, quando espessas, a desmineralização ocorreu parcialmente, sendo que a camada híbrida estava ausente ou se apresentava muito delgada.

Apesar da dentina afetada por cárie ser considerada como esclerótica, algumas características a diferem das demais. Ela apresenta os mesmos depósitos minerais que ocluem a luz dos túbulos dentinários, no entanto, ela possui menor dureza, provavelmente por ser parcialmente desmineralizada pelos ácidos bacterianos ${ }^{57}$. Nakajima et al. ${ }^{57}$, em 2000, avaliaram em M.E.V. camadas híbridas formadas pelos adesivos Single Bond (3M) e One-Step (Bisco) em dentina normal e afetada por cárie, quando condicionadas com concentrações diferentes de ácido fosfórico - 10 e 32\% para o One-Step e 10 e 35\% para o Single Bond. Elas foram mais espessas em dentina afetada por cárie em comparação com dentina normal, não importando a concentração de ácido utilizada. A camada híbrida de Single Bond e One Step apresentaram espessuras semelhantes e sem diferença estatística quando comparadas analogamente em quase todas as condições, salvo quando a dentina normal foi condicionada com ácido a $10 \%$, onde Single Bond apresentou média de espessura menor $(1,5 \mu \mathrm{m})$ que One-Step $(2,3 \mu \mathrm{m})$.

Yoshiyama et al. ${ }^{105}$, em 2000 , observaram em M.E.V. as camadas híbridas formadas com Single Bond (3M), realizadas com técnica úmida ou seca, e as produzidas por Fluorobond (Shofu), com técnica seca, em dentina normal e afetada por cárie. Foram observados depósitos minerais nos túbulos em dentina 
afetada por cárie, sendo que o Single Bond apresentou camadas híbridas espessas, maiores para técnica úmida $(5-10 \mu \mathrm{m})$. Em dentina normal, o Single Bond apresentou camadas híbridas típicas, sendo de menor espessura aquelas obtidas com técnica seca. O Fluorobond, um adesivo auto-condicionante,

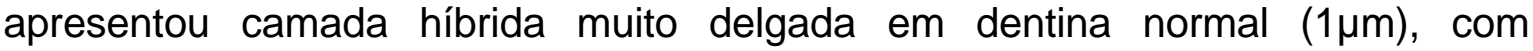
prolongamentos resinosos muito pequenos. Em dentina afetada este adesivo foi incapaz de se infiltrar nos túbulos ocluídos por depósitos minerais e dentina intertubular adjacente, não havendo evidência de formação de camada híbrida típica.

Yoshiyama et al. ${ }^{107}$, em 2002, observaram em M.E.T. o comportamento de um adesivo autocondicionante experimental, o $A B F$ (Kuraray), e de um adesivo de dois passos, o Single Bond (3M-ESPE), em dentina normal, afetada por cárie e infectada por cárie. Para ambos os adesivos, a camada híbrida observada em dentina afetada foi muito mais espessa que em dentina normal, sendo os túbulos freqüentemente observados com depósitos minerais em seu interior. O adesivo $A B F$ foi incapaz, em certas regiões, de condicionar e de se infiltrar além da camada de dentina infectada, e apresentou sítios bacterianos aprisionados internamente. Com o Single Bond, estes sítios também foram observados nos túbulos e dentro da camada formada pelo componente copolímero ácido polialcenóico, na superfície de sua camada híbrida formada sobre a dentina infectada. 


\section{Proposição}

Após ter sido realizada a revisão da Literatura, e considerando a necessidade de aprimoramento de materiais e/ou técnicas que objetivem a qualidade de adesão em substratos dentinários hipermineralizados, este estudo teve como propostas:

1) Comparar a resistência adesiva de um agente de união dentinário frente a dois tipos de substratos dentinários: normal e hipermineralizado artificialmente e,

2) Avaliar o efeito de um condicionamento por duplo ataque ácido sobre a resistência adesiva em substrato dentinário hipermineralizado artificialmente. 
Materiais e

métodos 


\section{4- MATERIAIS E MÉTODOS}
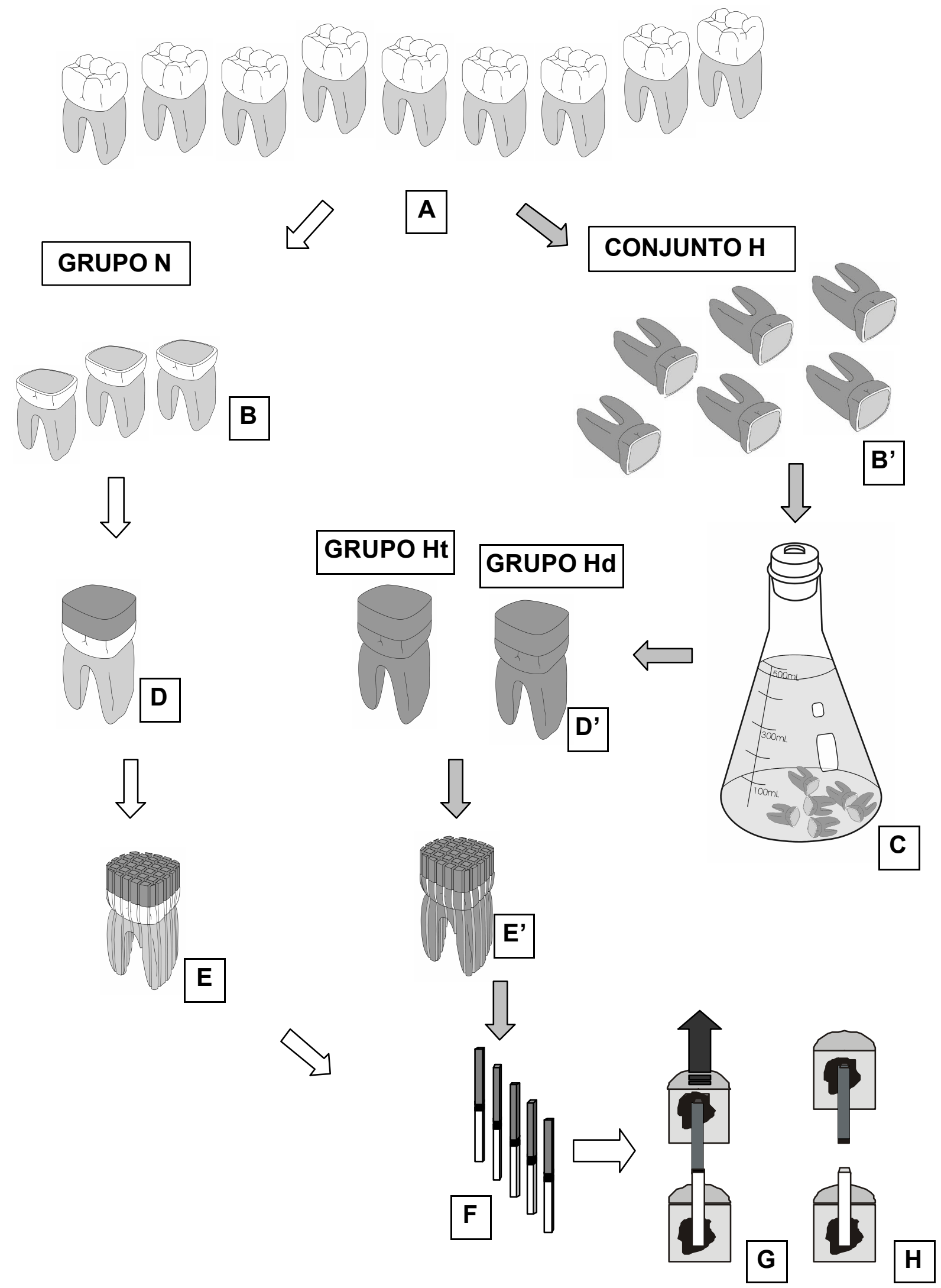

Figura 4.1 - Fluxograma ilustrativo do experimento 
4.2- Prancha colorida:
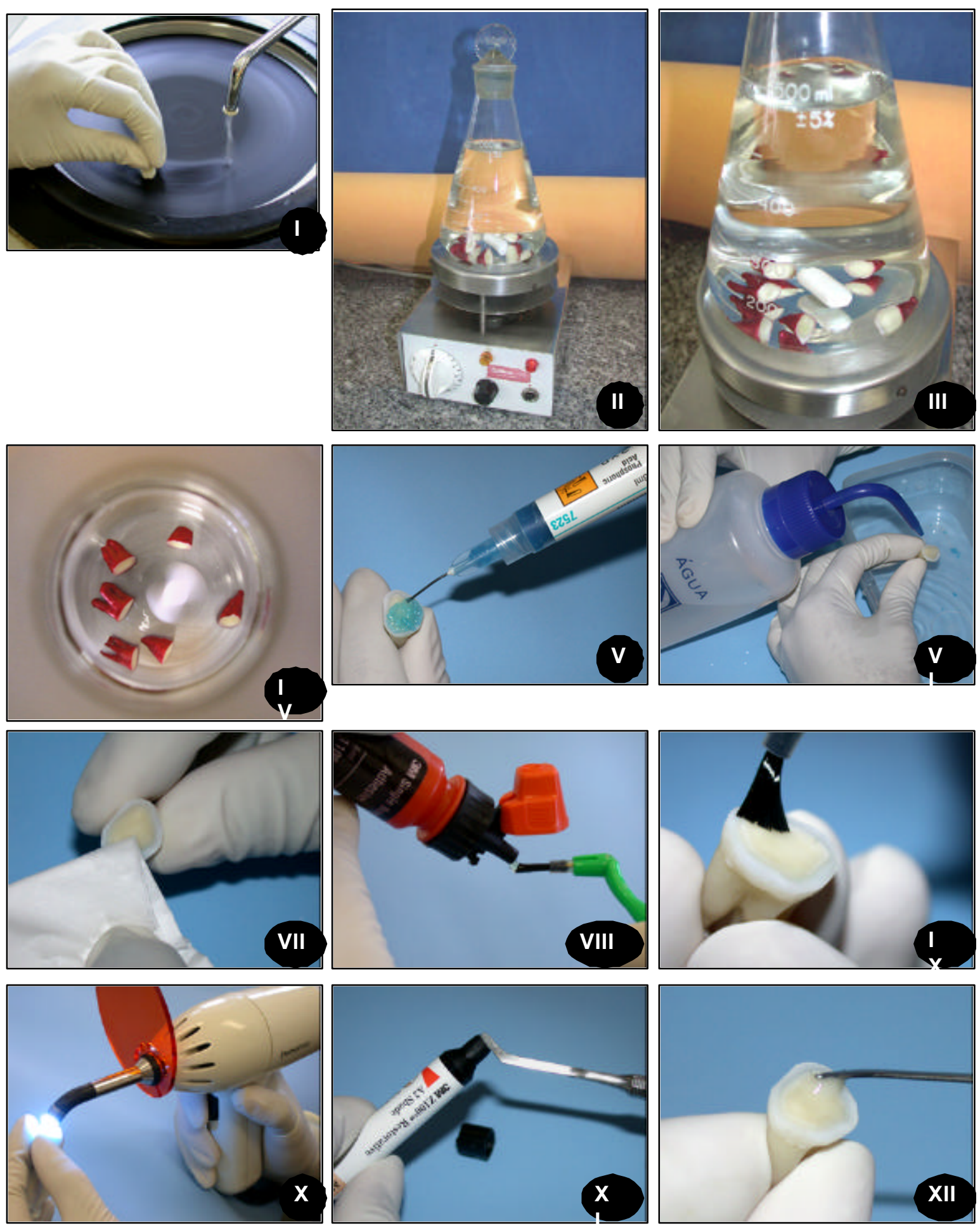

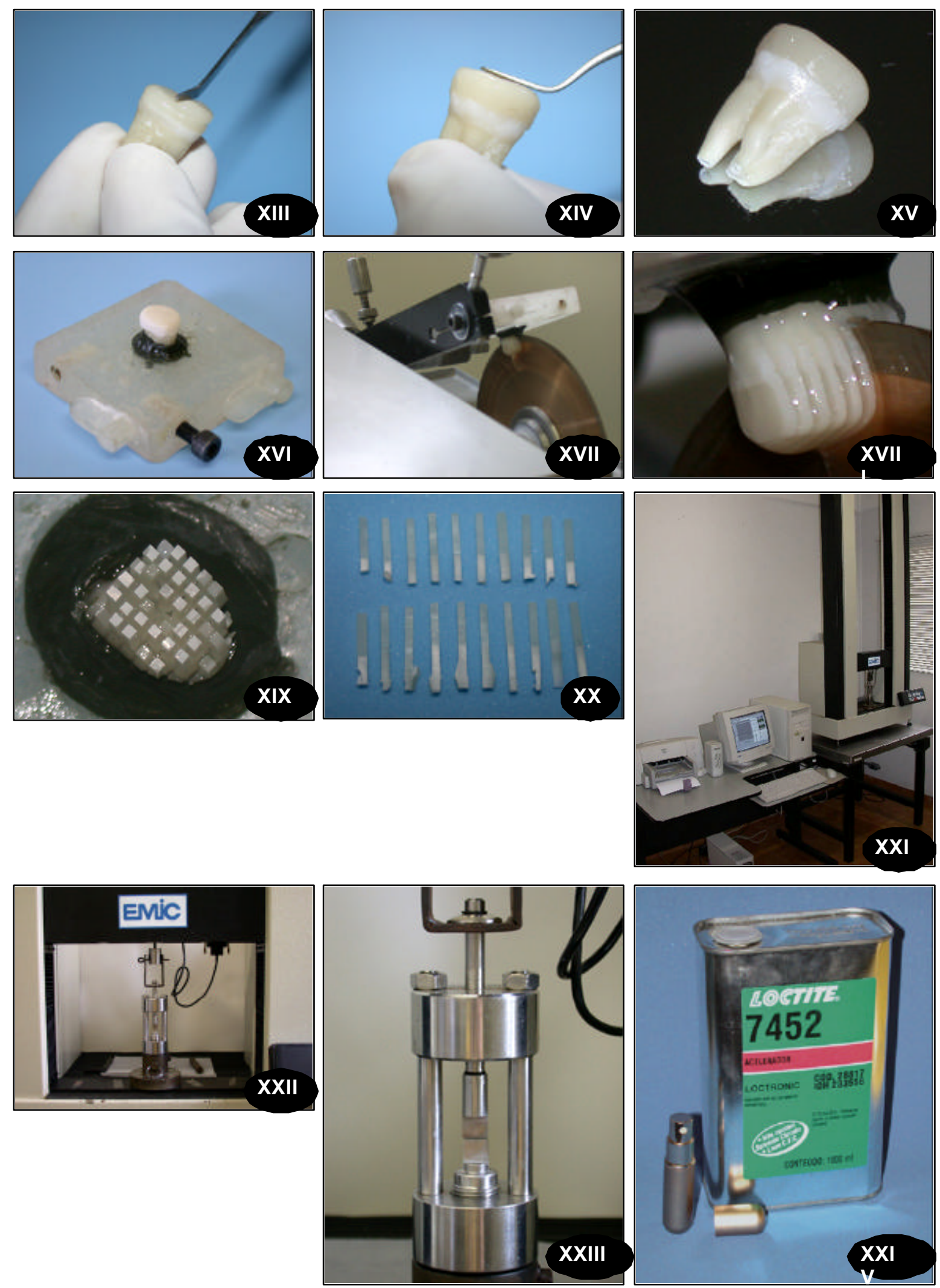

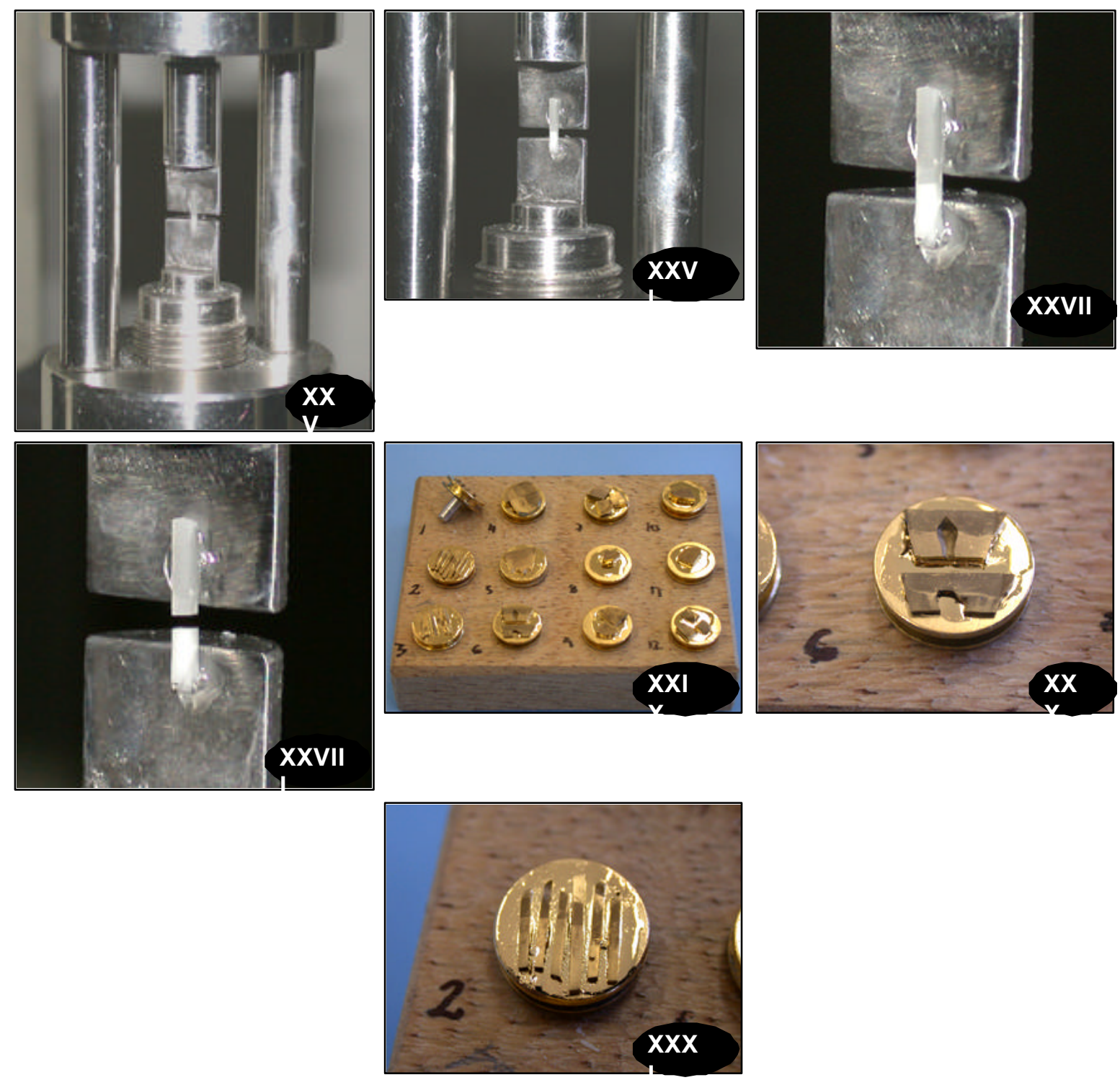

Fig. 4.2: Série de ilustrações de materiais e dos métodos empregados:

I: $\quad$ Modo de preparo da superfície de dentina através do lixamento/polimento;

II: $\quad$ Ilustração do aparelho agitador magnético;

III: Vista aproximada dos dentes na solução hipermineralizante sobre o agitador magnético. Entre os dentes podemos observar a barra imantada;

IV: Vista superior do erlenmeyer, demonstrando o agitamento da solução;

V: $\quad$ Ilustração do modo de ataque ácido da superfície de dentina;

VI: llustração da lavagem após aplicação do ácido; 
VII: Ilustração do modo de secagem e manutenção de umidade dentinária;

VIII: Adesivo sendo dispensado no pincel aplicador;

IX: Aplicação do adesivo;

X: $\quad$ Fotopolimerização do adesivo;

XI: Resina composta sendo dispensada na espátula de inserção;

XII: Inserção da resina;

XIII: Inserção da resina em camadas;

XIV: Finalização do bloco;

XV: Aspecto final do dente com o bloco de resina construído sobre a camada de adesivo;

XVI: Fixação do dente com godiva na plataforma para corte;

XVII: Seccionamento do dente na máquina de corte;

XVIII: Visão aproximada dos cortes sendo realizados;

XIX: Aspecto final do dente seccionado;

XX: Espécimes produzidos em forma de palitos;

XXI: Aspecto do conjunto de equipamentos para a produção dos ensaios mecânicos;

XXII: Vista frontal da máquina de ensaios, onde se observa o dispositivo para micro-tração acoplado;

XXIII: Dispositivo para micro-tração;

XXIV: Acelerador de presa do adesivo de cianoacrilato. Vê-se também, o burrifador utilizado para sua aplicação;

XXV: Vista aproximada do dispositivo para micro-tração com o espécime aderido com adesivo de cianoacrilato; 
XXVI: Outra vista aproximada, mostrando o espécime aderido no dispositivo;

XXVII: Nova vista bem aproximada da colagem do espécime no dispositivo;

XXVIII: Aspecto do espécime após o ensaio, ou seja, após ruptura;

XXIX: Aspecto dos espécimes montados em stubs e cobertos com camada de ouro para observação em M.E.V.;

XXX: Vista aproximada de um dos espécimes (cortes longitudinais do dente) para observação em M.E.V.;

XXXI: Outra visão de um stub com palitos preparados para observação em M.E.V.. 
4.1- Materiais selecionados para este estudo:

Tabela 4.1.1: Materiais selecionados:

\section{material}

composição

Scotchbond condicionador

ácido gel a 35\%

Ácido ortofosfórico a 35\%, sílica

(3M-ESPE - St. Paul, MN, coloidal/surfactantes; $\mathrm{pH} \sim 0,6$

E.U.A. $)^{a}$

Bis-GMA, HEMA, copolímero de ácido

Single Bond

policarboxílico, uretano dimetacrilato, etil-4-

(3M-ESPE - St. Paul, MN, dimetilaminobenzoato, glicerol dimetacrilato,

E.U.A. $)^{\mathrm{a}}$

água, etanol, difeniliodo-hexafluorfosfato,

canforoquinona.

Z 100

Bis-GMA, TEGDMA, fotoiniciadores,

(3M-ESPE - St. Paul, MN, estabilizadores, partículas de óxido de

E.U.A. $)^{b}-\operatorname{cor} A 2 \quad$ zircônia/sílica coloidal (66\%p.v.)

Super Bonder - Gel

Etilcianoacrilato (85-90\%), Polimetilmetacrilato

(Henkel-Loctite - SP, Brasil) $^{\mathrm{a}}$

(5-10\%), sílica coloidal (5-10\%), hidroquinona

$(0,1-0,5 \%)$

Loctronic

Acetona (95-100\%), iniciadores (N,N-

(Henkel-Loctite - SP, Brasil) $^{\mathrm{a}}$ dialquiltoluidina) (0,1-1\%).

a: informação do fabricante; b: Paul et al. ${ }^{66}$ (1999) 
Tabela 4.1.2: Identificação do lote e prazo de validade dos principais materiais

\begin{tabular}{ccc}
\hline materiais & lote & vencimento \\
\hline Scotchbond - ácido & OUN & $11 / 2003$ \\
fosfórico 35\% & 27071 & $04 / 2003$ \\
Single Bond & 2BK & $01 / 2005$ \\
Z100 & EF & $10 / 2002$ \\
\hline Super Bonder & O1DE254 & $04 / 2003$ \\
\hline Loctronic & & \\
\hline
\end{tabular}




\section{2- Métodos}

\subsection{1- Preparação dos espécimes:}

Doze dentes terceiros-molares humanos hígidos e extraídos foram selecionados para este estudo (Fig. 4.1-A). Estes, foram obtidos através de doação por pacientes com consentimento livre e esclarecido, tendo aval do Comitê de Ética em Pesquisa da Faculdade de Odontologia de Bauru - USP. Os mesmos permaneceram armazenados em solução de cloramina T a 0,5 \% (Carlo Erba Reagenti - Itália) por uma semana, sendo posteriormente armazenados em água deionizada até o momento do uso. Esta água era renovada a cada semana ${ }^{33}$.

A superfície oclusal dos dentes foi desgastada por meio de lixas de carbeto de silício (Norton - SP, Brasil) de granulação 120, em lixadeira com água corrente (DP 9a, Panambra - SP, Brasil), até que se produzisse uma superfície plana e uniforme de dentina sem a presença de esmalte em meio a esta (Fig. 4.2-I).

Esses dentes desgastados foram divididos em: Grupo $N$ - dentina normal - 4 dentes; Conjunto $H$ - dentina hipermineralizada - 8 dentes.

\subsection{2- Procedimento de hipermineralização (Heilman; Wefel ${ }^{30}$, 1989; Perdigão et} al. $\left.{ }^{69}, 1994\right):$

O conjunto $H$ recebeu tratamento para hipermineralização da superfície dentinária:

Para este processo, uma solução mineralizante $(\mathrm{pH}=7)$ contendo $1,5 \mathrm{mM}$ de cálcio (proveniente de $\mathrm{CaCl}_{2} \cdot 2 \mathrm{H}_{2} \mathrm{O}$ ), 0,9 mM de fosfato (proveniente de $\mathrm{K}_{2} \mathrm{PO}_{4}$ ), e 
0,15 M de cloreto de potássio fora formulada pelo departamento de Bioquímica da Faculdade de Odontologia de Bauru - Universidade de São Paulo.

Os dentes desgastados tiveram sua superfície oclusal isolada do resto do corpo do dente por meio de esmalte para unhas (de secagem rápida - RisquéStar, Niasi - SP, Brasil), para que somente ela ficasse em contato com a solução. Para tal procedimento, cada superfície foi aderida a uma fita adesiva, e assim, o restante do dente pode ser pintado com o esmalte. Após a secagem do esmalte, que ocorreu por volta de cinco minutos, as superfícies expostas foram novamente lixadas com a seqüência de lixas de carbeto de silício de granulação 320 e 600 (20 segundos em cada), padronizando-as (Fig. 4.1-B').

A dentina exposta de cada dente recebeu ataque com gel de ácido fosfórico 35\% (Scotchbond-3M-ESPE) por cinco segundos, para remoção da camada de detritos(ou smear-layer) e para a abertura/desobliteração dos túbulos dentinários (Fig. 5.2-V e VI). Depois, foi lavada por 20 segundos com jato de água deionizada.

Em seqüência, os dentes foram imersos em $480 \mathrm{~mL}$ da solução mineralizante e mantidos em temperatura ambiente. A solução foi renovada periodicamente a cada 24 horas por 14 dias, e permaneceu em constante agitação por meio de um agitador magnético ( $\mathrm{RH}$ 12, Rühromag - Alemanha) (Fig. 4.1-C; Figs. 4.2- II, III, IV). A quantidade utilizada de solução foi calculada utilizando-se como área circular base de cada dente como sendo $78,5 \mathrm{~mm}^{2}$ (diâmetro= $10 \mathrm{~mm}$ ), ou seja, cada milímetro quadrado de superfície exposta deveria corresponder a 0,76 mL de solução. 
Ao término dos 14 dias, a superfície dentinária foi considerada hipermineralizada para o posterior procedimento adesivo. Dois dentes desse conjunto foram separados para observação em microscópio eletrônico de varredura.

\subsection{3- Procedimento adesivo}

Para o procedimento adesivo, o conjunto $H$ foi dividido igualmente em dois grupos de três dentes: Ht (condicionamento tradicional) e $H d$ (duplo condicionamento) (Fig. 4.1-D’).

Previamente ao procedimento adesivo, as superfícies de dentina expostas do grupo $N$ foram lixadas com seqüência de lixas de carbeto de silício de granulação

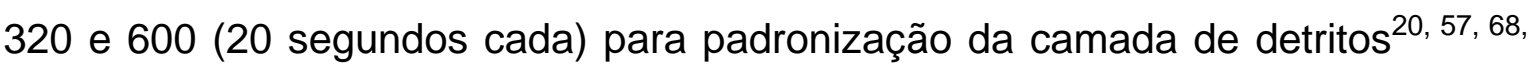
105 (Fig. 4.1-B). Um dente deste grupo também foi separado para a realização de microscopia eletrônica de varredura, portanto, o grupo $N$ permaneceu com três dentes para os ensaios de resistência.

As superfícies dentinárias dos dentes do grupo $\mathrm{N}$ e dos grupos $\mathrm{Ht}$ e $\mathrm{Hd}$ foram tratadas por 15 segundos de solução de ácido fosfórico a 35\% para condicionamento, expondo os túbulos dentinários (Fig. 4.2-V). As superfícies foram lavadas por 20 segundos com água deionizada e secas com papel absorvente (Figs. 4.2-VI, VII). O grupo $\mathrm{Hd}$ recebeu um tratamento adicional da dentina hipermineralizada com solução de ácido fosfórico 35\% por mais 15 segundos (duplo ataque ácido), sendo lavados novamente e secos da maneira já descrita. 
Em seguida, com a dentina se apresentando úmida (superfície brilhante quando refletida contra a luz), foi aplicado através de pincel, duas camadas de agente de união adesiva (Single Bond, 3M-ESPE - E.U.A.) ativamente, ou seja, sendo espalhado a quantidade deste agente de união diversas vezes com o pincel num tempo de 15 segundos (Figs. 4.2-VIII, IX). Após este período, aguardourse mais 15 segundos para que o solvente presente no adesivo pudesse melhor evaporar da superfície dentinária, para então fotopolimerizarmos por 10 segundos através de um aparelho fotopolimerizador de lâmpada halógena (Optilux, Demetron - E.U.A.) (Fig. 4.2-X) com potência luminosa em torno de $600 \mathrm{~mW} / \mathrm{cm}^{2}$ aferida por um radiômetro (modelo 100, Demetron - E.U.A.).

Sobre a camada de adesivo, foi confeccionado um bloco de resina composta (Z100-3M-ESPE) em incrementos de no máximo três milímetros e que foram fotopolimerizados por 40 segundos cada. O bloco teve altura de cinco milímetros, sendo suficiente para a realização do teste de resistência adesiva, cuja descrição veremos mais adiante (Figs. 4.1-D, D'; Figs. 4.2-XI, XII, XIII, XIV, XV).

Todo o procedimento adesivo e inserção da resina composta de todos os dentes foram realizados pelo mesmo operador e em ambiente com temperatura controlada, em torno de $23^{\circ} \mathrm{C}$, e umidade entre 40 e $50 \%$.

A partir deste ponto, os espécimes produzidos foram armazenados em água deionizada e em estufa com temperatura de $37^{\circ} \mathrm{C}$ por 24 horas.

\subsection{4- Preparo dos espécimes e ensaios de resistência adesiva}

Após o período de armazenamento, os dentes foram fixados com godiva (Kerr - E.U.A.) numa plataforma de acrílico (Fig. 4.2-XVI), que adaptada a uma máquina 
para cortes precisos com disco diamantado (Labcut 1010, Extec - E.U.A.), permitiu a produção de cortes paralelos aos seus longo-eixos em série, nos sentidos mésio-distal e vestíbulo lingual. Dessa forma, obteve-se espécimes de resina-adesivo-dentina em forma de palitos, com espessuras em torno de $0,8 \mathrm{~mm}$ (Figs. 4.1-E, E', F; Figs. 4.2-XVII, XVIII, XIX, XX). Os cortes que apresentaram união da resina restauradora ao esmalte periférico do dente foram descartados. Também, palitos com espessura remanescente de tecido dentinário menor que dois milímetros foram descartados para os ensaios, porém, alguns foram aproveitados para observação em M.E.V..

Cada espécime assim morfologicamente confeccionado foi fixado com adesivo à base de cianoacrilato (Super Bonder-Gel, Henkel-Loctite - SP, Brasil) ao dispositivo de micro-tração (Bencor Multi-T, Danville Engineering Co. - CA, E.U.A.) (Fig. 4.1-G; Figs. 4.2- XXV, XXVI, XXVII) em máquina de ensaios universais computadorizada (DL 500/EMIC-PR, Brasil) (Figs. 4.2-XXI, XXII) e submetido àforça de tração numa velocidade de $0,5 \mathrm{~mm} / \mathrm{min}$ até a ocorrência de ruptura (Figs. 4.1-H; Fig. 4.2-XXVIII). Para rapidez e tomada de presa do adesivo de cianoacrilato fora utilizado o acelerador de presa correspondente ao produto e de mesmo fabricante (Loctronic-acelerador 7452, HenkelLoctite - SP, Brasil) (Fig. 4.2-XXIV). Após a ruptura, a área adesiva dentinária foi obtida utilizando-se os valores das arestas da área de secção do espécime (quadrilátero formado), medindo-as com paquímetro eletrônico digital com precisão de 0,01 mm (Starrett, mod. 727-SP, Brasil). Com estes dados, pudemos converter os valores em quilograma-força (registrados pela máquina de ensaios) em valores de unidade mega-pascal. 


\subsection{5- Avaliação do padrão de ruptura obtida}

Os espécimes testados (porção dentinária) foram montados em plataformas de alumínio ou stubs, levados ao metalizador (MED 010, Balzers Union, Balzers Liechtenstein) para receberem cobertura de ouro de cerca de $10 \mathrm{~nm}$ e analisados um a um quanto ao padrão de ruptura adesiva ao tracionamento em microscópio eletrônico de varredura (DSM 940A, Zeiss - Alemanha), em aumentos de 100 a 200 vezes da imagem real. No entanto, aumentos maiores, de até 1000 vezes, foram ocasionalmente realizados, quando do surgimento de dúvidas. Para a categorização das rupturas, foram adotados os seguintes critérios:

a) Ruptura de origem adesiva (A): Quando a ruptura ficou restrita em $100 \%$ à interface adesiva, isto é, quando só foram observadas rupturas no agente de união e/ou na camada híbrida (topo, corpo ou base);

b) Ruptura coesiva em dentina (CD): quando a ruptura restringiu-se totalmente ao substrato dentinário;

c) Ruptura coesiva em resina composta (CR): quando a ruptura restringiurse totalmente àres ina composta;

d) Ruptura mista-dentina (M-D): quando a ruptura ocorreu de forma parcialmente adesiva e parcialmente coesiva em dentina;

e) Ruptura mista-resina composta (M-R): quando a ruptura ocorreu de forma parcialmente adesiva e parcialmente coesiva em resina composta;

f) Ruptura mista-dentina-resina composta (M-R/D): quando a ruptura ocorreu de forma parcialmente adesiva e parcialmente coesiva em dentina e em resina composta. 


\subsection{6- Observação em microscopia eletrônica}

Os dentes representantes do grupo $N$ e do conjunto $H$, anteriormente separados, foram preparados para ilustração do padrão dos respectivos substratos submetidos ao procedimento adesivo. Os cortes foram realizados através de disco diamantado em máquina para cortes precisos (Labcut 1010, Extec- E. U. A.).

O dente representante do grupo $N$ foi dividido longitudinalmente (paralelamente ao seu longo-eixo) em série até a metade da distância mésiodistal em fatias de aproximadamente $1 \mathrm{~mm}$ de espessura (cerca de três). Na outra metade, a superfície oclusal foi separada através de um corte transversal realizado a $2 \mathrm{~mm}$ abaixo da mesma, perfazendo uma fatia em forma de meia-lua. A face superior desta fatia (superfície preparada pelas lixas) foi dividida em duas regiões através de ranhuras feitas por um estilete. Uma delas foi utilizada para a observação do padrão de condicionamento da dentina normal durante o procedimento adesivo do grupo $N$, sendo realizado a aplicação do ácido por 15 segundos. A outra correspondeu à aplicação do ácido por cinco segundos, como parte dos procedimentos para a hipermineralização.

Um dos dentes representantes do conjunto $H$ foi seccionado da mesma maneira que o dente anterior, com a diferença de que a fatia em forma de meialua foi utilizada para a produção de fraturas, evidenciando os túbulos dentinários e permitindo a observação da espessura da camada hipermineralizada.

O outro dente representante do conjunto $H$ teve sua superfície hipermineralizada separada do restante do dente através também de um corte transversal a $2 \mathrm{~mm}$ abaixo da mesma. A superfície hipermineralizada foi dividida 
em três regiões através de ranhuras produzidas com estilete. Uma delas permaneceu intacta para observação da superfície hipermineralizada. As outras duas receberam tratamento condicionante por ataque ácido conforme realizado para os grupos $H t$ (tradicional: 15 segundos) e $H d$ (duplo ataque ácido: $15+15$ segundos).

Os espécimes produzidos por corte longitudinal foram lixados com a seqüência crescente de granulação de lixas de 600, 1000 e 1200 (20 segundos em cada). Depois, cada espécime teve a região escolhida para observação condicionada com gel de ácido fosfórico a 35\% (Scotchbond, 3M-ESPE) por cinco segundos para prover limpeza de detritos, sendo posteriormente lavadas com água deionizada por 20 segundos.

Alguns palitos representantes de cada grupo estudado foram preparados para observação de suas interfaces adesivas. Realizourse o preparo da superfície com a mesma seqüência de lixas já citadas acima e também com soluções abrasivas de alumina (Arotec - SP, Brasil) em ordem decrescente de tamanho de partículas, sendo $1 \mu \mathrm{m}, 0,3 \mu \mathrm{m}$ e $0,05 \mu \mathrm{m}$, respectivamente. Depois, a região correspondente à interface adesiva foi condicionada por dez segundos com gel de ácido fosfórico a 35\% (Scotchbond, 3M-ESPE), lavados abundantemente com água deionizada por 20 segundos, imersos em solução de hipoclorito de sódio a $2 \%$ por um minuto e lavados novamente com água deionizada por um minuto ${ }^{17}$. 
Os cortes transversais, condicionados da maneira descrita acima, juntamente com os cortes longitudinais, fraturas e palitos, receberam tratamento fixador ${ }^{29}$ e secagem ${ }^{70}$ da maneira seguinte:

1- Imersão em solução de glutaraldeído a 2,5\% em $0,1 \mathrm{M}$ tampão fosfato Sörensen $(\mathrm{pH} 7,4)$ por doze horas em temperatura de $4^{\circ} \mathrm{C}$;

2- Imersão em solução 0,2M tampão fosfato Sörensen $(\mathrm{pH} 7,4)$ por 60 minutos, sendo renovada a cada 20 minutos;

3- Lavagem com água deionizada por um minuto;

4- Desidratação por imersão na seqüência de soluções de etanol de $25 \%$ (20 minutos), $50 \%$ (20 minutos), 75\% (20 minutos), 95\% (30 minutos), 99,8\% (uma hora);

5- Desidratação por imersão em HMDS (hexametildisilazano) (Sigma Chemicals - E.U.A.) por 10 minutos.

6- Secagem final àtemperatura ambiente sobre filtro de papel, até visível total evaporação do HMDS.

Depois, os espécimes desidratados foram montados em plataformas de alumínio, ou stubs, e levados ao metalizador (MED 010) para receberem cobertura de ouro de aproximadamente $10 \mathrm{~nm}$. Os stubs foram acondicionados juntamente com sílica gel em embalagem vedada até o momento da observação em microscópio eletrônico de varredura (DSM 940A, Zeiss - Alemanha) (Figs. 4.2XXIX, XXX, XXXI). 
Resultados 


\section{5- RESULTADOS}

A média dos resultados individuais de cada dente, de acordo com o grupo que representa, estão ilustrados no gráfico 1seguinte:

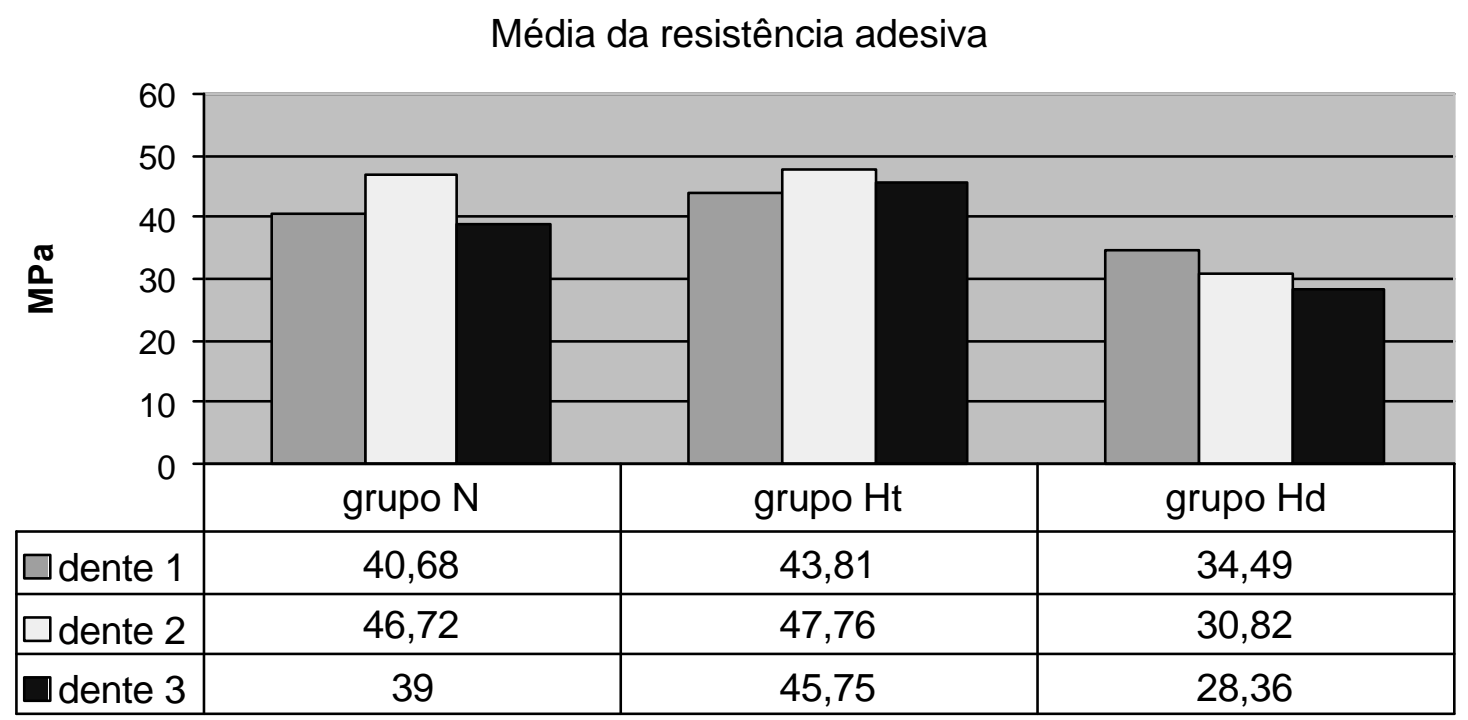

Fig. 5.1a: Gráfico 1, representando a média de resistência adesiva obtida pela dentina de cada dente de acordo com seu respectivo grupo.

A média da área adesiva entre os espécimes de cada dente está ilustrada no gráfico 2 seguinte.

Média da área adesiva submetida ao teste

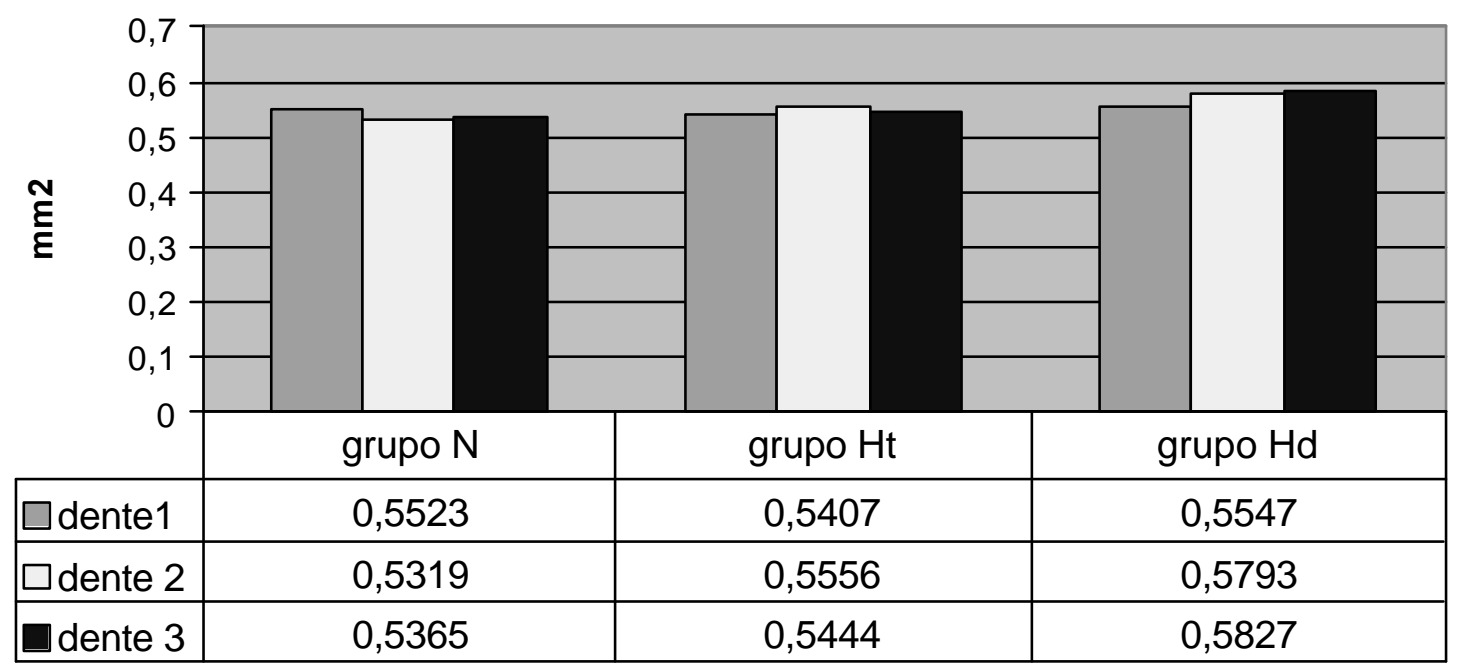

Fig. 5.1b: Gráfico 2, representativo da média da área adesiva dos espécimes submetidos ao teste de acordo com dente e grupo. 
A variabilidade entre os valores de resistência obtidos de cada dente, assim como a média, está ilustrado no gráfico 3, como segue:

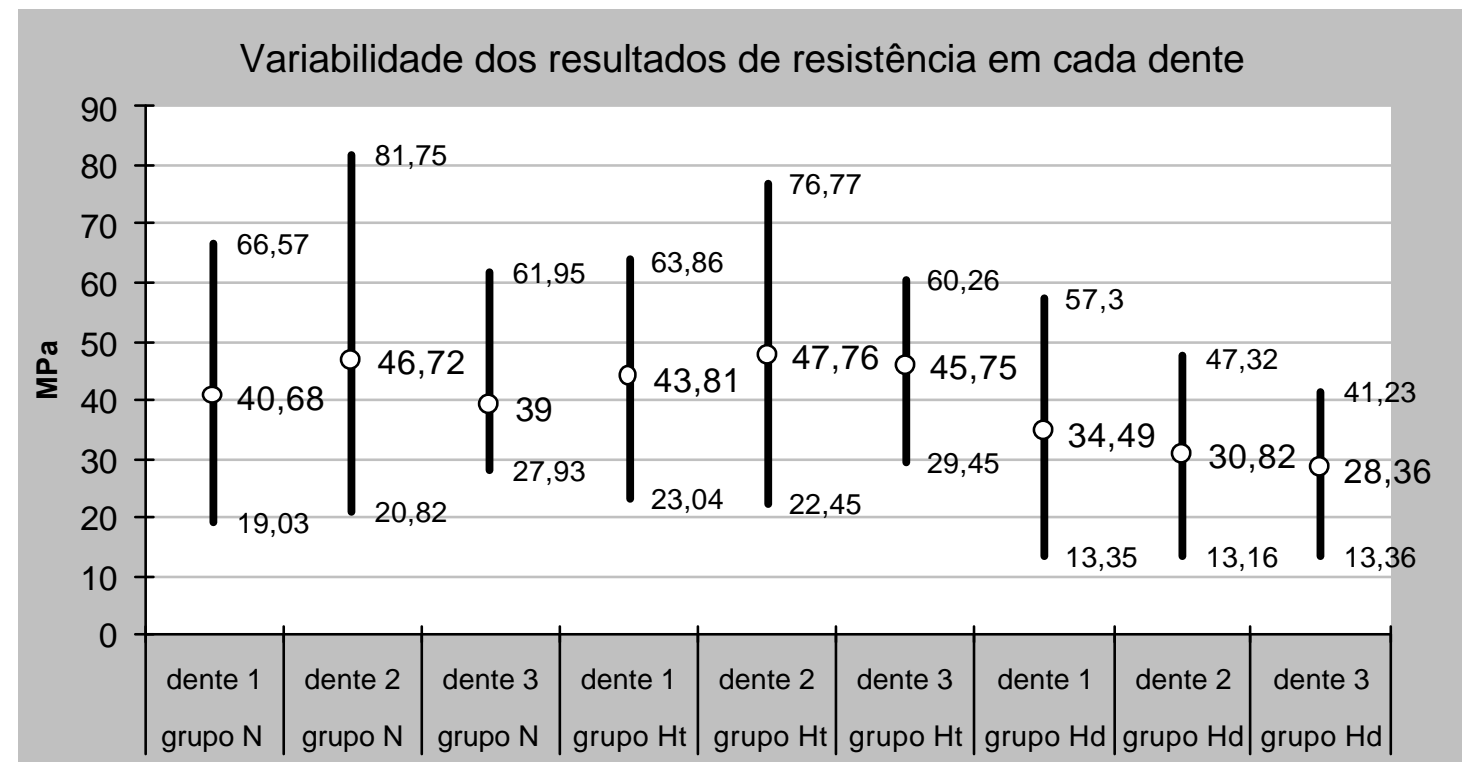

Fig. 5.1.c: Gráfico 3, representativo da variabilidade de resistência obtida pelos espécimes derivados de seus respectivos dentes e grupos. Obs: marcas representam a média.

O resultado final de resistência obtido por cada grupo, ou seja, a média das médias de resistência obtidas pelos seus respectivos dentes, está ilustrado no gráfico 4, a seguir:

Média de resistência entre os dentes dos grupos estudados

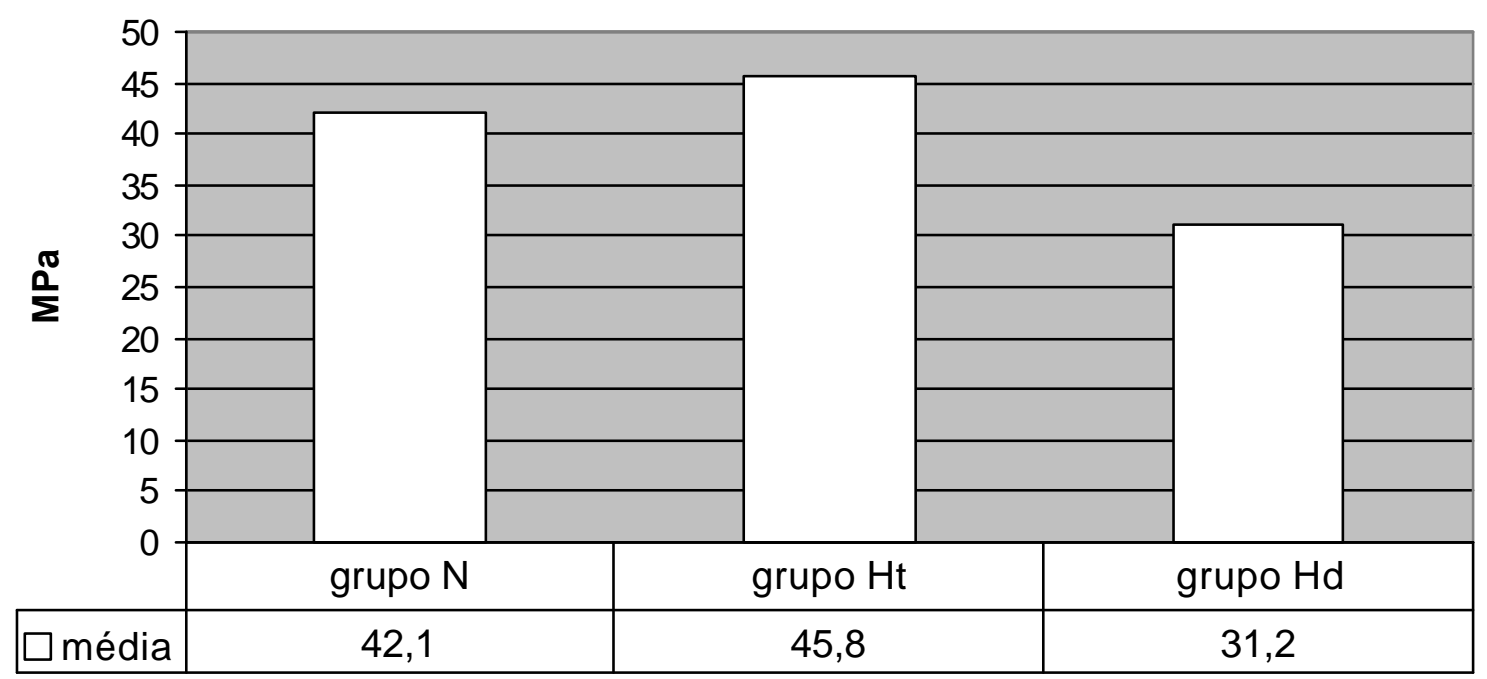

Fig. 5.1.d: Gráfico 4, representando a média de resistência adesiva obtida pelos grupos 
As caracterizações dos tipos de ruptura obtidas durante o teste estão representadas na tabela seguinte:

Tabela 5.1: Quantificação das rupturas apresentadas pelos espécimes de acordo com o tipo e grupos estudados

\section{Grupos}

Tipo de ruptura ${ }^{\mathrm{a}}$

$\begin{array}{lllllll}\text { A } & M-R & M-D & M-R / D & C R & C D & \text { total }\end{array}$

\begin{tabular}{lccccccr}
\hline $\mathbf{N}$ & 0 & $48(84 \%)^{\mathrm{b}}$ & 0 & $9(15,8 \%)$ & 0 & 0 & $57(1)^{\mathrm{C}}$ \\
$\mathbf{H t}$ & 0 & $63(78,7 \%)$ & $2(2,5 \%)$ & $17(21,2 \%)$ & 0 & 0 & $80(2)$ \\
Hd & 0 & $58(82,8 \%)$ & 0 & $12(17,1 \%)$ & 0 & 0 & $70(1)$
\end{tabular}

${ }^{a}$ tipos de ruptura: A: $100 \%$ adesiva; MR: mista, com parciais fraturas adesiva e coesiva em resina; M-D: mista, com parciais fraturas adesiva e coesiva em dentina; M-R/D: mista, com parciais fraturas adesiva e coesiva em resina e em dentina; CR: 100\% coesiva em resina; CD: $100 \%$ coesiva em dentina. ${ }^{b}$ porcentagem da ocorrência da respectiva fratura. ${ }^{c}$ número de espécimes perdidos durante processamento para M.E.V..

\section{$\underline{5.1-\text { Análise estatística }}$}

Diante dos resultados de resistência adesiva obtidos para os diferentes grupos, foi realizado o teste $t$ de Student, para verificação de diferença estatística entre os grupos $\mathrm{N}$ e $\mathrm{Ht}$ e entre os grupos $\mathrm{Ht}$ e $\mathrm{Hd}$, com nível de significância de $5 \%(a ́=0,05)$.

A análise não confirmou diferença entre os grupos $N$ e $H t \quad(p=0,108)$. Entretanto, na segunda situação, foi detectado diferença significativa entre os grupos Ht e Hd $(\mathrm{p}<0,0001)$. 
Tabela 5.1.1: Desvio padrão entre os valores de resistência adesiva em cada grupo

\begin{tabular}{lcc}
\hline GRUPO & Desvio padrão & $\mathbf{n}$ \\
\hline $\mathrm{N}$ & 12,80 & 58 \\
$\mathrm{Ht}$ & 10,32 & 82 \\
$\mathrm{Hd}$ & 9,87 & 71 \\
\hline
\end{tabular}

\section{2- Observação microscópica}

As fotomicrografias dos substratos e de suas respectivas interfaces de união, mostradas a seguir, foram produzidas para ilustração e para proporcionarem eventuais informações adicionais para especulação de explicações para os resultados obtidos. Algumas foram utilizadas na discussão dos resultados.
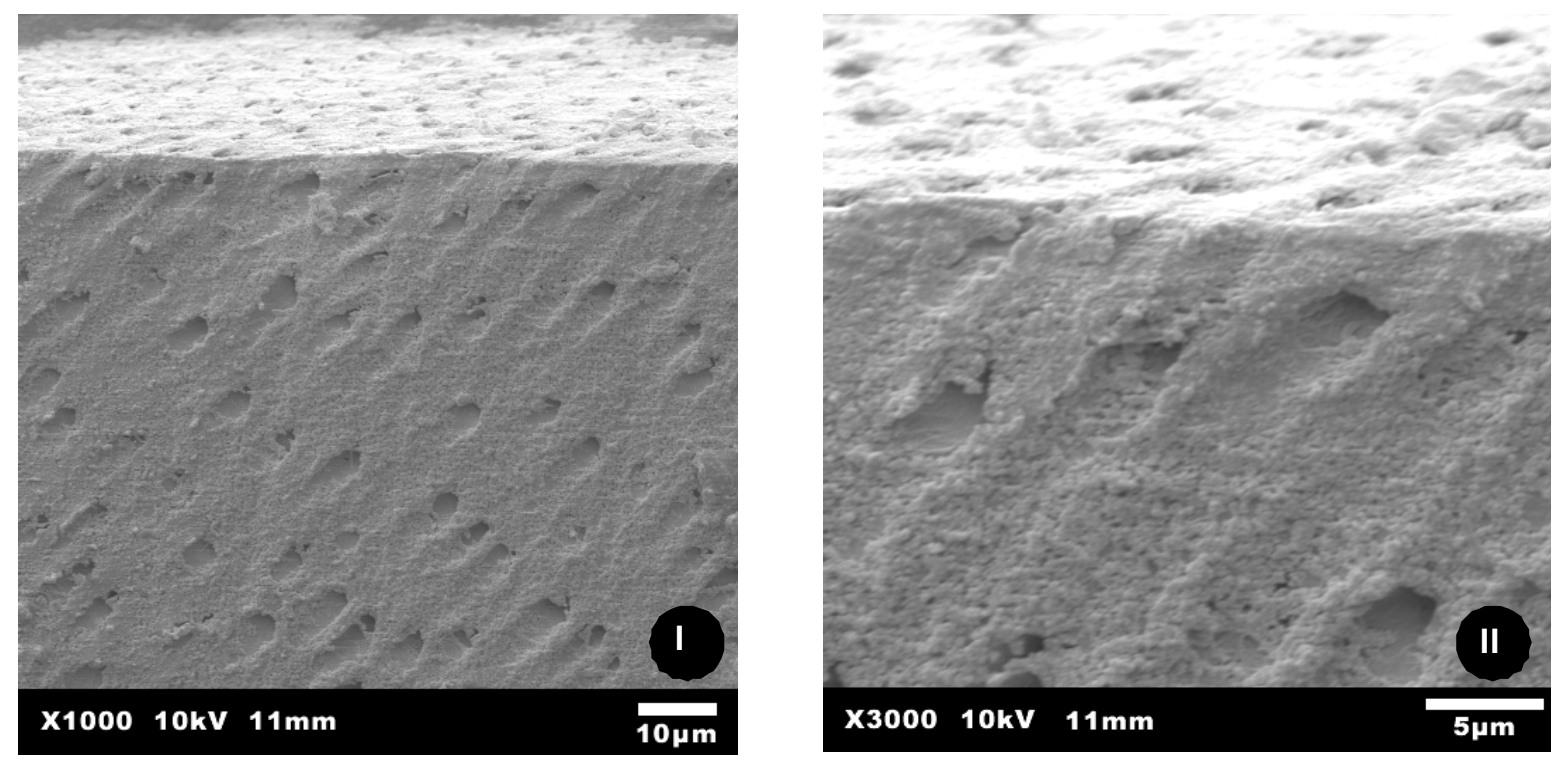

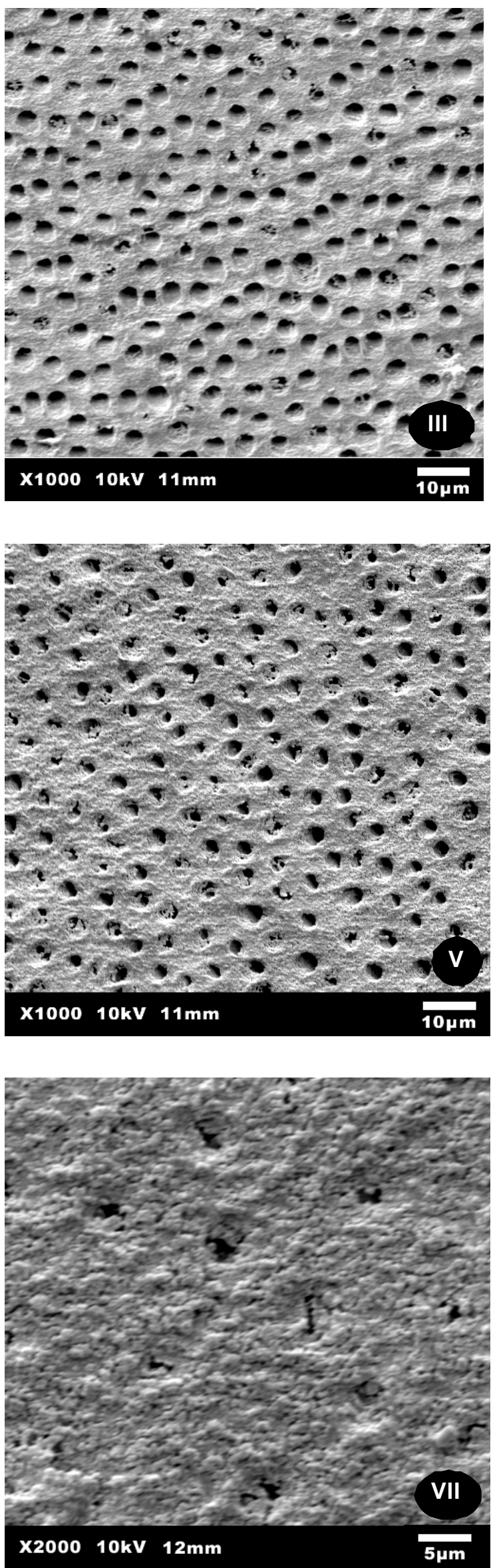
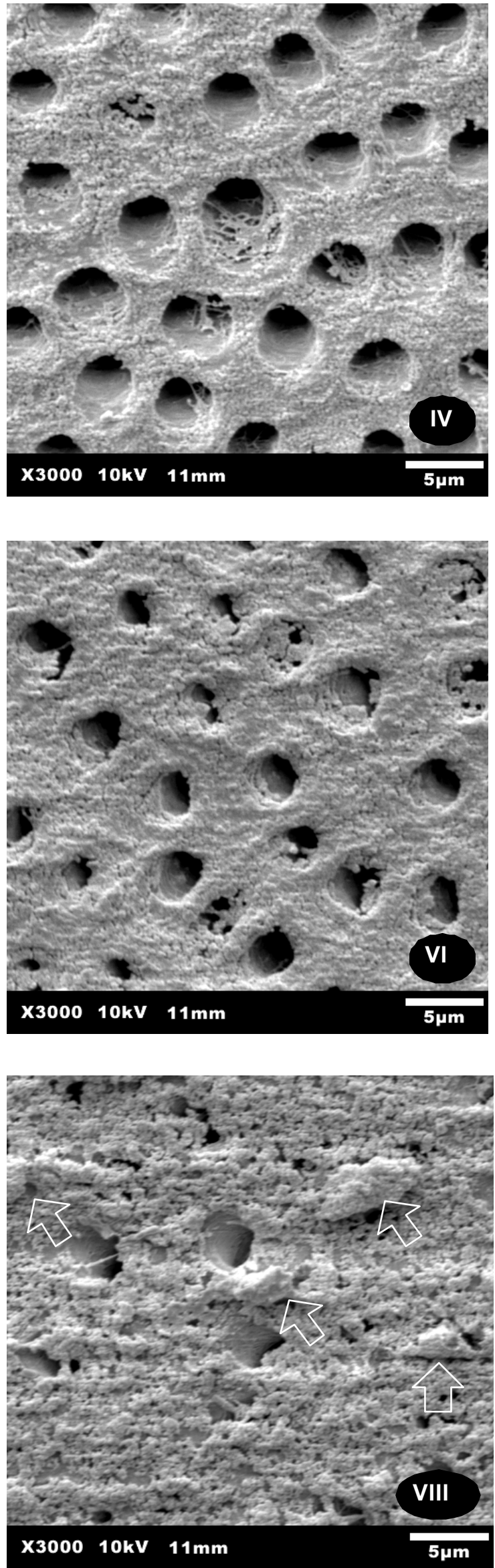

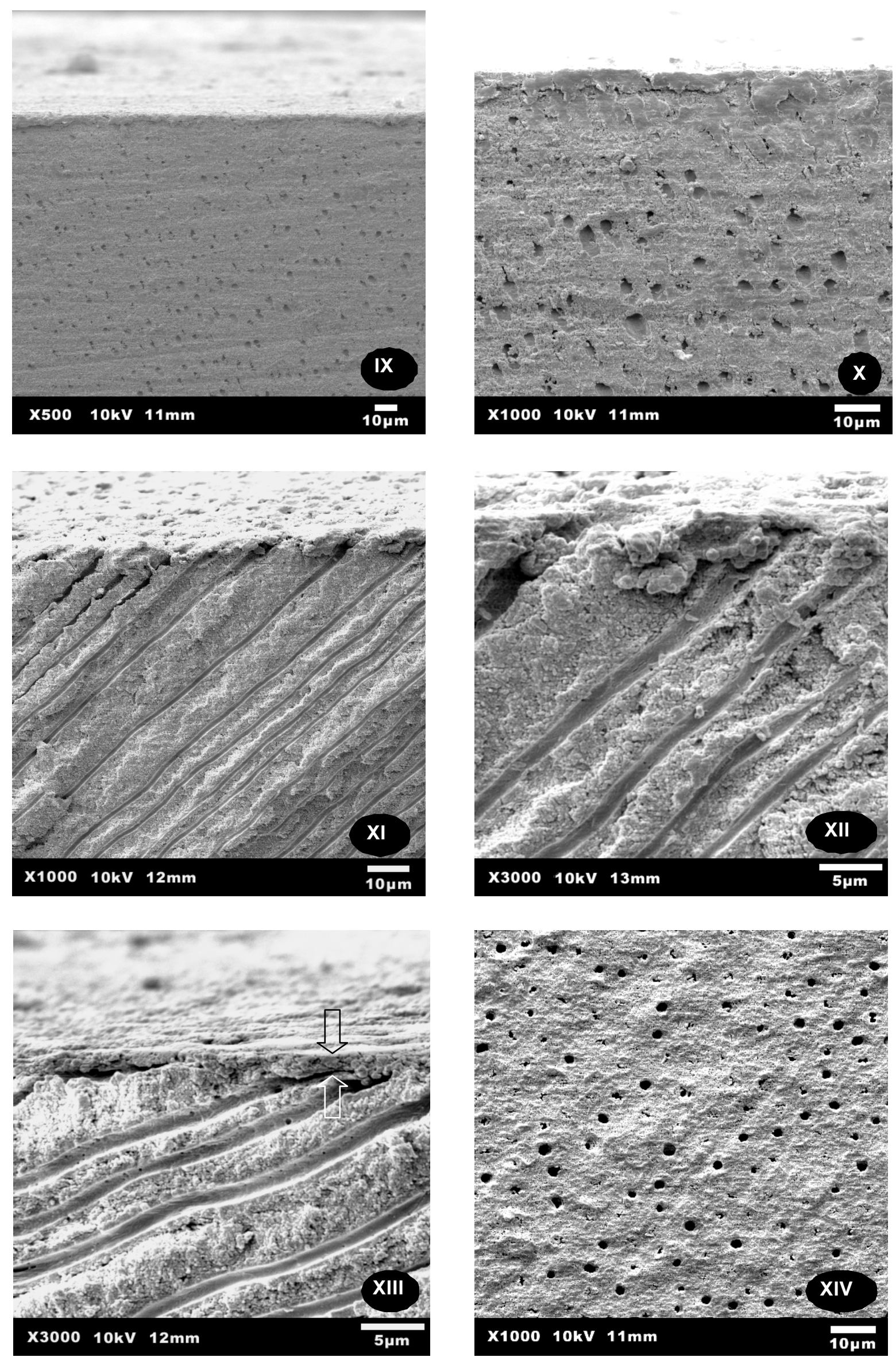

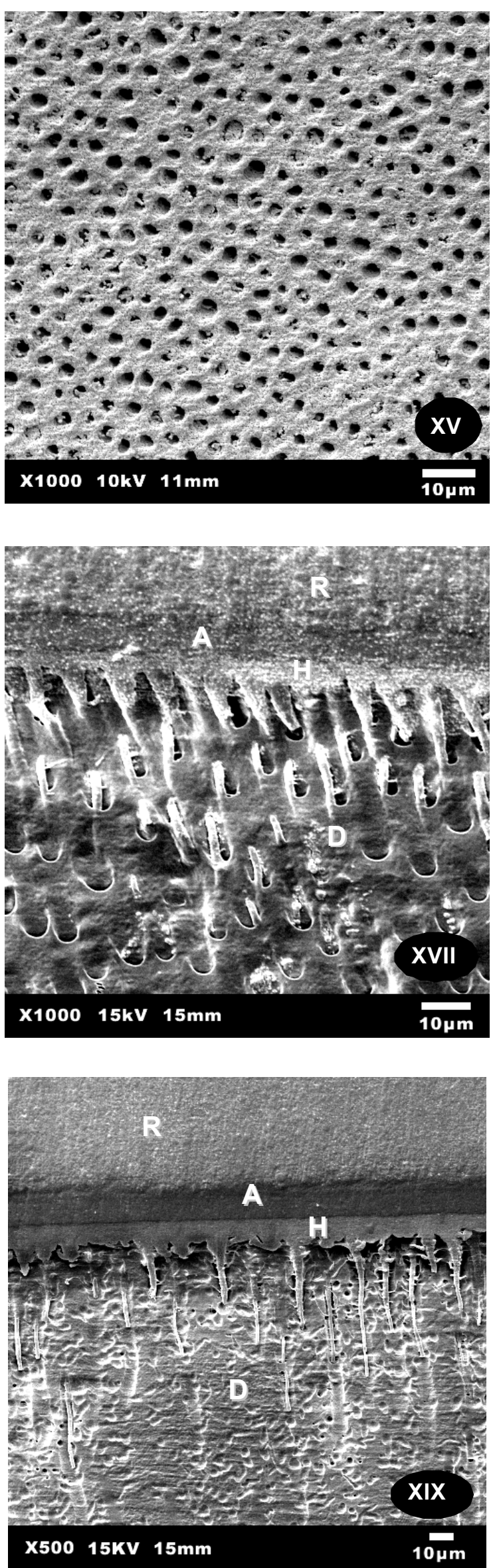
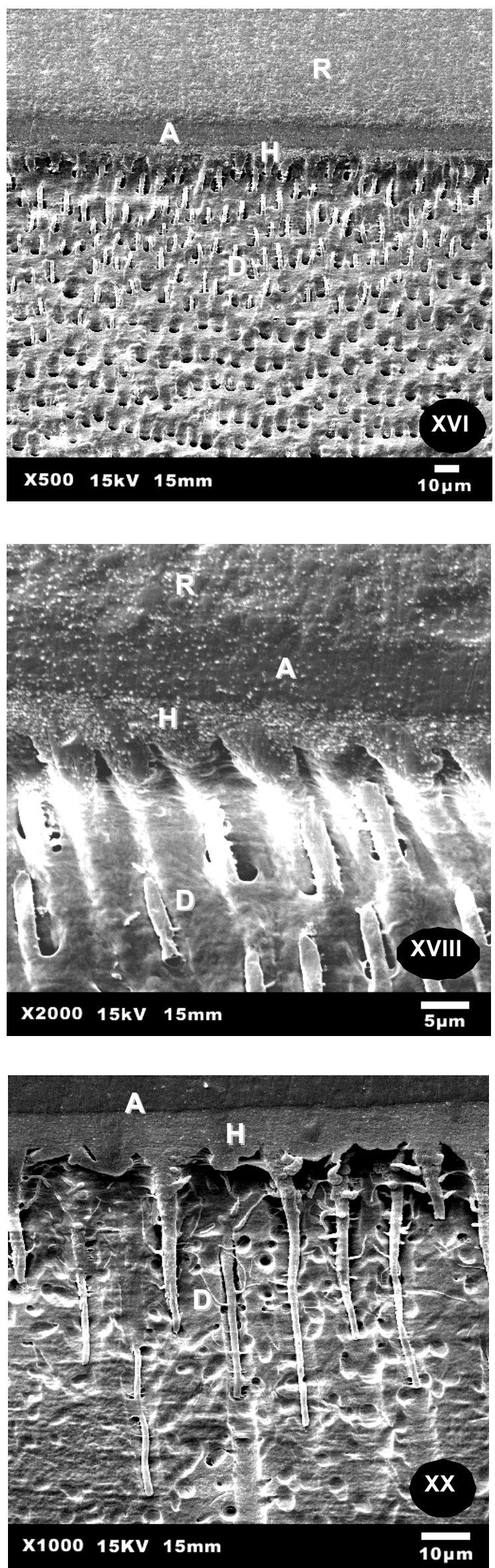

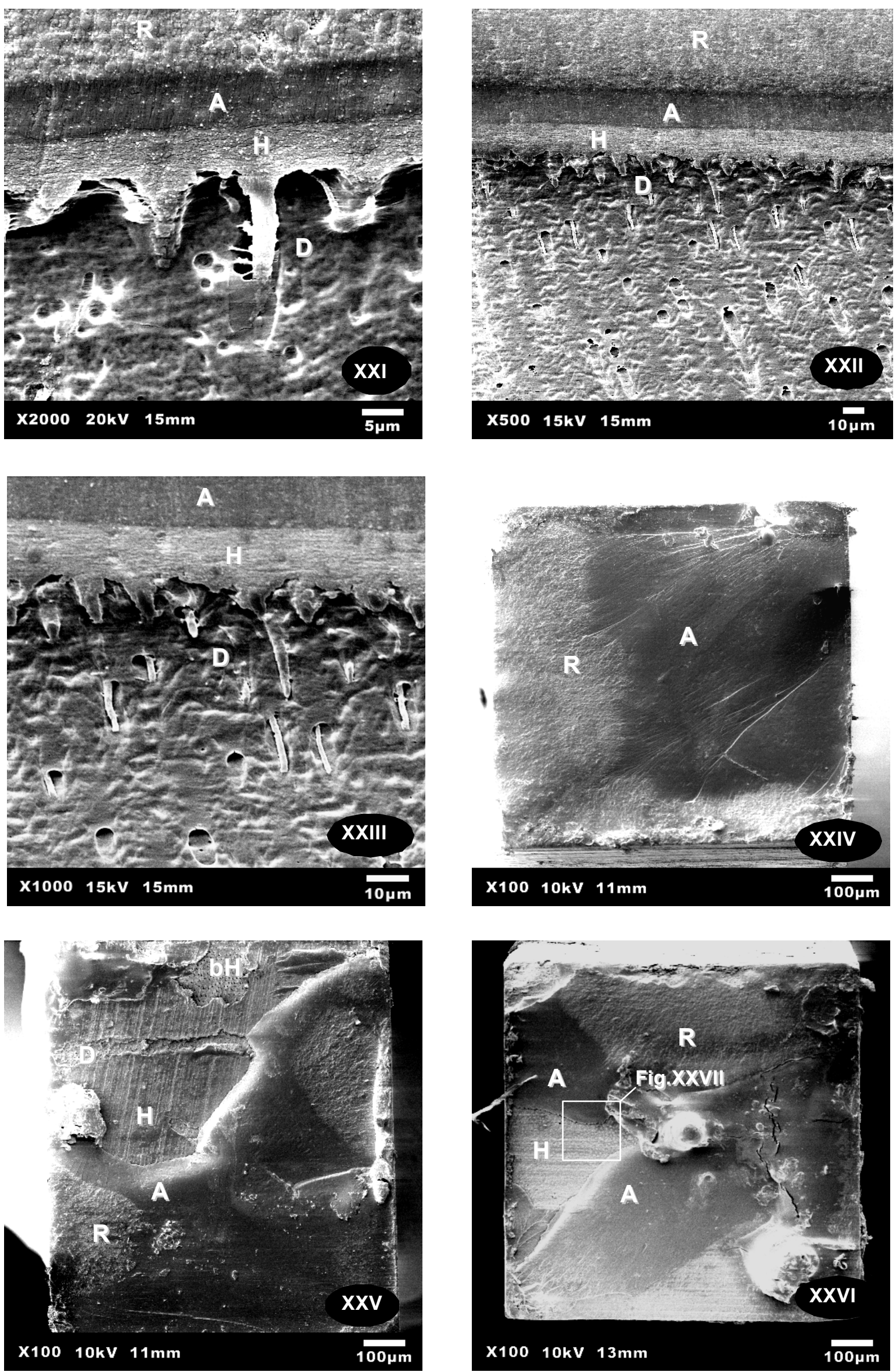

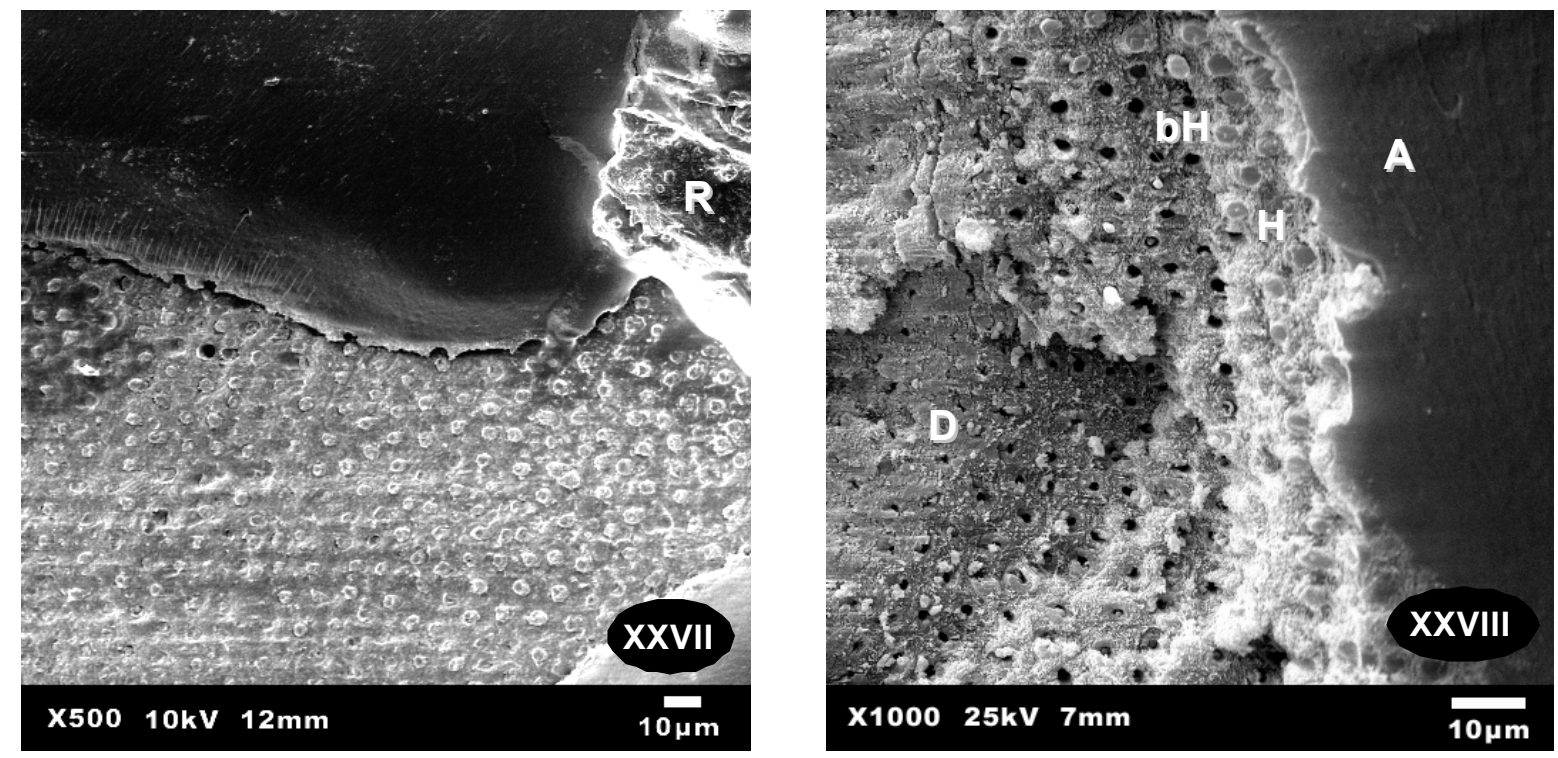

Fig. 5.2: Fotomicrografias ilustrativas:

Obs.: 1- As legendas indicam, respectivamente, o aumento da imagem real, a voltagem regulada no M.E.V., a distância de trabalho e a barra de comparação; 2A: adesivo; D: dentina; H: camada híbrida; $\mathrm{tH}$ : topo da camada híbrida; bH: base da camada híbrida (dentina subjacente); R: resina composta.

I: Dentina normal, corte transversal da superfície;

II: $\quad$ Mesmo espécime que $I$, em maior aumento;

III: Dentina normal: superfície condicionada por 15 segundos;

IV: $\quad$ Mesmo que III, em maior aumento;

V: Dentina normal, superfície condicionada por cinco segundos, como tratamento prévio para a hipermineralização artificial;

VI: $\quad$ Mesmo que $V$, em maior aumento;

VII: Dentina hipermineralizada. Nota-se o aglomerado mineral com aspecto semelhante de coral;

VIII: Dentina hipermineralizada. As setas apontam para a ocorrência de precipitados minerais que se destacam sobre a superfície;

IX: Dentina hipermineralizada, corte transversal da superfície;

$\mathrm{X}$ : $\quad$ Mesmo que $I X$, em maior aumento;

$\mathrm{XI} \quad$ Fratura de espécime de dentina hipermineralizada em visão oblíqua; 
XII: $\quad$ Mesmo que XI, em maior aumento;

XIII: Outra fratura de espécime de dentina hipermineralizada em visão oblíqua, onde se pode verificar a camada hipermineralizada superficial (entre setas);

XIV: Dentina hipermineralizada, condicionada por 15 segundos;

XV: Dentina hipermineralizada, duplamente condicionada por 15 segundos;

$\mathrm{XVI}$ : Interface adesiva, espécime (palito) representante do grupo $\mathrm{N}$;

XVII: Interface adesiva, espécime (palito) representante do grupo $\mathrm{N}$;

XVIII: Interface adesiva, espécime (palito) representante do grupo $\mathrm{N}$;

XIX: Interface adesiva, espécime (palito) representante do grupo $\mathrm{Ht}$;

$X X$ : $\quad$ Mesmo que $X I X$, em maior aumento;

XXI: Interface adesiva, espécime (palito) representante do grupo $\mathrm{Ht}$;

XXII: Interface adesiva, espécime (palito) representante do grupo $H d$;

XXIII: Mesmo que XXII, em maior aumento;

XXIV: Ruptura do tipo mista-resina;

XXV: Ruptura do tipo mista-resina/dentina;

XXVI: Ruptura do tipo mista-resina;

XXVII: Mesmo que XXVI, em maior aumento;

XXVIII: Espécime onde se pode identificar fraturas nas diversas estruturas. 


\section{Discussão}

Neste tópico, foram abordadas as discussões relativas aos resultados obtidos em nosso estudo e aquelas pertinentes àmetodologia empregada, confrontando com os achados de outros trabalhos da Lite ratura que apresentassem relações de semelhança ou de controvérsia.

Não foi a intenção desta discussão prender-se em análises profundas de metodologias de outros trabalhos como as já exploradas no tópico Revisão da Literatura, devido àpossibilidade de desvio de objetividade. Também, as dificuldades encontradas e algumas observações em relação àmetodologia foram consideradas, no intuito de contribuir para estudos futuros. 


\section{6- DISCUSSÃO}

\subsection{Sobre os resultados:}

Os resultados obtidos no presente estudo nos permitem afirmar que a variação de substrato dentinário, de normal para o hipermineralizado artificialmente, não resultou em diminuição da capacidade de um agente de união em resistir ao deslocamento adesivo, o que contradiz o trabalho pioneiro desta linha realizado por Perdigão et al. ${ }^{69}$ em 1994.

Não podemos também estabelecer correlações com os valores obtidos por Perdigão et al., por se tratarem de métodos de avaliação diferentes. Naquele estudo, foi utilizada a técnica de cisalhamento com espécimes de resina aderidos sobre grandes áreas de dentina. Em tais condições, torna-se muito grande a possibilidade de ocorrerem defeitos de superfícies e defeitos decorrentes do próprio procedimento adesivo ou de confecção dos espécimes. Esses defeitos atuariam como áreas concentradoras de estresses durante o ensaio, podendo levar à falhas prematuras, inviabilizando os resultados ${ }^{61,63,64,80}$. O processo de hipermineralização pode contribuir para a criação desses defeitos superficiais em dentina. A ocorrência da formação de precipitados minerais na superfície parece não ser uniforme, como visto na Fig. 5.2-VIII. A formação de grandes aglomerados em alguns pontos (Fig. 5.2-VIII (setas)), pode favorecer a criação de defeitos adesivos, os quais podem atuar como zonas de concentração de estresses. O método de avaliação da resistência ao deslocamento por microtração diminui as chances de lidarmos com um grande número de defeitos durante os ensaios, devido à pequena área adesiva que cada espécime apresenta $^{88}$. 
Os testes de cisalhamento, por sua vez, são muito criticados atualmente por provocarem um grande número de falhas coesivas, em dentina ou em resina, o que não representaria a real resistência de união que o adesivo proporciona. Perdigão et al. ${ }^{68}$, em 2000, obteve média de resistência de cisalhamento de 17,8MPa com o sistema Single Bond, onde metade das falhas observadas foi do tipo coesiva em dentina.

A média dos valores obtidos no presente trabalho para dentina normal $(42,1 \mathrm{MPa})$ apresentam semelhança com os valores obtidos por Paul et al. ${ }^{66} \mathrm{em}$ 1999 (40,19MPa), também pela técnica de micro-tração, onde utilizaram o mesmo sistema adesivo em dentina normal em condições semelhantes. Yoshiyama et al. ${ }^{107}$, em 2002, Yoshiyama et al. ${ }^{105}$ em 2000 e Nakajima et al. ${ }^{57}$ em 2000, encontraram altos valores de resistência para o sistema Single Bond em dentina normal (46MPa, 50,9MPa, 49,5MPa, respectivamente), também pela técnica de micro-tração, porém, com espécimes confeccionados em forma de ampulheta. Nestes mesmos estudos, os autores, respectivamente, encontraram valores de 27,1 MPa, 28,8MPa e 40,2MPa para a união de Single Bond com dentina afetada por cárie. Somente o estudo de Nakajima et al. ${ }^{57}$ não apresentou diferença estatística significativa quando comparados os valores entre os dois tipos de substrato.

Yoshiyama et al. ${ }^{106}$, em 1996, observou através também do método de micro-tração, a ocorrência de menores valores de resistência para substratos dentinários de lesões cervicais em comparação com substratos dentinários normais. Dentre os três adesivos avaliados, fora utilizado o sistema adesivo Scotchbond MP (3M), o qual é predecessor do sistema Single Bond. Em dentina 
normal, o Scotchbond MP obteve média de 23,5MPa, enquanto que em dentina esclerótica obteve média de 18,3MPa, apresentando diferença estatística significativa. Outro trabalho que se propôs avaliar a resistência adesiva em substrato esclerótico de lesões cervicais pelo método de micro-tração, é o trabalho de Kwong et al. ${ }^{42}$, de 2002. Neste, os autores avaliaram o efeito de se utilizar um primer autocondicionante (Clearfil Liner Bond 2V-Kuraray) com a técnica do condicionamento ácido total, que é a técnica utilizada pelos sistemas de frasco único, como o Single Bond empregado em nosso estudo. O grupo controle era representado pela aplicação do primer autocondicionante diretamente, conforme instruções do fabricante. O condicionamento total não resultou em aumento estatisticamente significativo em comparação com a técnica convencional em dentina normal (65,8MPa contra 69MPa, respectivamente) nem em dentina esclerótica (48,7MPa contra 53,1MPa respectivamente). Apesar da desmineralização proporcionada pelo ácido fosfórico a 40\%, mais a desmineralização proporcionada pelos monômeros acídicos do primer autocondicionante, não foi possível obter para a dentina esclerótica valores semelhantes de resistência aos observados para dentina normal.

Diante desses resultados encontrados na Literatura, percebemos haver freqüentemente uma queda nos valores de resistência adesiva em se tratando de substratos dentinários alterados quando comparados com a condição normal. A relação de semelhança entre os valores de resistência adesiva de nosso estudo, entre dentina normal (Grupo $N$ ) e dentina hipermineralizada artificialmente (Grupo $H t)$ foi , portanto, diferente da esperada. 
Vale a pena estabelecer aqui, a necessidade de fazer a distinção entre a dentina afetada por cárie e os outros tipos de dentina esclerótica, como a modificada pela idade e as modificadas por patologias como erosão, abrasão, abfração e exposição radicular. Estas últimas encontram-se geralmente em contato direto com o ambiente bucal por longo tempo, e assim, estão sujeitas aos constantes ciclos de desmineralização e remineralização ${ }^{61,64,96}$. Este é um fator considerado como responsável ao surgimento de uma camada superficial hipermineralizada altamente resistente àdesmineralização por ácidos.

Já a dentina afetada por cárie fica exposta indiretamente ao meio bucal, pois exibe uma camada de dentina infectada de bactérias sobre ela ${ }^{21}$. Ela, portanto, sofrendo influência dos ácidos bacterianos, se torna parcialmente desmineralizada $^{5}$ e, consequentemente, apresenta-se com maior permeabilidade. No entanto, apesar de apresentar alta permeabilidade intertubular, a mesma apresenta baixa permeabilidade intratubular, devido à obliteração dos túbulos dentinários com cristais e aglomerados minerais ácido-resistentes ${ }^{24,}$ 45, 57, 89, 106 oriundos da resposta dentinária àagressão. Estes fatores são os que determinam que esta variante dentinária apresente grandes espessuras de camada híbrida, porém, com má formação de prolongamentos resinosos ou tags ${ }^{57,72,105,107 .}$

Esta qualidade de substrato então, não possui relação com aquele que obtivemos artificialmente em laboratório.

A dentina hipermineralizada artificialmente poderia adquirir melhor semelhança com aquelas encontradas clinicamente nos casos de lesões de abrasão e erosão (corrosão), pois há evidências de que estas superfícies apresentam uma camada superficial mais densamente mineralizada ${ }^{42,47,96}$. Esta 
camada também é encontrada em lesões cervicais, nas adjacências dos locais acometidos por hiperestesia dentinária, ou seja, em regiões da lesão desprovidas de alta sensibilidade. Por sua vez, nos locais sensíveis os túbulos dentinários se apresentam abertos, sem obliteração (cerca de $75 \%)^{104}$, com regular densidade mineral apresentada pela dentina intertubular.

Com relação à esclerose dentinária estimulada pela idade, a dentina hipermineralizada artificialmente terá estabelecida sua semelhança apenas se o processo confirmar um alto grau de obstrução dos túbulos dentinários com precipitados minerais -fator que não observamos nos espécimes preparados para M.E.V. (Figs. 5.2-XI a XIII). Observamos apenas a criação de uma camada superficial delgada de precipitados minerais (2 a 3um - Figs. 5.2-XI a XIII) com a presença de eventuais tampões ocluindo a extremidade dos túbulos dentinários.

Também, nos espécimes de dentina hipermineralizada artificialmente, observados em M.E.V., não foi possível identificar aquelas estruturas características de esclerose dentinária, como os bastonetes hipermineralizados que ocluem as luzes dos túbulos. Após o condicionamento, eles se apresentariam protuídos na superfície, devido respectivamente a desmineralização de dentina intertubular e à resistência à desmineralização que é inerente aos mesmos ${ }^{41,97}$ (Figs. 5.2-XVI e XVII). Nos espécimes obtidos por fratura da dentina, algo semelhante também não foi observado (Figs. 5.2-XI a XIII). Estudos mais detalhados são necessários para verificar se a hipermineralização artificial pode simular tais condições. 
O duplo ataque ácido realizado, ofereceu resultados de resistência que indicariam a ocorrência de um sobrecondicionamento da superfície pelo ataque ácido, apesar de ao M.E.V. ela aparentemente se apresentar como um substrato com características favoráveis à adesão (Fig. 5.2 -XV), com desmineralização da camada hipermineralizada e aumento da permeabilidade intratubular com a completa abertura dos túbulos. Paul et al. ${ }^{66}$, em 1999, observaram um maior poder de desmineralização quando aumentados o tempo de aplicação do ácido de 15 segundos convencionais para 30 e 60 experimentais em dentina normal em conjunto com o sistema Single Bond (3M-ESPE). Surpreendentemente e ao contrário do que esperavam, os autores não encontraram diferenças estatisticamente significativas de resistência adesiva à micro -tração entre os diferentes tempos de condicionamento. A espessura da camada híbrida nos espécimes condicionados dobrou proporcionalmente aos aumentos de condicionamento, sendo média de $2,5 \mu \mathrm{m}$ para 15 segundos, $5 \mu \mathrm{m}$ para 30 e $10 \mu \mathrm{m}$ para 60.

Apesar de observarmos em M.E.V. maiores espessuras de interface adesiva nos espécimes dos grupos $H t$ e $H d$, estas não devem ser levadas em consideração, pois a técnica microscópica de nosso estudo não ter objetivou obter tais dados, o que determinaria a confecção de espécimes com medidas angulares extremamente padronizadas (interface adesiva exatamente paralela ao feixe de elétrons do aparelho) (Figs. 5.2- XIX a XXIII).

Como no presente estudo obteve-se uma queda significativa na resistência adesiva quando utilizourse da técnica do duplo ataque ácido em dentina 
hipermineralizada, e ainda, como viu-se que a hipermineralização artificial não teve influência nos valores de resistência quando comparada com dentina normal, especula-se que também haja uma semelhante queda se for realizado o duplo ataque ácido em dentina normal.

Ainda, Phrukkanon et al. ${ }^{74}$, em 1999, sugerem que o uso de ácidos muito agressivos como o fosfórico, possivelmente causa sobrecondicionamento de dentina normal com conseqüente colapso parcial da rede colágena superficial, o que levaria ao aparecimento da camada de dentina não-infiltrada pelo sistema adesivo. Especulam ainda, que o acúmulo de copolímero de ácido polialcenóico (um dos ingredientes do Single Bond) na superfície da camada de dentina desmineralizada, forma uma barreira para a difusão mais profunda dos monômeros resinosos. A camada formada por este copolímero pode ser observada numa fotomicrografia de M.E.T. presente no estudo de Yoshiyama et al. ${ }^{107}$ de 2002.

Paul et al. ${ }^{66}$ (1999) observaram em seu estudo que em situações de grande profundidade de desmineralização em dentina normal (ataque ácido por 30 ou 60 segundos), o tempo normal proposto pelo fabricante pareceu ser muito curto para a difusão dos monômeros durante a aplicação do adesivo até sua fotopolimerização e que a água presente na dentina desmineralizada para a realização da técnica úmida poderia estar competindo com os monômeros pelos espaços entre as fibras colágenas nas regiões mais profundas. Perdigão \& $\operatorname{Lopes}^{67}$, em 2001, afirmam que a realização do re-condicionamento dentinário, como nos casos em que na prática clínica ocorre contaminação por saliva, acaba 
também criando uma zona de dentina não-preenchida e desprotegida pelo adesivo, de maior susceptibilidade àdegradação.

Partindo dos relatos acima, reforça-se a idéia de ter ocorrido em nosso estudo um possível sobrecondicionamento da dentina dos dentes representantes do grupo $H d$ com o não-preenchimento de toda a espessura da trama de colágeno desmineralizada pelo sistema adesivo. Estes fatores podem ter sido os responsáveis pela queda de resistência adesiva em comparação com o grupo $\mathrm{Ht}$.

Portanto, a análise de nossos resultados e achados da Literatura nos permitem rejeitar a hipótese de que teríamos maiores valores de resistência à adesão com a realização da técnica do duplo condicionamento em dentina artificialmente hipermineralizada.

A hipermineralização artificial pareceu não ser capaz de oferecer resistência à efetividade do ácido fosfórico. No entanto, observamos em M.E.V. que com um único condicionamento por 15 segundos (Grupo $H t$ ), alguns restos de minerais aglomerados em formato semelhante de coral, como os também observados por Kwong et al. ${ }^{41}$ (2000) em dentina esclerótica natural, permaneciam aderidos à superfície (Fig. 5.2-XIV). Por outro lado, pudemos observar a formação de uma autêntica camada híbrida nos espécimes do grupo $H t$, com qualidade e uniformidade de prolongamentos resinosos intratubulares. A hipotética alta capacidade tampão que apresentariam as superfícies hipermineralizadas, com conseqüente diminuição da efetividade do ataque ácido e diminuição de resistência, pareceu não se confirmar para o substrato modificado artificialmente. 


\subsection{Sobre a metodologia:}

A princípio, julga-se necessário a discussão sobre a obtenção dos substratos de dentina. Na realidade, um pequeno espaço será aqui dedicado sobre a escolha de dentes humanos ou bovinos para a realização dos experimentos.

Inicialmente, este presente estudo optou pela utilização de dentes bovinos, devido à dificuldade atual de obtenção de dentes humanos intactos. A substituição de dentes humanos por dentes bovinos tem sido continuamente estudada e sugerida para estudos laboratoriais de resistência àadesão ${ }^{58,82,77,83}$. Entretanto, existe um receio por parte de alguns autores de que os resultados obtidos com este tipo de dente não são (ou não devem ser) comparados com aqueles obtidos com dentes humanos, e muito menos com aqueles obtidos em estudos clínicos. Portanto, não devem ser considerados como potenciais substitutos para testes de adesão àdentina ${ }^{54,75}$.

Durante o plano-piloto deste presente estudo (testes preliminares), foi descartada a possibilidade de utilização deste tipo de substrato. Os dentes obtidos em frigorífico são geralmente de animais de 2 a 4 anos de idade e, portanto, muito jovens. Percebe-se que a maioria dos dentes apresenta ápices abertos (rizogênese incompleta) com grande volume de câmara pulpar. Estes dados, aliados àcurvatura axial que eles apresentam, prejudicaram a confecção dos espécimes. A espessura de dentina da superfície vestibular em direção a polpa é muito delgada, o que resultava muitas vezes em superfícies profundas de dentina após sua planificação com seqüência de lixas, conforme também relatado por Retief et al. ${ }^{75}$, em 1990. Durante a confecção dos espécimes, objetivando o 
ensaio de micro-tração (seja palito ou ampulheta), a extrema maioria era perdida, o que poderia ser um indício da baixa resistência adesiva que este substrato estava proporcionando nestas condições. Já com dentes humanos, essa perda era rara.

Apesar de nossa experiência com dentes bovinos não ter sido bem sucedida, alguns poucos trabalhos recentes como o de Bouillaguet et al. ${ }^{5}$ (2002), utilizaram este tipo de dente em associação com o método da micro-tração. Entretanto, apenas a dentina radicular bovina foi escolhida como substrato para adesão. Schilke et al. $^{83}$, em 2000, desenvolveram um estudo onde compararam as diferenças morfológicas entre tecidos dentinários de dentes humanos e bovinos. Entenderam por desaconselhar o uso de dentina radicular bovina em testes de adesão, devido àalta densidade tubular que esta apresenta em comparação com a porção coronária dentinária de dentes bovinos e humanos, as quais apresentaram similaridade.

No tocante ao processo de hipermineralização artificial, fora formulada a mesma solução de acordo com o estudo de Perdigão et al. ${ }^{69}$ (1994), o qual usa como referência o trabalho de Heilman \& Wefe ${ }^{\beta 0}$, de 1989. Perdigão et al. utilizaram $600 \mathrm{~mL}$ de solução diários para imersão de 40 dentes com área de dentina exposta de $19,625 \mathrm{~mm}^{2}$ cada (área circular de $5 \mathrm{~mm}$ de diâmetro), totalizando uma área total de $785 \mathrm{~mm}^{2}$. Dividindo-se a quantidade de solução $(600 \mathrm{~mL})$, pela área total de dentina em contato com a mesma, temos $0,76 \mathrm{~mL}$ de solução por milímetro quadrado de dentina exposta. Este dado final foi utilizado para calcular a quantidade de solução necessária para a hipermineralização da 
superfície dentinária dos dentes de nosso estudo. Adotamos extrapoladamente, que cada dente teria uma área de 10 milímetros de diâmetro, ou seja, 78,5mm². Isto significa que para cada dente deveríamos ter $60 \mathrm{~mL}$ de solução diários.

A real intenção de todo este procedimento é a obtenção de uma superfície dentinária hipermineralizada e ao máximo possível padronizada, em toda sua extensão, procurando-se evitar diferenças morfológicas regionais. Assim, comparações entre técnicas ou diferentes materiais poderiam melhor serem realizadas. Percebe-se que, para a padronização de substratos dentinários escleróticos naturais para estudos de adesão, diversas variáveis se acham envolvidas. As amostras de dentina dependerão da idade do paciente, do tipo de patologia e da variabilidade individual.

A criação de um substrato que simule uma condição de esclerose dentinária seria, portanto, muito interessante para o desenvolvimento de sistemas adesivos que objetivem promover união confiável também com esse tipo de morfologia dentinária.

Durante o procedimento adesivo, algumas variações da técnica, de certa forma diferentes da que são recomendadas pelo fabricante, merecem destaque. A aplicação do gel de ácido ocorreu de forma convencional, porém sua lavagem foi feita com água deionizada. Não se optou por utilizar-se de seringa tríplice, pois não queríamos lidar com a possibilidade de contaminação da água ou do ar com quaisquer substâncias que poderiam prejudicar a qualidade de adesão, como óleo, sujidade e bactérias das tubulações. 
O procedimento de secagem da superfície foi feito com papéis absorventes, da mesma forma que Kanca $I I^{35,36}$ (1992), objetivando a adesão com a técnica úmida. Uma superfície úmida, sem excesso de água e brilhante quando refletida à claridade ou a luz, foi almejada.

Cada uma das duas camadas de adesivo aplicadas foi espalhada diversas vezes por meio de pincéis do próprio sistema adesivo, na tentativa de promover uma melhor evaporação dos solventes, uniformidade de constituição e espessura e melhor difusão dos monômeros ${ }^{99}$. Quinze segundos foi o tempo de espalhamento, sendo seguido de outro período de 15 segundos de espera (antes de foto-polimerizarmos) para promoção de uma evaporação final dos solventes. A presença do etanol na superfície, um dos solventes deste adesivo, pode ser prejudicial para a união posterior com a resina composta restauradora ${ }^{44}$.

A opção pelo método de micro-tração para avaliação de resistência adesiva foi devida a maior segurança que este teste oferece em termos de confiabilidade de resultados em comparação com os antecessores. Os autores que experimentaram esta metodologia em seus trabalhos admitem que a maioria das rupturas nos espécimes ocorre na interface adesiva. Nos tradicionais testes de tração e cisalhamento, muitas das rupturas ocorrem coesivamente (em resina composta ou em dentina) com a utilização de adesivos modernos. A maior incidência de falhas adesivas permite, segundo Pashley et al. ${ }^{60}$ (1995) a análise da real resistência de união entre os materiais envolvidos. Entretanto, percebemos durante a revisão de Literatura, não haver um consenso entre os 
pesquisadores quanto àclassificação do tipo de fratura e metodologia de análise, se por lupa estereoscópica ou por M.E.V..

Inicialmente, optou-se por realizar a análise do padrão de ruptura com aumentos de $40 \mathrm{X}$ da região correspondente por meio de uma lupa estereoscópica (Citoval 2, Carl Zeiss - Alemanha), conforme diversos trabalhos semelhantes encontrados na Literatura $56,57,80,106,108$. No entanto, este método gerava muitas dúvidas, e a interpretação dependia bastante da direção do feixe de luz incidente.

Por muito tempo acreditourse que os primeiros agentes de união, os quais uniam-se quimicamente com a camada de detritos, falhavam adesivamente durante os testes mecânicos. A partir de estudos mais minuciosos em M.E.V., verificourse que a extrema maioria das rupturas ocorria coesivamente na própria camada de detritos, pois ambas as partes fraturadas apresentavam os detritos característicos $^{63}$.

Durante a realização de fotomicrografias ilustrativas do padrão de ruptura em M.E.V. para o presente estudo, percebeu-se a maior riqueza de detalhes e informações que este método oferecia, o que poderia favorecer a avaliação. Trabalhos recentes demonstram a tendência de se adotar este método para realizar este tipo de análise ${ }^{42,57,71,73,74,85}$.

Mesmo considerando que a observação em M.E.V. não é um método infalível (pois ainda assim depende da subjetividade do examinador), resolveurse montar todos os palitos (porção dentinária) em stubs para observação. Esta, por sinal, é uma das vantagens do método de micro-tração. Num único stub conseguiu-se montar mais de cinqüenta palitos. 
Segundo Pashley et al. $^{63}$ (1995), em adesão à tecidos como a dentina, apenas é interessante avaliar se a ruptura ocorreu no topo da camada híbrida, ou se a camada híbrida falhou coesivamente, ou ainda se a ruptura ocorreu na subsuperfície desta mesma camada. Este tipo de análise seria a que realmente indicaria o desempenho e a capacidade de interação do agente de união com a dentina. No presente estudo, todas essas ocorrências foram classificadas como falhas adesivas. A interpretação de cada um destes tipos de ruptura não fora considerada relevante devido ’̀s falhas não serem exclusivamente restritas ao adesivo ou à camada híbr ida, pois a extrema maioria dos espécimes apresentou falhas coesivas em resina composta. Entretanto, pode-se perceber para os espécimes do grupo $H d$, durante a observação, uma maior ocorrência de rupturas parciais adesivas na base da camada híbrida (dados não quantificados). Este fato pode estar relacionado com o especulado sobrecondicionamento dentinário já relatado anteriormente.

As rupturas foram consideradas mistas mesmo quando pequenas porções de resina ou pequenas fraturas dentinárias eram observadas na superfície, pois as mesmas poderiam ter origem nestes pontos. As rupturas do tipo mista-resina, isto é, com parcial ruptura adesiva e parcial ruptura coesiva em resina foram as que prevaleceram.

O método micro-tração apresenta grandes vantagens em relação aos testes tradicionais de cisalhamento e tração ${ }^{63}$. No entanto, durante sua execução, exige certa habilidade e treinamento por parte do operador. Apresenta um grande número de passos e depende de equipamentos caros e sensíveis. Estes fatores prejudicam sua popularização em grande parte da comunidade pesquisadora ${ }^{88}$. 


\section{Conclusão}

Considerando os limites deste trabalho, entendemos possivel concluir:

1) Não houve diferença entre os valores de resistência adesiva frente àvariação de substrato dentinário, de normal para

hipermineralizado artificialmente;

2) O duplo ataque ácido da superfície da dentina hipermineralizada artificialmente resultou em queda significativa de resistência adesiva.

Nota final:

Este trabalho contou em parte com o apoio CNPq de $N^{\circ} 132602 / 02-4$ 


\section{Anexos}

Neste tópico estão incluídos os dados colhidos com todos os espécimes submetidos aos ensaios mecânicos de resistência ao deslocamento, organizados pelos respectivos grupos e dentes. 
Tabela 8.1: Espessura e área dos palitos de cada dente em seus respectivos grupos e valores em kgf e em MPa obtidos pelos mesmos durante o teste. Valores em negrito na base da tabela representam a média.

\begin{tabular}{|c|c|c|c|c|c|c|c|c|c|c|c|}
\hline \multicolumn{4}{|c|}{ N D1 } & \multicolumn{4}{|c|}{ N D2 } & \multicolumn{4}{|c|}{ N D3 } \\
\hline kgf & espessura $(\mathrm{mm})$ & área $\left(\mathrm{cm}^{2}\right)$ & $\mathrm{MPa}$ & kgf & espessura $(\mathrm{mm})$ & área $\left(\mathrm{cm}^{2}\right)$ & $\mathrm{MPa}$ & kgf & espessura (mm) & área $\left(\mathrm{cm}^{2}\right)$ & $\mathrm{MPa}$ \\
\hline 2,129 & $0,81 \times 0,74$ & 0,005994 & 34,84 & 1,838 & $0,73 \times 0,78$ & 0,005694 & 31,67 & 1,682 & $0,79 \times 0,61$ & 0,004819 & 34,24 \\
\hline 2,279 & $0,68 \times 0,81$ & 0,005508 & 40,59 & 2,985 & $0,73 \times 0,72$ & 0,005256 & 55,71 & 2,347 & $0,64 \times 0,73$ & 0,004672 & 49,28 \\
\hline 2,349 & $0,74 \times 0,75$ & 0,00555 & 41,52 & 3,417 & $0,84 \times 0,78$ & 0,006552 & 51,16 & 2,465 & $0,80 \times 0,79$ & 0,00632 & 38,26 \\
\hline 1,323 & $0,76 \times 0,68$ & 0,005168 & 25,11 & 2,843 & $0,70 \times 0,72$ & 0,00504 & 55,34 & 2,91 & $0,72 \times 0,64$ & 0,004608 & 61,95 \\
\hline 2,141 & $0,76 \times 0,71$ & 0,005396 & 38,92 & 1,349 & $0,70 \times 0,72$ & 0,00504 & 26,26 & 1,951 & $0,88 \times 0,66$ & 0,005808 & 32,95 \\
\hline 1,847 & $0,73 \times 0,68$ & 0,004964 & 36,50 & 1,972 & $0,74 \times 0,73$ & 0,005402 & 35,81 & 1,345 & $0,66 \times 0,64$ & 0,004224 & 31,24 \\
\hline 3,917 & $0,78 \times 0,74$ & 0,005772 & 66,57 & 2,007 & $0,70 \times 0,71$ & 0,00497 & 39,62 & 1,857 & $0,74 \times 0,72$ & 0,005328 & 34,19 \\
\hline 1,150 & $0,76 \times 0,78$ & 0,005928 & 19,03 & 2,005 & $0,71 \times 0,68$ & 0,004828 & 40,74 & 1,148 & $0,63 \times 0,64$ & 0,004032 & 27,93 \\
\hline 2,346 & $0,74 \times 0,76$ & 0,005624 & 40,92 & 2,969 & $0,68 \times 0,69$ & 0,004692 & 62,08 & 2,245 & $0,89 \times 0,83$ & 0,007387 & 29,81 \\
\hline 1,669 & $0,68 \times 0,68$ & 0,004624 & 35,41 & 3,597 & $0,73 \times 0,74$ & 0,005402 & 65,32 & 2,394 & $0,83 \times 0,64$ & 0,005312 & 44,21 \\
\hline 2,276 & $0,71 \times 0,73$ & 0,005183 & 43,08 & 2,226 & $0,68 \times 0,69$ & 0,004692 & 46,54 & 1,729 & $0,71 \times 0,83$ & 0,005893 & 28,78 \\
\hline 3,364 & $0,82 \times 0,72$ & 0,005904 & 55,90 & 2,458 & $0,72 \times 0,69$ & 0,004968 & 48,54 & 2,395 & $0,77 \times 0,65$ & 0,005005 & 46,94 \\
\hline 3,097 & $0,78 \times 0,82$ & 0,006396 & 47,50 & 1,166 & $0,68 \times 0,72$ & 0,004896 & 23,36 & 1,733 & $0,66 \times 0,76$ & 0,005016 & 33,89 \\
\hline 1,460 & $0,81 \times 0,74$ & 0,005994 & 23,89 & 2,349 & $0,69 \times 0,73$ & 0,005037 & 45,75 & 3,62 & $0,79 \times 0,84$ & 0,006636 & 53,51 \\
\hline 2,510 & $0,73 \times 0,78$ & 0,005694 & 43,24 & 3,778 & $0,83 \times 0,71$ & 0,005893 & 62,89 & 2,801 & $0,85 \times 0,64$ & 0,00544 & 50,51 \\
\hline 2,774 & $0,69 \times 0,74$ & 0,005106 & 53,30 & 1,307 & $0,81 \times 0,76$ & 0,006156 & 20,83 & 1,95 & $0,89 \times 0,75$ & 0,006675 & 28,66 \\
\hline 2,129 & $0,74 \times 0,70$ & 0,00518 & 40,32 & 2,215 & $0,71 \times 0,82$ & 0,005822 & 37,32 & 1,508 & $0,65 \times 0,62$ & 0,00403 & 36,71 \\
\hline 2,055 & $0,70 \times 0,77$ & 0,00539 & 37,40 & 4,08 & $0,72 \times 0,68$ & 0,004896 & 81,75 & & & & \\
\hline 3,062 & $0,83 \times 0,68$ & 0,005644 & 53,22 & 2,456 & $0,70 \times 0,83$ & 0,00581 & 41,47 & & & & \\
\hline 2,049 & $0,82 \times 0,67$ & 0,005494 & 36,59 & 3,382 & $0,72 \times 0,74$ & 0,005328 & 62,27 & & & & \\
\hline 2,257 & $0,74 \times 0,74$ & 0,005476 & 40,43 & & & & & & & & \\
\hline 2,294 & & 0,005523 & 40,68 & 2,520 & & 0,005319 & 46,72 & 2,122 & & 0,005365 & 39,00 \\
\hline
\end{tabular}




\begin{tabular}{|c|c|c|c|c|c|c|c|c|c|c|c|}
\hline \multicolumn{4}{|c|}{$\mathrm{Ht}$ D1 } & \multicolumn{4}{|c|}{ Ht D2 } & \multicolumn{4}{|c|}{ Ht D3 } \\
\hline kgf & espessura (mm) & área $\left(\mathrm{cm}^{2}\right)$ & $\mathrm{MPa}$ & kgf & espessura $(\mathrm{mm})$ & área $\left(\mathrm{cm}^{2}\right)$ & $\mathrm{MPa}$ & kgf & espessura (mm) & área $\left(\mathrm{cm}^{2}\right)$ & $\mathrm{MPa}$ \\
\hline 1,454 & $0,66 \times 0,71$ & 0,004686 & 30,44 & 3,155 & $0,82 \times 0,80$ & 0,00656 & 47,18 & 3,345 & $0,87 \times 0,74$ & 0,006438 & 50,97 \\
\hline 1,564 & $0,70 \times 0,79$ & 0,00553 & 27,74 & 1,506 & $0,94 \times 0,70$ & 0,00658 & 22,45 & 2,343 & $0,75 \times 0,70$ & 0,00525 & 43,78 \\
\hline 2,04 & $0,72 \times 0,67$ & 0,004824 & 41,49 & 2,302 & $0,69 \times 0,76$ & 0,005244 & 43,06 & 2,164 & $0,71 \times 0,73$ & 0,005183 & 40,96 \\
\hline 1,882 & $0,77 \times 0,67$ & 0,005159 & 35,79 & 1,657 & $0,67 \times 0,74$ & 0,004958 & 32,79 & 2,341 & $0,87 \times 0,60$ & 0,00522 & 43,99 \\
\hline 2,915 & $0,73 \times 0,72$ & 0,005256 & 54,41 & 3,603 & $0,84 \times 0,79$ & 0,006636 & 53,26 & 1,995 & $0,61 \times 0,69$ & 0,004209 & 46,50 \\
\hline 2,803 & $0,69 \times 0,73$ & 0,004347 & 63,26 & 3,475 & $0,74 \times 0,60$ & 0,00444 & 76,78 & 2,854 & $0,84 \times 0,76$ & 0,006384 & 43,86 \\
\hline 2,053 & $0,80 \times 0,81$ & 0,00648 & 31,08 & 3,108 & $0,85 \times 0,88$ & 0,00748 & 40,76 & 2,082 & $0,71 \times 0,77$ & 0,005467 & 37,36 \\
\hline 3,3 & $0,72 \times 0,73$ & 0,005256 & 61,59 & 2,273 & $0,79 \times 0,75$ & 0,005925 & 37,63 & 1,556 & $0,71 \times 0,73$ & 0,005183 & 29,45 \\
\hline 2,446 & $0,75 \times 0,70$ & 0,00525 & 45,71 & 2,436 & $0,71 \times 0,60$ & 0,00426 & 56,10 & 2,861 & $0,86 \times 0,75$ & 0,00645 & 43,51 \\
\hline 1,302 & $0,77 \times 0,72$ & 0,005544 & 23,04 & 2,039 & $0,70 \times 0,61$ & 0,00427 & 46,84 & 2,528 & $0,69 \times 0,72$ & 0,004968 & 49,92 \\
\hline 2,619 & $0,67 \times 0,78$ & 0,005226 & 49,16 & 2,666 & $0,88 \times 0,75$ & 0,0066 & 39,63 & 2,963 & $0,77 \times 0,70$ & 0,00539 & 53,93 \\
\hline 2,631 & $0,79 \times 0,74$ & 0,005846 & 44,15 & 2,638 & $0,78 \times 0,72$ & 0,005616 & 46,08 & 2,315 & $0,61 \times 0,76$ & 0,004636 & 48,99 \\
\hline 2,085 & $0,79 \times 0,71$ & 0,005609 & 36,47 & 2,905 & $0,70 \times 0,65$ & 0,00455 & 62,63 & 3,056 & $0,73 \times 0,72$ & 0,005256 & 57,04 \\
\hline 2,522 & $0,75 \times 0,68$ & 0,0051 & 48,51 & 2,288 & $0,85 \times 0,66$ & 0,0051 & 44,01 & 2,9 & $0,84 \times 0,77$ & 0,006468 & 43,98 \\
\hline 1,694 & $0,80 \times 0,72$ & 0,00576 & 28,85 & 2,974 & $0,80 \times 0,70$ & 0,0056 & 52,10 & 3,568 & $0,92 \times 0,73$ & 0,006716 & 52,12 \\
\hline 2,765 & $0,67 \times 0,76$ & 0,005092 & 53,27 & 2,579 & $0,67 \times 0,71$ & 0,004757 & 53,18 & 2,353 & $0,73 \times 0,65$ & 0,004745 & 48,65 \\
\hline 2,497 & $0,74 \times 0,76$ & 0,005624 & 43,56 & 2,899 & $0,90 \times 0,74$ & 0,00666 & 42,70 & 1,807 & $0,75 \times 0,75$ & 0,005625 & 31,51 \\
\hline 2,487 & $0,72 \times 0,74$ & 0,005328 & 45,79 & 4,331 & $0,87 \times 0,71$ & 0,006177 & 68,78 & 2,283 & $0,72 \times 0,61$ & 0,004392 & 50,99 \\
\hline 2,29 & $0,69 \times 0,71$ & 0,004899 & 45,86 & 2,369 & $0,82 \times 0,66$ & 0,005412 & 42,94 & 3,283 & $0,83 \times 0,71$ & 0,005893 & 54,65 \\
\hline 2,778 & $0,76 \times 0,66$ & 0,005016 & 54,33 & 2,218 & $0,82 \times 0,63$ & 0,005166 & 42,12 & 2,174 & $0,63 \times 0,73$ & 0,004599 & 46,37 \\
\hline 3,76 & $0,76 \times 0,76$ & 0,005776 & 63,86 & 2,481 & $0,70 \times 0,67$ & 0,00469 & 51,89 & 2,154 & $0,61 \times 0,73$ & 0,004453 & 47,45 \\
\hline 2,359 & $0,80 \times 0,75$ & 0,006 & 38,57 & & & & & 3,533 & $0,71 \times 0,81$ & 0,005751 & 60,27 \\
\hline 2,846 & $0,73 \times 0,74$ & 0,005402 & 51,68 & & & & & 2,205 & $0,76 \times 0,74$ & 0,005624 & 38,46 \\
\hline 2,231 & $0,77 \times 0,71$ & 0,005467 & 40,03 & & & & & 2,567 & $0,74 \times 0,74$ & 0,005476 & 45,99 \\
\hline 2,129 & $0,77 \times 0,78$ & 0,006006 & 34,77 & & & & & 2,114 & $0,73 \times 0,81$ & 0,005913 & 35,07 \\
\hline 3,149 & $0,71 \times 0,70$ & 0,00497 & 62,16 & & & & & 2,606 & $0,74 \times 0,79$ & 0,005846 & 43,73 \\
\hline 2,072 & $0,74 \times 0,72$ & 0,005328 & 38,15 & & & & & & & & \\
\hline 2,222 & $0,73 \times 0,71$ & 0,005183 & 42,06 & & & & & & & & \\
\hline 2,098 & $0,76 \times 0,71$ & 0,005396 & 38,14 & & & & & & & & \\
\hline 1,989 & $0,77 \times 0,73$ & 0,005621 & 34,71 & & & & & & & & \\
\hline 2,944 & $0,75 \times 0,77$ & 0,005775 & 50,01 & & & & & & & & \\
\hline 1,682 & $0,73 \times 0,78$ & 0,005694 & 28,98 & & & & & & & & \\
\hline
\end{tabular}




\begin{tabular}{cccc}
\hline 3,433 & $0,76 \times 0,70$ & 0,00532 & 63,30 \\
\hline 2,637 & $0,76 \times 0,78$ & 0,005928 & 43,64 \\
2,19 & $0,77 \times 0,72$ & 0,005544 & 38,75
\end{tabular}

\begin{tabular}{lllllllllll}
\hline 2,396 & 0,005407 & 43,81 & & 2,662 & 0,005556 & 47,76 & 2,537 & 0,005444 & 45,75 \\
\hline
\end{tabular}

\begin{tabular}{|c|c|c|c|c|c|c|c|c|c|c|c|}
\hline \multicolumn{4}{|c|}{ Hd D1 } & \multicolumn{4}{|c|}{ Hd D2 } & \multicolumn{4}{|c|}{ Hd D3 } \\
\hline kgf & espessura (mm) & área $\left(\mathrm{cm}^{2}\right)$ & $\mathrm{MPa}$ & kgf & espessura (mm) & área $\left(\mathrm{cm}^{2}\right)$ & MPa & kgf & espessura (mm) & área $\left(\mathrm{cm}^{2}\right)$ & $\mathrm{MPa}$ \\
\hline 2,411 & $0,83 \times 0,70$ & 0,00581 & 40,71 & 1,963 & $0,77 \times 0,71$ & 0,005467 & 35,22 & 1,666 & $0,80 \times 0,80$ & 0,0064 & 25,54 \\
\hline 1,566 & $0,72 \times 0,64$ & 0,004608 & 33,34 & 1,219 & $0,76 \times 0,65$ & 0,00494 & 24,21 & 2,366 & $0,77 \times 0,77$ & 0,005929 & 39,15 \\
\hline 1,691 & $0,70 \times 0,81$ & 0,00567 & 29,26 & 1,291 & $0,78 \times 0,83$ & 0,006474 & 19,56 & 0,9168 & $0,74 \times 0,71$ & 0,005254 & 17,12 \\
\hline 1,854 & $0,65 \times 0,82$ & 0,00533 & 34,12 & 0,8789 & $0,84 \times 0,78$ & 0,006552 & 13,16 & 2,162 & $0,90 \times 0,71$ & 0,00639 & 33,19 \\
\hline 1,493 & $0,81 \times 0,70$ & 0,00567 & 25,83 & 2,443 & $0,77 \times 0,77$ & 0,005929 & 40,42 & 2,133 & $0,74 \times 0,79$ & 0,005846 & 35,79 \\
\hline 1,986 & $0,80 \times 0,73$ & 0,00584 & 33,36 & 1,922 & $0,77 \times 0,83$ & 0,006391 & 29,50 & 2,149 & $0,72 \times 0,71$ & 0,005112 & 41,24 \\
\hline 1,556 & $0,70 \times 0,65$ & 0,00455 & 33,55 & 2,254 & $0,78 \times 0,77$ & 0,006006 & 36,82 & 1,946 & $0,73 \times 0,73$ & 0,005329 & 35,82 \\
\hline 1,887 & $0,76 \times 0,72$ & 0,005472 & 33,83 & 1,35 & $0,75 \times 0,67$ & 0,005025 & 26,36 & 2,675 & $0,80 \times 0,80$ & 0,0064 & 41,00 \\
\hline 0,764 & $0,69 \times 0,81$ & 0,005589 & 13,41 & 1,711 & $0,78 \times 0,78$ & 0,006084 & 27,59 & 1,007 & $0,84 \times 0,88$ & 0,007392 & 13,36 \\
\hline 1,631 & $0,77 \times 0,73$ & 0,005621 & 28,46 & 2,551 & $0,79 \times 0,72$ & 0,005688 & 44,00 & 1,711 & $0,71 \times 0,73$ & 0,005183 & 32,38 \\
\hline 2,261 & $0,68 \times 0,72$ & 0,004896 & 45,30 & 1,493 & $0,78 \times 0,69$ & 0,005382 & 27,21 & 1,435 & $0,75 \times 0,84$ & 0,0063 & 22,35 \\
\hline 3,743 & $0,72 \times 0,89$ & 0,006408 & 57,30 & 1,324 & $0,87 \times 0,83$ & 0,007221 & 17,99 & 1,016 & $0,89 \times 0,72$ & 0,006408 & 15,55 \\
\hline 1,834 & $0,73 \times 0,65$ & 0,004745 & 37,92 & 0,8847 & $0,83 \times 0,66$ & 0,005478 & 15,84 & 1,277 & $0,83 \times 0,71$ & 0,005893 & 21,26 \\
\hline 2,695 & $0,67 \times 0,86$ & 0,005762 & 45,88 & 1,983 & $0,79 \times 0,72$ & 0,005688 & 34,20 & 1,807 & $0,67 \times 0,74$ & 0,004736 & 37,43 \\
\hline 2,608 & $0,73 \times 0,84$ & 0,006132 & 41,72 & 0,9939 & $0,75 \times 0,78$ & 0,00585 & 16,67 & 1,214 & $0,88 \times 0,67$ & 0,005896 & 20,20 \\
\hline 2,529 & $0,82 \times 0,70$ & 0,00574 & 43,22 & 1,451 & $0,84 \times 0,78$ & 0,006552 & 21,73 & 1,646 & $0,73 \times 0,77$ & 0,005621 & 28,73 \\
\hline 2,17 & $0,76 \times 0,82$ & 0,006232 & 34,16 & 2,119 & $0,80 \times 0,77$ & 0,00616 & 33,75 & 2,186 & $0,89 \times 0,78$ & 0,006942 & 30,89 \\
\hline 1,238 & $0,72 \times 0,69$ & 0,004968 & 24,45 & 2,583 & $0,77 \times 0,75$ & 0,005775 & 43,88 & 1,083 & $0,73 \times 0,71$ & 0,005183 & 20,50 \\
\hline 2,079 & $0,75 \times 0,82$ & 0,00615 & 33,16 & 2,071 & $0,72 \times 0,66$ & 0,004752 & 42,75 & 1,921 & $0,73 \times 0,83$ & 0,006059 & 31,10 \\
\hline 2,132 & $0,73 \times 0,79$ & 0,005767 & 36,27 & 2,388 & $0,75 \times 0,66$ & 0,00495 & 47,33 & 1,158 & $0,77 \times 0,75$ & 0,005775 & 19,67 \\
\hline 2,702 & $0,80 \times 0,70$ & 0,0056 & 47,33 & 2,216 & $0,76 \times 0,73$ & 0,005548 & 39,18 & 1,585 & $0,75 \times 0,71$ & 0,005325 & 29,20 \\
\hline 1,623 & $0,72 \times 0,65$ & 0,00468 & 34,02 & 2,298 & $0,77 \times 0,72$ & 0,005544 & 40,66 & 1,416 & $0,74 \times 0,75$ & 0,00555 & 25,03 \\
\hline 0,812 & $0,84 \times 0,71$ & 0,005964 & 13,36 & & & & & 1,855 & $0,75 \times 0,68$ & 0,0051 & 35,68 \\
\hline 2,324 & $0,79 \times 0,71$ & 0.005609 & & & & & & & & & \\
\hline
\end{tabular}




$$
\text { Referências }
$$

Bibliográficas 


\section{9- REFERÊNCIAS BIBLIOGRÁFICAS *}

1- ANUSAVICE, K. J. Phillips - Materiais Dentários. 10. ed. Rio de Janeiro, Guanabara-Koogan, 1998. p. 15.

2- ASMUSSEN, E.; UNO, S. Adhesion of restorative resins to dentin: chemical and physicochemical aspects. Oper. Dent., p. 68-74, 1992. Supplement 5

3- BARKMEIER, W. W.; COLLEY, R. L. Laboratory evaluation of adhesive systems. Oper. Dent., p. 52-61, 1992. Supplement 5

4- BHASKAR, S. N. Histologia e embriologia oral de Orban. 10. ed. São Paulo, Artes Médicas, 1989.

5- BOUILLAGUET, S.; GYSI, P.; WATAHA, J. C.; CIUCCHI, B.; CATTANI, M.; GODIN, CH.; MEYER, J. M. Bond strength of composite to dentin using conventional, one-step, and self-etching adhesive systems. J. Dent, v. 29, n. 1, p. 55-61, Jan. 2001.

6- BOWEN, R. L.; MARJENHOFF, W. A. Development of an adhesive bonding system. Oper. Dent., p. 75-80, 1992. Supplement 5

7- BUONOCORE, M. G. A simple method for increasing the adhesion of acrylic filling materials to enamel surfaces. J. dent. Res., v. 34, p. 849-853, Dec. 1955.

8- BUONOCORE, M. G.; WILLEMAN, W.; BRUDEVOLD, F. A report on a resin composition capable of bonding to human dentin surfaces. J. dent. Res., v. 35, p. 846-851, 1956.

\footnotetext{
Normas recomendadas para o uso no âmbito da Universidade de São Paulo, com base no documento "Referências Bibliográficas: exemplos", emanado do Conselho Superior do Sistema Integrado de Bibliotecas da USP, em reunião de 20 de setembro de 1990.
} 
9- CARVALHO, R. M. As relações entre alterações dimensionais, permeabilidade e propriedades mecânicas da matriz de dentina desmineralizada. Estudo sob a óptica da teoria dos parâmetros de solubilidade. Bauru, 2002. 92p. Tese (Livre-docência) - Faculdade de Odontologia de Bauru, Universidade de São Paulo.

10-CARVALHO, R. M.; YOShIYAMA, M.; PASHLEY, E. L.; PASHLEY, D. H. In vitro study of dimensional changes in dentin after demineralization. Arch. oral Biol., v. 41, n. 4, p. 369-77, Apr. 1996.

11- DARVELL, B. W. Materials science for dentistry. 7. ed. Hong Kong, s. ed., 2002. p. 234-9.

12- DAVIDSON, C. L. Principles of adhesion. In: DALL'OROLOGIO, G. D.; FUZZI, M.; PRATI, C. Adhesion on restorative dentistry. Proceedings of the international symposium, Bologna, Nov. 18, 1995, s. ed., s. I., 1995. p. 1-4.

13- DUKE, E. S.; LINDEMUTH, J. S. Polymeric adhesion to dentin: contrasting substrates. Amer. J. Dent., v.3, n. 6, p. 264-70, Dec. 1990.

14- DUKE, E. S.; LINDEMUTH, J. S. Variability of clinical dentin substrates. Amer. J. Dent., v. 4, n. 5, p. 241-6, Oct. 1991.

15- ERICKSON, R. L. Surface interactions of dentin adhesive materials. Oper. Dent., v. 17, p. 81-94, 1992. Supplement 5

16- FEILZER, A. J.; DE GEE, A. J.; DAVIDSON, C. L. Setting stress in composite resin in relation to configuration of the restoration. J. dent. Res., v. 66, n. 11, p. 1636-9, Nov. 1987. 
17- FERRARI, M., MANOCCI, F.; VICHI, A.; DAVIDSON, C. L. Effect of two etching times on the sealing ability of clearfil liner bond 2 in class $v$ restorations. Amer. J. Dent., v. 10, n. 2, p. 66-70, Apr. 1997.

18- FINGER, W. J.; UNO, S. Bond strength of gluma CPS using the moist dentin bonding technique. Amer. J. Dent., v. 9, n. 1, p. 27-30, Feb. 1996.

19- FINGER, W. J.; FRITZ, U. Laboratory evaluation of one-component enamel/dentin bonding agents. Amer. J. Dent., v. 9, n. 5, p. 206-10, Oct. 1996.

20- FOWLER, C. S.; SWARTZ, M. L., MOORE, B. K., RHODES, B. F. Influence of selected variables on adhesion testing. Dent. Mater., v. 8, n. 4, p. 265-269, July 1992.

21- FUSAYAMA, T. New concepts in operative dentistry. Differentiating two layers of carious dentin and using an adhesive resin. Chicago, Quintessence Publishing Co., Inc., 1980.

22- FUSAYAMA, T.; NAKAMURA, M.; KUROSAKI, N.; IWAKU, M. Non-pressure adhesion of a new adhesive restorative system. J. dent. Res., v.58, n. 4, p.1364-1370, Apr. 1979.

23- GRIFFITH, A. A. The phenomena of rupture and flow in solids. Phil. Trans. $\mathbf{R}$. Soc. Lond., v. A221, p. 168-198, 1920 apud SANO, H.; SHONO, T.; SONODA, H.; TAKATSU, T.; CIUCCHI, B.; CARVALHO, R.; PASHLEY, D. H. Relationship between surface area for adhesion and tensile bond strength - evaluation of a micro-tensile bond test. Dent. Mater., v. 10, n.4, p. 236-240, July 1994. 
24- GWINNETT, A. J.; JENDRESEN, M. D. Micromorphologic features of cervical erosion after acid conditioning and its relation with composite resin. $\mathbf{J}$. dent. Res., v. 57, n. 4, p. 543-9, Apr. 1978.

25- GWINNETT, A. J.; KANCA, J. Interfacial morphology of resin composite and shiny erosion lesions. Amer. J. Dent., v. 5, n. 6, p. 315-7, Dec. 1992.

26- HAGGER, O. Swiss patent n. 278946, 1951 apud SÖDERHOLM, K.-J. M. Does resin based dentine bonding work? Int. dent. J., v. 45, n. 6, p. 37181, Dec. 1995.

27- HARNIRATTISAI, C.; INOKOSHI, S.; SHIMADA, Y.; HOSODA, H. Interfacial morphology of an adhesive composite resin and etched caries-affected dentin. Oper. Dent., v. 17, n. 6, p. 222-8, Nov. -Dec. 1992.

28- HARNIRATTISAI, C.; INOKOSHI, S.; SHIMADA, Y.; HOSODA, H. Adhesive interface between resin and etched dentin of cervical erosion/abrasion lesions. Oper. Dent., v.18, n. 4, p. 138-43, July-Aug.1993.

29- HAYAT, M. A. Principles and techniques of electron microscopy: biological applications. 4. ed. Cambridge, Cambridge University Press, 2000. p.935.

30- HEILMAN, J. R. \& WEFEL, J. S. Effect of remineralization on demineralized root surfaces. J. Dent Res., v. 57, p. 543, 1989. /Abstract n. 1354/

31- HEYMANN, H. O., STUDERVANT J. R.; BAYNE, S.; WILDER, A. D.; SLUDER, T. B.; BRUNSON, W. D. Examining tooth flexure effects on cervical restorations: a two-year clinical study. J. Amer. dent. Assoc., v. 122, p. 41-7, 1991 
32- HEYMANN, H. O.; BAYNE, S. C. Current concepts in dentin bonding: Focusing on dentinal adhesion factors. J. Amer. dent. Assoc., v. 124, n. 5, p. 26-36, May 1993.

33- INTERNATIONAL ORGANIZATION FOR STANDARDIZATION. Technical report ISO TR 11405. Dental materials - guidance on testing of adhesion to tooth structure. Switzerland, ISO, s. d.

34- JENDERSEN, M. D.; GLANTZ, P. O. Clinical adhesiveness of selected dental materials - An in vivo study. Acta odont. Scand., v. 39, p. 39-45, 1981.

35- KANCA III, J. Resin bonding to wet substrate. I. bonding to dentin. Quintessence Int., v. 23, n. 1, p. 39-41, Jan. 1992a.

36- KANCA III, J. Effect of resin primer solvents and surface wetness on resin composite bond strength to dentin. Amer. J. Dent., v. 5, n. 4, p. 213-5, Aug. 1992b.

37- KAWAKAMI, T.; TAKEI, N.; EDA, S. Crystals closing tubules in sclerosed coronal dentin of the aged. In: SHIMONO, M.; MAEDA, T.; SUDA, H.; TAKAHASHI, K. Dentin-Pulp Complex. Proceedings of the international conference on Dentin/pulp complex, Chiba, 1995. Tokio, Quintessence Publishing, 1996. p.285-6.

38- KINLOCH, A. J. Adhesion and adhesives. Science and technology. London, Chapman and Hall, s. d. apud VAN MEERBEEK, B.; LAMBRECHTS, P.; INOKOSHI, S.; BRAEM, M.; VANHERLE, G. Factors affecting adhesion to Mineralized Tissues. Oper. Dent., v. 17, p. 111-24, 1992. Supplement 5 
39- KRAMER, I. R. H.; MC LEAN, J. W. Alterations of the staining reaction of dentine resulting of a constituent in a self polymerising resin. Brit. dent. J., v. 6, p. $150-153,1952$.

40- KUSUNOKI, M.; ITOH, K.; HISAMITSU, H.; WAKUMOTO, S. The efficacy of dentine adhesive to sclerotic dentine. J. Dent., v. 30, n. 2-3, p. 91-7, FebMar. 2002.

41- KWONG, S-M; TAY, F. R.; YIP, H-K; KEI, L-H; PASHLEY, D. H. An ultrastructural study of the application of dentine adhesives to acidconditioned sclerotic dentine. J. Dent., v. 28, n. 7, p. 515-28, Sep. 2000.

42- KWONG, S. M.; CHEUNG, G. S. P.; KEI, L. H.; ITTHAGARUN, A.; SMALES, R. J.; TAY, F. R.; PASHLEY, D. H. Micro-tensile bond strengths to sclerotic dentin using a self-etching and a totaletching technique. Dent. Mater., v. 18, n. 5, p. 359-69, Jul. 2002.

43- LAMBRECHTS, P.; BRAEM, M.; VANHERLE, G. Evaluation of clinical performance for posterior composite resins and dentin adhesives. Oper. Dent., v. 12, n. 2, p. 53-78, Spring 1987.

44- LI, H.; BURROW, M.; TYAS, M. J. Nanoleakage patterns of four dentin bonding systems. Dent. Mater., v. 16, n. 1, p. 48-56, Jan. 2000.

45- MARSHALL JUNIOR, G. W.; CHANG, Y. J.; SAEKI, K.; GANSKY, S. A.; MARSHALL, S. J. Citric acid etching of cervical sclerotic dentin lesions: an AFM study. J. biomed. Mater. Res., v. 49, n. 3, p. 338-44, Mar. 2000.

46- MARSHALL JUNIOR, G. W.; MARSHALL, S. J.; KINNEY, J. H.; BALOOCH, M. The dentin substrate: structure and properties relating to bonding. $\mathbf{J}$. Dent., v. 25, n. 6, p. 441-58, Nov. 1997. 
47- MIXSON, J. M.; SPENCER, P.; MOORE, D. L. Surface morphology and chemical characterization of abrasion/erosion lesions. Amer. J. Dent., v. 8, n. 1, p. 5-9, Feb. 1995.

48- MJÖR, I. A.; FEJERSKOV, O. Human oral biology and histology. Copenhagen, Munksgaard, 1986 apud VAN MEERBEEK, B. Dentine adhesion: morphology, physico-chemical and clinical aspects. Leuven, 1993. PhD Dissertation. Catholic University of Leuven.

49- MIYAZAKI, M.; IWASAKI, K; ONOSE, H. Adhesion of single application bonding systems to bovine enamel and dentin. Oper. Dent., v. 27, n. 1, p.88-94, Jan.-Feb. 2002.

50- MONDELLI, J. Proteção do complexo dentino-pulpar. São Paulo, Artes Médicas: EAP-APCD (Série EAP-APCD; 1), 1998.

51- MUNKSGAARD, E. C. Wet or dry, normal or deproteinized dentin surfaces as substrate for dentin adhesives. Acta odont. Scand., v. 60, n. 1, p. 60-4, Jan. 2002.

52- MUNKSGAARD, E. C.; IRIE, M.; ASMUSSEN, E. Dentin-polymer bond promoted by gluma and various resins. J. dent. Res., v. 64, n. 12, p. 140911, Dec. 1985.

53- NAKABAYASHI, N.; SAIMI, Y. Bonding to intact dentin. J. dent. Res., v. 75, n. 9, p. 1706-15, Sept. 1996.

54- NAKABAYASHI, N.; PASHLEY, D. H. Hibridização dos tecidos dentais duros. São Paulo, Quintessence Editora Ltda., 2000. 
55- NAKABAYASHI, N.; KOJIMA, K.; MASUHARA, E. The promotion of adhesion by the infiltration of monomers into tooth substrates. J. biom. Mater. Res., v. 16, n. 3, p. 265-73, May 1982.

56- NAKAJIMA, M.; SANO, H.; BURROW, M. F.; TAGAMI, J.; YOSHIYAMA, M.; EBISU, S.; CIUCCHI, B.; RUSSEL, C. M.; PASHLEY, D. H. Tensile bond strength and SEM evaluation of caries-affected dentin using dentin adhesives. J. dent. Res., v. 74, n. 10, p. 1679-88, Oct. 1995.

57- NAKAJIMA, M.; SANO, H.; URABE, I.; TAGAMI, J.; PASHLEY, D. H. Bond strengths of single-bottle dentin adhesives to caries-affected dentin. Oper. Dent., v. 25, n. 1, p. 2-10, Jan.-Feb. 2000.

58- NAKAMICHI, I.; IWAKU, M.; FUSAYAMA, T. Bovine teeth as possible substitutes in the adhesion test. J. dent. Res., v. 62, n. 10, p. 1076-81, Oct. 1983.

59- PASHLEY, D. H. The effects of acid etching on the pulpodentin complex. Oper. Dent., v. 17, n. 6, p. 229-42, Nov.-Dec. 1992.

60- PASHLEY, D. H. Bonding strength versus dentine structure: a modelling approach. Arch. oral Biol., v. 40, n.12, p.1109-18, Dec.1995.

61- PASHLEY, D. H.; CARVALHO, R. M. Dentine permeability and dentine adhesion. J. Dent., v. 25, n. 5, p. 355-72, Sept. 1997.

62- PASHLEY, D. H; HORNER, J. A.; BREWER, P. D. Interactions of conditioners on the dentin surface. Oper. Dent., v. 17, p. 137-50, 1992. Supplement 5

63- PASHLEY, D. H.; SANO, H.; CIUCCHI, B.; YOSHIYAMA, M.; CARVALHO, R. M. Adhesion testing of dentin bonding agents: a review. Dent. Mater., v. 11, n. 2, p. 117-25, Mar. 1995. 
64- PASHLEY, D. H.; SANO, H.; YOSHIYAMA, M.; CIUCCHI, B.; CARVALHO, R. M. Dentin, a dynamic bonding substrate: the effects of dentin variables on resin adhesion. In: SHIMONO, M.; MAEDA, T.; SUDA, H.; TAKAHASHI, K., Dentin-Pulp Complex. Proceedings of the international conference on Dentin/pulp complex, Chiba, 1995. Tokio, Quintessence Publishing, 1996. p.11-21.

65- PASHLEY, D. H.; CARVALHO, R. M.; SANO, H.; NAKAJIMA, M.; YOSHIYAMA, M.; SHONO, Y.; FERNANDES, C. A.; TAY, F. The microtensile bond test. A review. J. adhes. Dent., v. 1, n. 4, p. 299-309, Winter 1999.

66- PAUL, S. J.; WELTER, D. A.; GHAZI, M.; PASHLEY, D. H. Nanoleakage at the dentin adhesive interface vs $\mu$ tensile bond strength. Oper. Dent., v. 24, n. 3, p. 181-8, May-June 1999.

67- PERDIGÃO, J.; LOPES, M. The effect of etching time on dentin demineralization. Quintessence Int., v. 32, n. 1, p. 19-26, Jan. 2001.

68- PERDIGÃO, J.; MAY JUNIOR, K. N.; WILDER JUNIOR, A. D.; LOPES, M. The effect of depth of dentin demineralization on bond strengths and morphology of the hybrid layer. Oper. Dent., v. 25, n. 3, p. 186-94, MayJune 2000.

69- PERDIGÃO, J.; SWIFT JUNIOR, E. J.; DENEHY, G. E.; WEFEL, J. S.; DONLY, K. J. In vitro bond strengths and SEM evaluation of dentin bonding systems to different dentin substrates. J. Dent. Res., v. 73, n. 1, p. 44-55, Jan. 1994. 
70- PERDIGÃO, J.; LAMBRECHTS, P.; VAN MEERBEEK, B.; VANHERLE, G.;

LOPES, A. L. B. Field emission SEM comparison of four postfixation drying techniques for human dentin. J. biom. Mat. Res., v. 29, n. 9, p. 1111-20, Sept. 1995.

71- PEREIRA, P. N. R.; OKUDA, M.; SANO, H.; YOSHIKAWA, T.; BURROW, M.; TAGAMI, J. Effect of intrinsic wetness and regional difference on dentin bond strength. Dent. Mater., v. 15, n. 1, p. 46-53, Jan. 1999.

72- PRATI, C.; CHERSONI, S.; MONGIORGI, R.; MONTANARI, G.; PASHLEY, D. H. Thickness and morphology of resin-infiltrated dentin layer in young, old, and sclerotic dentin. Oper. Dent., v. 24, n. 2, p. 66-72, Mar.-Apr. 1999.

73- PHRUKKANON, S.; BURROW, M.; TYAS, M. J. Effect of cross-sectional surface area on bond strengths between resin and dentin. Dent. Mater., v. 14, n. 2, p. 120-8, Mar. 1998.

74- PHRUKKANON, S.; BURROW, M.; TYAS, M. J. The effect of dentine location and tubule orientation on the bond strengths between resin and dentine. J. Dent., v. 27, n. 4, p. 265-74, May 1999.

75- RETIEF, D. H.; MANDRAS, R. S.; RUSSELL, C. M.; DENYS, F. R. Extracted human versus bovine teeth in laboratory studies. Amer. J. Dent., v. 3, n. 6, p. 253-8, Dec. 1990.

76- RUYTER, I. E. The chemistry of adhesive agents. Oper. Dent., v. 17, p. 3243, 1992. Supplement 5

77-RUSE, N. D.; SMITH, D. C. Adhesion to bovine dentin - surface characterization. J. dent. Res., v. 70, n. 6, p. 1002-8, June 1991. 
78- SAKOOLNAMARKA, R.; BURROW, M. F.; TYAS, M. J. Micromorphological study of resin-dentin interface of non-carious cervical lesions. Oper. Dent., v. 27 , n. 5, p. 493-9, Sept. -Oct. 2002.

79- SANO, H.; CUCCHI, B.; MATTHEWS, W. G.; PASHLEY, D. H. Tensile properties of mineralized and demineralized human and bovine dentin. $\mathbf{J}$. dent. Res., v. 73, n. 6, p. 1205-11, June 1994.

80- SANO, H.; SHONO, T.; SONODA, H.; TAKATSU, T.; CIUCCHI, B.; CARVALHO, R.; PASHLEY, D. H. Relationship between surface area for adhesion and tensile bond strength - evaluation of a micro-tensile bond test. Dent. Mater., v. 10, n. 4, p. 236-240, July 1994.

81- SANO, H.; TAKATSU, T.; CIUCCHI, B.; HORNER, J. A.; MATTHEWS, W. G.; PASHLEY, D. H. Nanoleakage: leakage within the hybrid layer. Oper. Dent., v. 20, n. 1, p. 18-25, Jan.-Feb.1995.

82- SAUNDERS, W. P. The shear impact retentive strengths of four dentine bonding agents to human and bovine dentine. J. Dent., v. 16, n. 5, p. 22338, Oct. 1988.

83- SCHILKE, R.; BAUß, O.; LISSON, I. A.; SCHUCKAR, M.; GEURTSEN, W. Bovine dentin as a substitute for human dentin in shear bond strength measurements. Amer. J. Dent., v. 12, n. 2, p. 92-6, Apr. 1999.

84- SELTZER, S.; BENDER, I. B. A polpa dental. Rio de Janeiro, Editorial Labor do Brasil, 1979. p. 102.

85- SHIMADA, Y.; YAMAGUCHI, S.; TAGAMI, J. Micro-shear bond strength of dual-cured resin cement to glass ceramics. Dent. Mater., v. 18, n. 5, p. 380-8, July 2002. 
86- SÖDERHOLM, K-J. M. Does resin based dentine bond work? Int. dent. J., v. 45, n. 6, p. 371-81, Dec. 1995.

87- StANLEY, H. R.; PEREIRA, J. C.; SPIEGEL, E.; BROOM, C.; SCHULTZ, M. The detection and prevalence of reactive and physiologic sclerotic dentin, reparative dentin and dead tracts beneath various types of dental lesions according to tooth surface and age. J. Pathol., v.12, n. 4, p. 257-89, 1983.

88- SUDSANGIAM, S.; VAN NOORT, R. Do dentin bond strength tests serve a useful purpose? J. adhes. Dent., v. 1, n. 1, p. 57-67, Spring 1999.

89- SWIFT JUNIOR, E.; PERDIGÃO, J.; HEYMAN, H. O. Bonding to enamel and dentin: A brief history and state of the art, 1995. Quintessence Int., v. 26, n. 2, p. 95-110, Feb. 1995.

90- TAGAMI, J.; NAKAJIMA, M.; SHONO, T.; TAKATSU, T.; HOSODA, H. Effect of aging on dentin bonding. Amer. J. Dent., v. 6, n. 3, p. 145-7, June 1993.

91- TAO, L.; PASHLEY, D. H. Shear bond strengths to dentin: effects of surface treatments, depth and position. Dent. Mater., v. 4, n. 6, p. 371-8, Dec. 1988.

92- TAY, F. R.; PASHLEY, D. H. Aggressiveness of contemporary self-etching systems. I: depth of penetration beyond dentin smear layers. Dent. Mater., v. 17 , n. 4 , p. 296-308, July 2001.

93- TAY, F. R.; GWINNETT, A. J.; WEI, S. H. Y. The overwet phenomenon: an optical, micromorphological study of surface moisture in the acidconditioned, resin-dentin interface. Amer. J. Dent., v. 9, n. 1, p. 43-8, Feb. 1996. 
94- TAY, F. R.; PASHLEY, D. H.; SUH, B. I.; CARVALHO, R. M.; ITTHAGARUN, A. Single-step adhesives are permeable membranes. J. Dent., v. 30, n. , p. 371-82, 2002.

95- UNO, S.; FINGER, W. J. Effects of acidic conditioners on dentine demineralization and dimension of hybrid layers. J. Dent., v. 24, n. 3, p. 211-6, May 1996.

96- VAN MEERBEEK, B. Dentine adhesion: morphology, physico-chemical and clinical aspects. Leuven, 1993. PhD Dissertation. Catholic University of Leuven.

97- VAN MEERBEEK, B.; BRAEM, M.; LAMBRECHTS, P.; VANHERLE G. Morphological characterization of the interface between resin and sclerotic dentine. J. Dent., v. 22, n. 3, p. 141-6, June 1994.

98- VAN MEERBEEK, B.; PERDIGÃO, J.; LAMBRECHTS, P.; VANHERLE, G. The clinical performance of adhesives. J. Dent., v. 26, n.1, p. 1-20, Jan. 1998.

99- VAN MEERBEEK, B.; VARGAS, M.; INOUE, S.; YOSHIDA, Y.; PEUMANS, M.; LAMBRECHTS, P.; VANHERLE, G. Adhesives and cements to promote preservation in dentistry. Oper. Dent., p. 119-44, 2001. Supplement 6

100- VAN NOORT, R.; NOROOZI, S.; HOWARD I. C.; CARDEW, G. A critique of bond strength measurements. J. Dent., v. 17, n. 2, 61-7, Apr. 1989.

101- VAN RENSBURG, B. G. J. Oral biology. Carol Stream, Quintessence Publishing Co., Inc., 1995. 
102- VAN STRJIP, A. J. P., KLONT, B.; CATE, T. Solubilization of dentin matrix collagen in situ. J. dent. Res., v. 71, n. 8, p. 1498-502, Aug. 1992 apud PERDIGÃO, J.; SWIFT JR., E. J.; DENEHY, G. E.; WEFEL, J. S., DONLY, K. J. In vitro bond strengths and SEM evaluation of dentin bonding systems to different dentin substrates. J. dent. Res., v. 73, n. 1, p. 44-55, Jan. 1994.

103- VASILIADS, L.; DARLING, A. I.; LEVERS, B. G. H. The histology of human root dentine. Arch. oral Biol., v. 28, n. 8, p. 693-700, 1983.

104- YOSHIYAMA, M.; MASADA, J.; UCHIDA, A.; ISHIDA, H. Scanning electron microscopic characterization of sensitive vs. insensitive human radicular dentin. J. dent. Res., v. 68, n. 11, p. 1498-502, Nov. 1989.

105- YOSHIYAMA, M.; URAYAMA, A.; KIMOCHI, T.; MATSUO, T.; PASHLEY, D. H. Comparison of conventional vs self-etching adhesive bonds to caries-affected dentin. Oper. Dent., v. 25, n. 3, p. 163-9, May-June 2000.

106- YOSHIYAMA, M.; SANO, H.; EBISU, S.; TAGAMI, J.; CIUCCHI, B.; CARVALHO, R. M.; JOHNSON, M. H.; PASHLEY, D. H. Regional strengths of bonding agents to cervical sclerotic root dentin. J. dent. Res., v. 75, n. 6, p. 1404-1413, June 1996.

107- YOSHIYAMA, M.; TAY, F. R.; DOI, J.; NISHITANI, Y.; YAMADA, T.; ITOU, K.; CARVALHO, R. M.; NAKAJIMA, M.; PASHLEY, D. H. Bonding of selfetch and total etch adhesives to carious dentin. J. dent, Res., v. 81, n. 8, p. 556-60, Aug. 2002. 
108-ZHENG, L.; PEREIRA, P. R. N.; NAKAJIMA, M.; SANO, H.; TAGAMI, J. Relationship between adhesive thickness and microtensile bond strength. Oper. Dent., v. 26, n. 1, p. 97-104, Jan-Feb. 2001. 
Abstract 


\section{ABSTRACT}

This present study aimed to analyze bond strengths of a totaletch adhesive to different substrates of dentin such as normal and artificially hypermineralized ones. Analysis of the effect of a double-etch treatment of the surface of the hypermineralized dentin aiming to demonstrate the hypothesis that this procedure will result in significant increase in bond strengths relating to this type of substrate was also an objective of this study. Twelve extracted human sound third molars were selected for this study. Two groups were formed: a group of three teeth, called $N$ (for normal dentin) and a group of six teeth, called $H$ (for hypermineralized dentin). The other three teeth were prepared for Scanning Electron Microscope observation. Occlusal surfaces of teeth were ground flat, removing occlusal enamel and exposing mid-coronal dentin. These surfaces of Group $\mathrm{H}$ were artificially hypermineralized and teeth were subdivided equally in two subgroups: $\mathrm{Ht}$ and $\mathrm{Hd}$. Dentin of subgroup $\mathrm{Ht}$ and dentin of group $\mathrm{N}$ received bonding treatment according to directions of the manufacturer of the restorative system. Dentin of the subgroup $H d$ was re-etched after rinsing of the first acidetching step. After creation of a $4 \mathrm{~mm}$-high composite build-up over the adhesive layer in increments, teeth were serially sectioned into resin-adhesive-dentin beams of $0.8 \mathrm{~mm}$ thick by means of a diamond saw. A number of 58,82 and 71 beams were obtained for the groups $N, H t$ and $H d$, respectively. Specimens were evaluated for bond strength by a micro-tensile test, in a universal test machine at $0,5 \mathrm{~mm} /$ minute. Student's $t$ test showed statistically similar values on bond strengths between group $N$ and subgroup $H t(p=0,108)$. Subgroup $H d$ showed statistical difference compared to subgroup $H t(p<0,0001)$. Altered form of dentin 
by artificial hypermineralization showed similar bond strength values compared to normal dentin, regarding conditions of this work. Double-etch with 35\% phosphoric acid significantly reduced bond strengths of hypermineralized dentin. 
Apêndice 


\section{TERMO DE CONSENTIMENTO LIVRE E ESCLARECIDO}

\section{INFORMAÇÃO AO PACIENTE DOADOR:}

Caro paciente,

Seus dentes extraídos, nesta ocasião, serão muito úteis para pesquisas que serão realizadas na Faculdade.

Com eles, tentaremos simular o que acontece na boca quando restauramos um dente que foi destruído por cárie. Nestes dentes que você doará, serão feitas restaurações com resina composta, que são aquelas que possuem a mesma cor do dente. Depois, será avaliada a resistência dessas restaurações. Com os resultados desse trabalho, poderemos compreender melhor sobre o comportamento da resina quando usada na boca, vendo se elas descolam do dente facilmente ou não.

Agradecemos muito sua colaboração.

\section{CONSENTIMENTO DO PACIENTE:}

Pelo presente instrumento que atende às exigências legais, o Sr. (a)

, portador da cédula

de identidade $\mathrm{n}^{\circ}$ , ciente das informações prestadas acima, firma seu

CONSENTIMENTO LIVRE E ESCLARECIDO concordando na doação de seus dentes extraídos para a realização da pesquisa proposta.

Fica claro que o paciente ou seu representante legal, pode a qualquer momento retirar seu CONSENTIMENTO LIVRE E ESCLARECIDO e deixar de participar desta pesquisa, ciente de que todas as informações prestadas tornaram-se confidenciais e guardadas por força de sigilo profissional (Art. $9^{\circ}$ do Código de Ética Odontológica).

Por estarem de acordo assinam o presente termo.

de de

Assinatura do Paciente

Telefone:
Renato Cilli - Pesquisador

Telefone: (14) 2358261 


\section{Universidade de São Paulo Faculdade de Odontologia de Bauru}

Al. Dr. Octávio Pinheiro Brisolla, 9-75 - Bauru-SP-CEP 17012-901 - C.P. 73 PABX (0XX14)235-8000-FAX (0XX14)223-4679

Comitê de Éfica en Pesquisa

Processo $\mathrm{n}^{\circ} 003 / 2003$

Bauru, 23 de abril de 2003

Senhor Professor,

Informamos que após o envio da documentaçāo pendente, o projeto de pesquisa encaminhado a este Comitè denominado "Resistência adesiva de um agente de uniăo $\mathrm{cm}$ substrato dentinârio normal e hipermineralizado" de autoria de Rcnato Cilli, que será desenvolvido sob sua orientaçāo, foi APROVADO, nesta data.

Comunicamos que após o cnvio do trabalho concluido, este Comitẽ enviarà o parecer final, que scrá utilizado para a publicação do trabalho.

Atenciosamente,

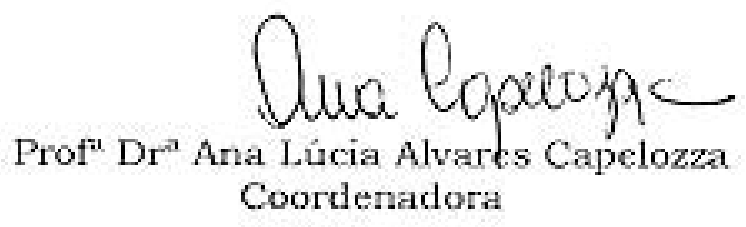

$\mathrm{Ilm}^{\circ} \mathrm{Sr}$. Prof. Dr. Paulo Amarante de Araújo

DD. Docente do Departamento de Dentistica, Endodontia e Materiais Dentários 